HISTOIRE NATURELLE

\title{
DES INSECTES.
}

\author{
TOME III.
}




\section{Ouvrages qui se trouvent chez le méme Libraire.}

Cozurs de Thêmes pour les quatrième, troisjème et seconde classes, à l'usage des colléges; par M. Planche, professeur de rhétorique au Collége royal de Bourbon; ouvrage recommandé pour les colléges par le conseil royal de l'Université. Un vol, in-12, 1824 , cart.

$x$ fr. $50 \mathrm{c}$.

Description des Maurs, Usages et Coutumes do tous les Peuples du Monde, contenant une foule d'Anecdotes sur les sauvages d'Afrique, d'Amérique, les Anthropophages, Hottentots, Caräbes, Patagons, etc., etc. Seconde édition, tres augmentée. 2 vol, in-18, ornés de 12 gravuree.

$5 \mathrm{fr}$.

Épilepsie ( de $l^{\prime}$ ) on géndral, et particulièrement de celle quí est déterminée par des causes morales; par M. Doussin-Dubreuill. Un vol. in-12. Deuxième édition, 1825 .

$3 \mathrm{fr}$.

Esprit (de l') des Lois; par Montesquieu. Nouvelle édition, ornée da portrait de l'auteur. 4 gros vol. in-12, 1822. $12 \mathrm{fr}$.

Glaires (des), de leurs causes, de leurs effets, et des indications à remplir pour les combattre. Neuviéme édition; par M. Dous$\sin -$ Dubreuil, in $-8 ., 1824$.

$4 \mathrm{fr}$.

Noupeaux Apercus sur les causes et les effets des Glaires; parle mếme. Un rol. in-8.

2 fr.

De l'emploi du remède contre les Glaires, et observations sur ses effets. Un vol. in -3 .

Graissinet ( $M$. ) on Qu'est-il donc? histoire comique, satirique et véridique, publiée par M. Dupal. Quatre vol. in-12, 1823.

$10 \mathrm{fr}$.

Grammaire française (nouvelle), sur un plan très méthodique, avec de nombreux exercices d'orthographe, de syntaxe et de ponctuation, tirés de nos meilleurs anteurs, et distribués dans l'ordre des règles; par MM. Nöl et Chapsal; ouvrage mis au nombre des livres classiques par le conseil royal de l'Université. Huitième édition. Deux vol. in-12, 18 a 7 .

$3 \mathrm{fr}$.

Lo Corrigd des exeroices, par les mêmes. Un vol. in-12, $182 \eta$.

Grummaire franģaise de Restaut; gros volume in-13, 1834 . $2 \mathrm{fr}$. $2 \mathrm{fr}, 50 \mathrm{c}$.

Grandeur (la) des Romains; par Montesquieu. 1 vol, in-12, 1822 .

$2 \mathrm{fr}$.

Guide (nouveau) de la Politesse; par Émerio. Secoude édition 1822 . Un vol. in-8.

$5 \mathrm{fs}$.

DH X'IMPRIMERIE DB CRAPELET, rue de Vaugirard, $^{\circ} 9$. 


\section{HISTOIRE NATURELLE}

\section{DES INSECTES

COMPOSEE

D'APRÉS RÉAUMUR, GEOFFROX, DEGÉER, ROESEL, LINNÉ, FABRICIUS,

Et les rneilleurs Ouvrages qui ont paru sur cette partie;

RÉDTGÉE SUTVANT LA MÉTHODE D'OUTVIER, ET ORNÉE DE FIGURES DESSINÉES D'APRÈS NATURE.

PAR F. M. G. T. DE TIGNY,

Membre de la Société d'Histoire naturelle de Paris.

TROISIĖME ÉDTTION,

Repue, augmentée et mise au niveau des connaissances actuelles,

PAR M. F. E. GUÉRIN,

Membre de la Société d'Histoire naturelle de Paris

et de plusieurs autres Sociétés savantes.

TOME TROISIËME.

AU COIN DE CETLE DU BATTOIR. 


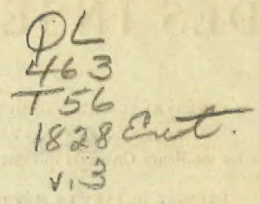

202349 


\section{HISTOIRE NATURELLE}

\section{DES INSECTES.}

\section{V Ie GENRE.}

HANNETON.

Caractères génériques. Antennes en masse allongée, feuilletée, composées de dix articles, dont le premier est gros et presque sphérique. - Quatre antennules inégales, filiformes; les antérienres un pen plus longues, composées de quatre arricles; les postérienres de trois. - Jambes antérieures avec denx petites dentelures.

Linkx́, Degéer et M. Geoffroy ont placé les hannetons parmi les scarabées; mais M. Fabricius les en a séparés et en a formé un genre, que les auteurs qui ont écrit depuis lui ont adopté. On distingue facilement les hannetons des scarabées, par la forme dú corps.

Les hannetons ont les antennes composées de dix articles, dont le premier est gros et 
assez long; le second est gros et court; le troisième est un peu plus allongé; les suivans sont presque égaux; les trois, quatre ou quelquefois les sept derniers forment une masse feuilletée, allongée et arquée.

Ils ont le chaperon quelquefois très avancé, arrondi ou échancré, et plus ou moins bordé.

La bouche est composée d'une lèvre supérieure, de deux mandibules courtes, épaisses, comprimées, quelquefois dentées à leur extrémité; de deux mâchoires, d'une lèvre inférieure, et de quatre antennules filiformes, dont les antérieures sont un peu plus longues que les autres, composées de quatre articles, et les postérieures de trois.

Le corselet est un peu convexe, plus large que la tête, arrondi sur les côtés, et plus ou moins bordé; l'écusson est triangulaire ; les élytres sont plus courtes que l'abdomen; elles ont un rebord très petit de chaque côté, et elles recouvrent deux ailes membraneuses, repliées quand l'insecte n'en fait point usage. 
L'abdomen est allongé, triangulaire à l'extrémité.

Les pates sont de longueur moyenne, plus minces que celles des scarabées; les jambes antérieures ont quelques dentelures, les autres ont quelques épines; les tarses ont cinq articles, dont le dernier, plus long que les autres, est un peu arqué et terminé par deux crochets assez forts et aigus.

Les hannetons ne sont que trop connus, par le tort qu'ils font aux arbres en les dépouillant de leurs feuilles. Pendant toute leur vie, ces insectes se nourrissent de substances végétales; sous l'état de larve, ils rongent et détruisent les racines des plantes vivaces, des arbrisseaux et même des arbres les plus durs. Dans les climats froids et tempérés, les larves restent engourdies pendant l'hiver : elles sont alors enfoncées assez profondément en terre, enfermées dans une loge qu'elles construisent en automne; mais au printemps on voit paraître l'insecte parfait; c'est sous cet état que le hanneton dévore les feuilles des arbres; dans de certaines annćes, ces insectes sont 
si abondans aux environs de Paris, qu'ils dépouillent presque entièrement les arbres de leurs feuilles. Dans le midi de la France, on en trouve une espèce qui y est assez commune, qui mange les feuilles des vignes, et qui attaque les saules, les peupliers et la plupart des arbres fruitiers. Ce genre est assez nombreux; mais toutes les espèces ne sont pas également nuisibles. Celle qui fait le plus de tort est le hanneton vulgaire. C'est ordinairement au printemps qu'on voit paraître ces insectes; pendant la plus grande partie du jour, ils sont comme engourdis, et restent immobiles attachés aux branches et aux feuilles des arbres; mais pressés par le besoin de manger, et surtout de s'accoupler, dès que le soleil est couché, et mème un peu avant, ils prennent l'essor et volent de tous côtés. Leur vol est lourd; en volant ils font entendre un bourdonnement semblable à celui des grosses abeilles. Ces insectes, qui vivent à peine huit jours sous leur dernière forme, s'accouplent peu de temps après être sortis de terre, et leur accouplement dure vingt-quatre heures. Pen- 
dant l'accouplement, le mâle pend au derrière de la femelle, ayant le dos renversé; dans cette position, il se laisse entraîner partout où elle veut le conduire; peu de temps après il tombe épuisé et meurt. Mais la femelle vit plus long-temps. Aussitôt après qu'elle a été fécondée, elle creuse un trou en terre, à l'aide de ses pates antérieures, s'y enfonce à la profondeur d'un demi-pied, y dépose des ceufs oblongs, d'un jaune claị, que quelquefois elle arrange les uns auprès des autres, et après sa ponte elle sort du trou, mange encore pendant quelques jours, et meurt ensuite.

Les larves qui sortent de ces œufs sont molles, allongées; elles ont six pates courtes, écailleuses; la tête grosse et écailleuse; deux antennes composées de cinq articles, et neuf stigmates de chaque côté; leur corps est composé de treize anneaux. Ces larves, qui sont connues des jardiniers sous le nom de vers blancs, vivent trois ou quatre années sous cette forme, et changent plusieurs fois de peau : elles restent engourdies pendant l'hiver, et ne mangent qu'au commen- 
le devant de la tête est comme coupé, et on voit de chaque côté du chaperon une petite dent peu avancée; la partie supérienre est munie d'une corne très courte, avancée; le corselet est convexe; l'écusson est très petit, et arrondi postérieurement; les élytres sont pointillées, et ont des lignes longitudinales peu élevées, peu apparentes; l'abdomen est d'un rouge plus ou moins pâle; les pates sont d'un vert bleuâtre.

On trouve cet insecte en Afrique, sur la côte de Barbaric.

\section{Le Hanneton Renard, Melolontha Vulpes.}

\section{G. Amphicome. Latr.}

Il est un peu plus petit que le précédent; son chaperon est carré, avec les bords un peu relevés; tout le corps est couvert de poils longs, fins, serrés, et d'une belle couleur fauve; la tète et le corselet sont pointillés et d'un jaune doré; l'écusson est arrondi; le corps est noirâtre en dessous, mais l'abdomen est d'un rouge brun; les 


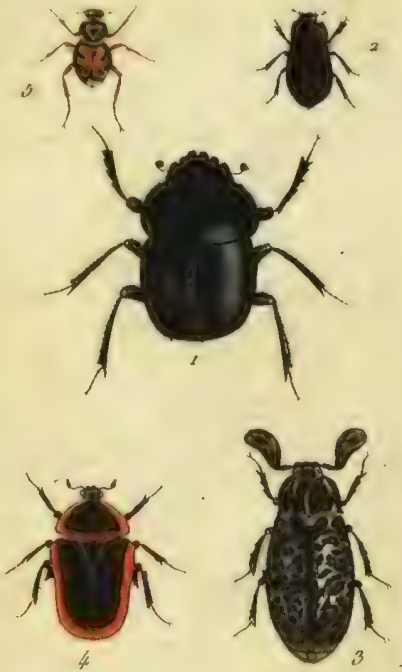

Barabind del.

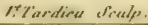

1. Scaralsi sacré.

2, Tirox Sabule

3. Janneton. 
pates sont d'un vert cuivreux brillant, avec les tarses îjoirs bronzés.

On le trouve dans les déserts de la Sibérie méridionalợ, près du Volga.

\section{Le Hanneton chevelu, Melolontha siritia. \\ G. Anisonyz. YLitr.}

Il a près de iquatre lighes de long; tout son corps est copuver de poils longs, fins et noirs; mais la têtẹ le corselet, les cuisses postérieures, et surtout les ćlytres, sont couverts d'une poussière écailleuse, verte, luisante; le chaperon est avancé et échancré ; l'écusson est noir et triangulaire, les pates sont noires et velues.

On trouve cet insecte au cap de BonneEspérance, il y est commun.

Le Hanneton foulon, Melolontha fullo.

Il a environ quinze lignes de longr; les antennes du inâle sont terminées par une masse très longue, arquée, composéc de sept feuillets; la masse de celles de la fe- 
melle est petite et ovale; le chaperon est très peu échancré et peu bordé; le corps est fauve ou brun; la tête est couverte de petites écailles; le corsclet a trois lignes longitudinales blanches, et de petites taches de méme couleur; l'écusson est en cœur, avec deux taches blanches; les élytres sont plus ot moins marquées de taches irrégulières et de points blanes; le dessous du corselet et de la poitrine est couvert de poils d'un gris fauve; l'abdomen est cendré; les pates sont de même coulcur que le corps.

On le trouve en quantité dans les dunes de la Hollande, dans les départemens méridionaux de la France, en Italie, et sur les côtes de Barbarie.

\section{Le IIanneton vulgaire, Melolontha vulgaris.}

Cette espèce, la plus commune de celles des environs de Paris, est longue d'un pouce cnviron : elle est noire; les antennes, lebord antéricur du chaperon, les élytres, les pates, excepté la majeure partie des cuisses prosté- 
ricures, sont d'un bai rougeatre; le corselet a ses bords latéraux un peu dilatés et arrondis au milicu, et une cicatrice près des bords de chacun d'eux; les élytres ont chacune quatre nervures longitudinales; la poitrine est d'un gris cotonneux; les bords de l'abdomen ont une rangée de taches blanches triangulaires.

Cette espèce est très commune dans les contrées tempérées de l'Europe et de la France; on n'en trouve pas dans nos provinces méridionales.

Le Hanneton du marronnier d'Inde, Melolontha hippocastani.

Il ne diffère du précédent qu'en ce que Ia tête, excepté sa partic postéricure, et le corsclet sont rougeâtres, ainsi que les élytres et les pates; les élytres et l'abdomen ont un duvet très fin, grisâtre; les cuisses postéricures n'ont pas de noir.

On le trouve aux environs de Paris, oi il est aussi commun que le précédent; il est confondu avec lui dans les bois de 
Bondy, AIcudon, etc., et nous pensons qu'il . n'en est qu'une variété.

Le Hanneton cotonneux, Melolontha villosa.

Il est un peu plus grand que le hanneton vulgaire; ses antennes sont testacées; la masse est allongée, arquuée, composéc de sept feuillets; le chaperon est un peu échaneré, un peu bordé; la tête et le corselet sont bruns, converts d'un duvet cendré ; l'écusson est noirittre, en cour, couvert de poils courts, cendrés; les élytres sont testacées, couvertes d'un duvet cotonneux cendré; le dessous du corps est brun et entièrement couvert de poils fins, assez longs, cendrés: on voit de chaqque côté de l'abdomen plusieurs taches noiritres triangulaires; les pates sont testacées; l'abdomen est terminé en pointe allongéc inclinée.

On le trouve en Europe au printemps, sur les arbres; il est moins commun aux environs de Paris que le hanneton vulgaire. 
Le Hanneton villageois, Melolontha pagana:

Il a environ six lignes de long; ses antennes sont brunes, avec les trois dernicrs articles en masse feuilletée; la tête est noire, avec quelques poils cendrés; Ic chaperon est arrondi, rebordé; le corselet est noirâtre, couvert de poils cendrés; les élytres sont testacies, avec un peu du bord extérieur et la suture noirâtres; la poitrine est velue; l'abdomen est lisse et jaunâtre; les patè sont noires.

Il habite l'Europe; il n'est pas commun aux environs de Paris.

Le Manneton marqué, Melolontha 'signata.'

Il a environ sept lignes; la tète est d'un brun pâle antérieurement, et noire postérieurement ; le corselet est luisant, testace, avee deux lignes longitudinales noires, moins longues que le corselet; les élytres sont testacées, finement pointillées, avec quel- 
ques taches noires, oblongues, et quelquefois sans taches; le dessous du corps et les pates sont testacés; l'abdomen et les tarses sont noirs.

On le trouve à Saint-Domingue, à Cayenne et at Surinam.

Le Hanneton laineux, Melolontha

$$
\begin{aligned}
& \text { lanigera. } \\
& \text { G. Rutcle. L.srr. }
\end{aligned}
$$

Il a environ dix lignes; les antennes sont brunes; la masse est composće de trois feuillets; le chaperon est un peu échaneré; la téte est d'un jaune vert doré; le corselet et l'écusson sont d'un jaune vert doré trìs brillant; les élytres sont jaunes et pointillées; le dessous du corps est vert brillant, couvert d'un duvet long et serré, de courleur grise; les pates sont d'un jaune verdâtre brillant:

On le trouve à l'A mérique septentrionale, it la Nouvelle-York, et dans le Maryland. 


\section{Le Haineton ponctué, Melolontha} punctata.

\section{G. Rutile: Latr.}

Il est de la grandeur du précédent, mais un pen moins gros; les antennes sont brunes; la masse est composíe de trois feuillets; lc chajeron est arrondi ; la téte est d'un vert cuivreux, lisse ; le corsclet est lisse, testacé, luisant, avec un point noir de chaque côté; l'écusson est triangulaire, d'un vert cuivreux; les élytres sont lisses, testacées, avec trois points noirs sur chaque, placés sux une mème ligone le long du bord extérieur; le dessous du corps et les pates sont d'un vert noirittre luisant.

On le trouve dans le Maryland, la Virginie, et la Caroline.

\section{Le Hameton d'Orey, Melolontha Orcyi.}

G. Rutile, Laxn.

Il a environ huit lignes; Ie chaperon est íchancré; les antenues sont testacées; la 
masse est composéc de trois feuillets; la tête est d'un jaune testacé, avec une ligne longitudinale noire de chaque còté; le corselet est lisse, testacé; il a quatre lignes longitudinales courtes, noires, et un point de mème couleur de chaque côté; les élytres sont d'un jaunc testacé, lisses, avec la suture et quelques lignes longitudinales courtes, noires; le dessous du corps est d'un brun plus ou moins foncé, avec quelques lignes jaunes.

On le trouve à Saint-Domingue.

\section{Le Hanneton de la vigne, Melolontha vitis.}

Il est à peu près de la grandeur du précédent; il est d'un vert brillant en dessus, et d'un vert brillant cuivreux en dessous; les antennes sont jaunâtres ; le chaperon est arrondi; la tète et le corselet sont finement pointillés; il a de chaque côté une tache jaune; l'écusson est arrondi; les élytres sont striées et pointillíes; les pates sont bronzées. 
Il se trouve dans presque toute l'Europe et en $\Lambda$ mérique, sur la vigne, dont il mange les feuilles.

Le Hanneton brun, Melolontha brunea.

Il a environ cinq lignes; il est entic̀rement de coulcur testacée mate; la masse des antennes est allongće et composée de trois feuillets; les yeux sont noirs; l'écusson est allongé, triangulaire; les élytres sont striées; les pates sont longues et minces.

On le trouve dans toute l'Europe, sur les plantes et les arbres, dont il mange les ferilles.

Le Hanneton Ours, Melolontha Ursus. G. Anisonyx. Latr.

Il est de la grandeur du précédent; tout son corps est noir, entièrement couvert de poils roux; les antennes sont brunes et lat masse est composée de trois feuillets; les élytres sont un pen plas coartes que l'abdomen, de coulcur brune, avec trois lignes 
longitudinales jaunes; les pates sont noires, couvertes de poils roux.

On le trouve en Afrique.

Le Hanneton farineux, Melolontha farinosa.

Il a environ quatre lignes de long; les antemnes sont testacées; le chaperon est arrondi, un peu bordé; tout le dessus du corps est couvert de petites éeailles d'un jaune verdâtre, point brillantes; les élytres sont lisses, elles ont une petite bosse de chaque côté de leur base; le dessous du corps est couvert de petites écailles d'un blane argenté très brillant; les pates sont noirâtres; les cuisses sont couvertes d'écailles argentées.

On le trouve dans presque toute l'Europe : il est très commun dans les départemens méridionaux de la France, sur les fleurs : on ne le trouve point aux environs de Paris. 


\section{Le Hanneton écailleux, Melolontha}

\section{squamosa.}

Il est de la grandeur du précédent; ses antennes sont brunes; la masse est noire, ovale, comprosée de trois feuillets; tont le: dessus du corps est d'une belle couleur blene brillante, produite par de petites écailles semblables à celles qui couvrent les ailes des papillons; le dessous du corps et les pates sout couverts d'écailles d'un blane verdattre argenté, très brillantes; les ćlytres sont lisses, sans stries.

On le trouve dans presque toute la jrance. 


\section{X X V I I' GENRE.}

\section{CETOINE.}

Caractères génériques. Antennes courtes, en masse; dix articles, dont le premier plas gros, les trois deruiers en masse ovalc, feuilletćc. - Quatre antennules filiformes, presque égales; les antérienres composées de quatre articles, dont le dernier allongé; les postérieures de łrois. - Mandibules presque membraneuses, peu apparentes. - Jambes antérieures dentées. - Pièce triangulaire, plus ou moins distincte, à la base extéricure des élytres.

M. Fabricius a séparé ces insectes des scarabées, parmi lesquels Linnć et $\boldsymbol{M}$. Geoffroy les ont placés; et M. Olivier a adopté ce genre.

Il est facile de distinguer les cétoines des scarabées, par la forme du chaperon, et par les parties de la bouche. Les scarabées des deux premieres familles ont des mandibules fortes et cornées, au lien que celles des cétoines sont extrêmement minces et membraneuses; le chaperon grand et arrondi des. scarabées de la troisième famille, et l'absence 
de l'écusson, les' font aisément reconnaître d'avec les cétoines. Celles-ci se rapprochent un peu plus des hannetons, dont elles différent cependant, par la forme du corps qui est plus carré, par une pièce triangulairc à la base des élytres, par l'absence de la lèvre supéricure, et par des mandibules minces, tandis que celles des hannetons sont fortes et cornées:

Les cétoines ont les antennes composées de dix articles, dont le premier est assez long et assez gros ì son extrémitć; le second est un peu plus petit; les suivans sont grenus; les trois derriiers forment une masse ovale, composíe de trois feuillets.

La téte est penchéc, assez étroite; le chaperon est avancé, échancré; les yeux sont petits, arrondis et saillans; la bouche est composéc de deux mandibules membrancuses très minees; de deux mâchoires cornées it leur base, terminées par deux lobes; d'une lèvre inféricure, et je quatre antennules, dont les antéricures sont composées de quatre articles, et les postérieures de trois.

Le corselet a une forme triangulaire; il 
est un peu bordé, échancré postécienrement pour recevoir l'écussón, ou terminé par une pointe qui se prolonge entre les élytres et qui remplace l'écusson.

Les élytres ont une forme presque carréc; elles sont un peu plus courtes que l'abdomen; elles recouvrent deux ailes membraneuses, replićes quand l'insecte n'en fait point usage pour voler; a la base latérale des élytres, on voit une pièce triangulaire plus ou moins saillantc; clle se trouve comme enchâsséc entre les élytres et le corselet ; mais cette pièce manque à quelques espèces; lc sternum d'un grand nombre est plus ou moins avancé. On trouve ce caractère sur quelques hannctons, qui se rapprochent des cétoines par le brillant et le poli de leurs élytres.

Les pates sont de longueur moyenne; les jambes antérieures sont un peu moins aplaties que celles des scarabées; elles ont quelques dents latérales; les intermédiaires et les postérieures sont souvent ciliées; les tarses sont composés de cinc articles, dont les quatre premicrs sont prespue égaux, le der- 
nier est plus long et terminé par deux crochets recourbés, longs, assez forts et pointus.

L'abdomen est composé de six anneaux; a la base latérale du premier, près de l'insertion des cuisses, on voit une grande pièce écailleuse, qui se lève quand l'insecte remue les pates; les élytres sont un peu échancrées dans cet endroit.

On trouve les cétoines, pendant l'été, sur les fleurs en ombelles et les fleurs composćes. Ces insectes ne sont point aussi malfaisans que les hannetons; sous leur dernière forme ils ne se nourrissent que du sue des fleurs; en volant d'une fleur à l'autre, ils font entendre un bourdonnement assez fort.

Leurs larves ont te corps mou, allongé, cylindrique, un peu aplati en dessous; il cst composé de douze anneaux per distincts, sur lesquels sont placés neuf stigmates de chaque côté; leur tête est écailleuse, munie de dents très fortes et de deux antennes filiformes, composées de cinq árticles; lcurs yeux sont rachés sous les enveloppes de larve et de nymphe; elles ont six pates écailleuses, placérs sur les trois premiers 
anneaux; elles vivent dans les terres grasses et humides, le terreau et les terres argileuses, et, se nourrissent de leurs sucs; quelques unes mangent des feuilles ou des racines à demi pourries. Comme celles des liannetons, les larves sont trois ou quatre ans avant de parvenir à l'état parfait. Elles passent Thiver sans prendre de nourriture; elles sont alors engourdies et enfoncées très avant dans la terre, d'où elles sortent au commencement de la belle saison pour manger; elles changent trois ou quatre fois de peau, c'est-it-dire une fois chaque annéc, lorsqu'clles ont pris tout leur accroissement. Elles font une coque solide, composće de substances dont clles sc nourrissent, auxquelles elles en ajoutent d'étrangères, telles que de petites pierres et de petits morceaux de bois; de sorte que ces coques sont irrigulieres en dessus, mais leur intérieur est lisse; les larves s'enferment dans ces roques et s'y changent en nymphe. On distingue sur la nymphe toutes les parties que doit avoir l'insecte parfait.

Nous séparerons des cétoines les insectes 
dont M. Fabricius a formé son genre trichius, quoique M. Olivier les ait réunis : parce que, malgré la ressemblance qui se trouve entre les parties de la bouche de ces insectes, les trichies diffèrent assez des ccitoines, par la forme du corps, et par la manière dont clles vivent sous l'état de larves, pour faire un gुenre séparé. Les trichies forment unc des trois familles du genre cétoine de M. Olivicr, ainsi ce genre ne sera composé que de deux familles, dont la premic̀re comprendra toutes les espèces qui ont des mandibules membraneuses, et la pièce triangulaire a la base des élytres; la seconde, celles qui n'ont point de pièce triangulaire : celles-ci ont les mandibules cornées, elles se rapprochent de quelques espèces de hannetons, dont le sternum est avancé et les élytres brillantes et polies comme celles des cétoines. Les larves des cétuines de cette famille ne sont point connues, majs on présume qu'elles vivent dans la terre, et qu'elles ressemblent d celles des hannetons.

Ce genre est composé de plus de cent 111. 
espèces; on n'en trouve que cing ou six aux environs de Paris. Nous en décrirons quelques unes.

\section{La Cétoine Cacique, Cetonia Cacicus.}

$$
\text { G. Goliath, I.ATR. }
$$

Elle a près de trois pouces de long et un pouce et demi de large à la base des élytres; ses antennes sont noires; la tète est couverte d'un duvet jaunatre; elle a de chaque côté une dent aiguë noire; le chaperon est avancé et terminé par deux cornes noires atrquées; le corselet jaunâtre, marqué de six raies noires; l'écusson est triangulaire et jaunâtre; les élytres sont d'un blanc argrenté avec tous les bords noirs; le dessous du corps est couvert de poils roussâtres; les pates sont noires, avec le bord interne des jambes convert de poils serrís roussitres.

On la tronve dans l'Amérique méridionale. 


\section{La Cétoine Polyphême, Cetonia Polyphemus. \\ G. Goliath. Latr.}

Elle est moins grande que la précédente ; la tête est couverte d'un duvet d'un gris verdâtre, arméc de trois cornes noires, dont une bifide plus longue que les autres; le corselet est d'un vert mat un peu foncé, avec cing lignes longitudinales jamatres; les élytres sont de la mime couleur que le corselct, avec trois rangées longitudinales de taches irrégulières d'un jaune sale; les élytres ont a leur extrémité une petite épine courte; la pièce triangulaire est grisâtre; le dessous du corps est d'un vert luisant, avec les cútés grisittres, et denx taclies de la méme coulcur à l'extrúmité de l'abdomen; les pates sont d'un vert luisant, avec un peu de gris aux cuisses et a la partic interne des jambes postéricures.

On la trouve dans l'Afrique équinoxiale. 
La Cétoine éclatante, Cetonia micans.

\section{G. Goliath, IATR.}

Elle est moins grande que la précédente; les antennes sont noires, tout le corps est d'un vert très brillant; la tète a antérieurement une corne saillante, bifide, dont les divisions sont divergentes, et de chaque côté deux dentelures; le corselet est lisse, finement pointillé; les élytres sont lisses, in peu plus courtes que l'abdomen, et terminées par une petite épine; les pates sont vertes, avec les tarses noirs; les jambes antérieures ont quelques dents aiguës; le sternum est avancé et marq̧ué d'une ligne ferrugineuse.

On la trouve dans l'Afrique équinoxiale.

La Cétoine fastueuse, Cetonia fastuosa.

Cette belle espèce est presque une fois aussi grande que la cćtoine dorée, d'un beau vert mélé d'or et luisant, tant en dessus qu'en dessous; le dessus du corps 
paraît uni, et n'offre de petits points enfoncés que vers les bords; le sternum a une forte ligne imprimée; la lance pectorale a son angle inféricur et latéral couthé en une pointe aiguë; les tarses sont d'un vert bleuâtre; chaque élytre a vers son extrémité la petite bosse que l'on observe dans les autres.

On la trouve dans les provinces mexidionales de la France et en Allemagne.

\section{La Cétoine doréc, Cetonia aurata.}

Elle varie par la grandeur depuis sept jusqu'd dix lignes; sa couleur varic aussi ; elle a les antennes noires, la tète verte, le corselet d'un vert doré, finemont pointillé, les ćly tres d'un beau vert doré ou cuivreux, avec plusicurs taches blanches ondées, et quelques élévations longitudinales; le dessous du corps est cuivreux, très brillant; les patessont d'un vert cuivreux, avec des poils roussâtres sur les cuisses; la poitrine et les côtés de l'abdomen ont aussi des poils de la mème couleur; clle est quelquefois sans ta- 
ches et toute verte, oil entièrement cuivreuse, avec des taches blanches ondées.

On la tronve dans toute l'Europe, sur les fleurs.

\section{La Cétoine verte, Cetonia viridis.}

Cette espèce est de la même taille que la cétoine dorée; elle est entièrement verte; le dessus de son corps est mat, le dessous est luisant; les points dont elle est chargée sont extrèmement petits, ct se confondent sur les élytres, de manière que vues à la loupe ces élytres paraissent très fincment chagrinćes; elles n'ont point d'impression; lcur cólé extérieur offre de petits traits transversaux et irréguliers blanes; leur extrémité a une bosse; une très faible côte ou nervure y aboutit; le dessous de la poitrine, les pates, les côtés de l'alsdomen, ont un duvet comme dans la cétoine dorée.

On trouve cette espèce dans la Hongrie, en Allemagne. 


\section{La Cétoine Morio, Cetonia Morio.}

Elle est encore de la taille de la cétoine dorée; son dessus est d'un noir mat; le dessous est de la même couleur, mais luisant et lavé d'un peu de rougeâtre; les élytres ont une légère côte terminée par une gibbosité; la poitrine et les pates ont un duvet d'un roussâtre obscur.

On la trouve dans le midi de la France; on commence d la rencontrer aux environs de Paris, à Fontaineblcau.

\section{La Cétoine marbrée, Cetonia mar- morata.}

Elle ressemble beaucoup a la cútoinc; dorée les antennes sont noires; elle est d'un vert bronzé brillant; le corsclet a plusicurs petites taches blanches; l'écusson est grand; les élytres sont lisses et convertes de taches blanches irrégulières qui forment des bandes transversales; tout le dessous du corps et les pates sont d'un vert bronzé brillant; on voit quelques poils roux sous le curselet et la poitrine. 
On la trouve en Allemagne, sur le chéue; elle est rare aux environs de Paris.

La Cétoine brillante, Cetonia nitida.

Elle a environ un pouce de long; elle est d'un vert mat, velouté en dessus, et d'un vert doré très brillant en dessous; les antennes sont noires; le chaperon est relevé antérieurement en forme de corne plate; la tète a sur son milieu une épine couchée et avancée en devant; le corselet est bordé de jaune, testacé sur les côtés, et prolongé en pointe entre les élytres, en forme d'écusson ; l'ćcusson est très petit, d'un vert brillant; les élytres sont bordées par une large bande d'un jaune testacé, et souvent elles ont sur le milieu une ligne longitudinale de la mème couleur.

On la trouve dans l'Amérique septentrionale, la Caroline, et la Jamaïque.

La Cétoine marginée, Cetonia marginata.

Elle varie pour la grandeur, clle a quel- 
yuefois un pouce de long; les antennes sont noires; la tète est brune, sans taches; le corsclet est brun, bordé d'une ligne d'un jaune testacé tout autour; l'écusson est triangulaire; les élytres sont brunes et bordées tout antour par une large bande d'un jaune testacé; tout le dessous du corps et les pates sont noirs.

Elle est quelquefois d'un brun plus foncé. On la trouve a Sicrra-Leona et au Sénégal.

\section{La Cétoine du Cap, Cetonia Capensis.}

Elle est un peu moins grande que la précédente; les antennes sont noires; la téte est noire, un peu velue; lc corselet est velu, d'un rouge foncé, arec quelques points blanes et une ligne enfoncée; l'écusson est noir; les élytres sont d'un ronge foncé, avec beaucoup de points blancs, la suture noire et quelques lignes élevíes: le dessous du corps et les pates sont noirs, couverts de poils roussittres; les jambes antéricures ont quelques dents laténales.

Elle se trouve fréquemment sur le's fleurs, au cap de Bonne- Espérance. 


\section{La Cétoine ondée, Cetonia undata.}

Elle a environ huit lignes de long; ses antennes sont noires; la tête est noirâtre, avec quelques taches jaunes; le corselet noirâtre, avec des taches jaunes irrégulières; il se prolonge en pointe entre les élytres, en forme d'écusson; les élytres sont noirûtres, comme veloutées, avec des taches irrégulières jaunes qui forment des lignes transversales en zigzag; le dessous du corps est un peu bronzé; les pates sont noirîtres, avec des poils cendrés.

On la trouve à Cayenne.

La Cétoine interrompue, Cetonia interrupta.

Elle a environ sept lignes; les antennes sont noires; la tête est noire; le corselet noir; il a de chaque côté une ligne d'un rouge jaunâtre, et une ligne longitudinale de même couleur sur le milicu; l'écusson est rouge; les élytres sont noires, avec le bord extérieur rouge, une tache à la base, 
et deux lignes transversales interrompues, de même couleur, sur le milien; le dessous du corps et les pates sont d'un noir luisant. On la trouve au Sénégal.

\section{La Cétoine fasciculée, Cetonia fascicularis.}

Elle a cnviron dix lignes; les antenues sont noires; le corselet est lisse, noir, avec quatre lignes longitudinales enfoncées, blanches; l'écusson est lisse; les élytres sont d'un vert mat foncé; le dessous du corps est noir, couvert de poils serrés assez longs, qui paraissent disposés par faisceaux de chaque côté de l'abdomen; les pates sont noires; les cuisses et le bord intéricur des jambes sont couverts de poils fauves.

On la,trouve an cap de Bonne-Espérance.

La Cétoine versicolor, Cetonia versicolor.

Fille a environ sept lignes de long; les antennes sont noires; la tète est noive; le 
corselet est d'un rouge foncé, bordé de noir, avec deux taches noires et une ligne blanche; l'écusson est noir; les élytres sont d'un rouge foncé, bordées de noir, avec plusieurs taches blanches; le dessous du corps est noir, avec deux taches blanches de chaque côté de la poitrine, et deux rangées de points blancs de chargue cóté de l'abdomen; les pates sont noires, les cuisses velues.

On la trouve aux Indes orientales, et en Egypte.

La Cétoine linéole, Cetonia lineola. G. Rutele. Latn:

Elle a environ huit lignes de long; les antennes sont brunes; elle est d'un brun noir luisant, la tête a une ligne longitudinale jaune sur le milieu; le corselet a une tache jaune de chaque côté, sur larjuclle est un petit point noir; l'écusson est noir, avec une tache jaune; les élytres ont quelquefois une tache jaunc; le dessous du corps est brun mílangé de jaune; les pates sont brunes; les cuisses sont mélangées de brun et de jaune. 
On la trouve à Cayenne, à Surinam, au Brésil.

\section{La Cétoine bicolor, Cetonia bicolor.}

G. Rutèle, Latr.

Elle a environ un pouce de long; ses antennes sont brunes; la tête, le corselet et l'écusson sont d'un vert forcé très luisant; les élytres sont brunes et sillonnées; le dessous du corps et les pates sont d'un vert foncé très luisant.

On la trouve dans l'Amérique méridionale.

\section{La Cétoine velue, Cetonia hirta.}

Cette cétoine est plus petite que les précódentes: son corps est d'un noirâtre obscur, tout hérissé de poils d'un gris rougeâtre; le chaperon est échancré, avec les angles latéraux aigus; le corselet a une cavène longitudinale; les élytres ont quelques petites taches grisatres.

On la trouve aux environs de Paris, en Allemagne, et dans le midi de la France. 


\section{La Cétoine stictique, Cetonia stictica.}

Elle est encore plus petite que la précédente, d'un noir luisant, mếé d'une teinte verdàtre ou bleuatre, peu velue; le chaperon a son bord antérieur concave, avec les angles obtus; la tête a une petite carène; on en voit aussi une le long du milieu du corselet; le dessus du corps, l'anus et les bords de l'abdomen ont des points blanes.

On la trouve dans les mimes lieux que la précédente.

\section{I, X X V II I $I^{e}$ G F N R E. TRICHIE.}

Caractires génériques. Antennes conztes, en masse, composées de dix articles, le premier gros, velu, les suivans presque éganx, arrondis, les trois derniers en masse ovale fevilletec. - Quatre antennules égales, filiformcs, les antéricares composices de quatre articles, les postérieures de trois. Jaubes autérieures dentécs. - Corps conrt, ramassé.

L.r.s trichics sont des scarabées de Linnéc et de M. Geoffroy, dont M. Fabricius a fait un 
genre. Mais M. Olivier a réuni ces insectes aux cétoines, et en a fait une famille de ce genre.

Comme lè trichies diffèrent des cétoines par la forme du corps et par la manière dont elles vivent sous l'état de larves, nous suivrons ce genre établi par Mr. Fabricius.

Ces insectes ont les antennes composćes de dix articles, dont les trois derniers forment une masse ovale, feuilletée; la tète inclinée, allongée, plus étroitc que le corsclet; le chaperon est àvancé, rebordé et échaneré; les yeux sont petits, arrondis, saillans; la bouche est composće de deux mandibules presque membraneuses, obtuses, épaisses et sans dentelures; de deux mîchoires divisées en deux et terminćes par un lobe velu; d'une lèvre inférieure et de quatre antennules égales.

Lc corselet est moins large que le corps; il est bordé, un peu convexe, arrondi postéricurement et sur les côtés; l'écusson est triangulairc.

Les dytres sont de forme carréc, un peu aplaties en dessus, un peu bossues à la base 
et échancries a l'extrémité; clles couvrent deux ailes membrancuses, replices quand l'insecte n'en fait point usage pour voler.

I.e corps est court, ramassć ; l'abdomen cst composé de six ameaux, dont le dernier est dans une position presque verticale par rapport aux autres, et terminé en pointe mousse. Dans quelques especes, la femelle a une tarière assez longue, pointue, denteléc supérieurement, ou sans dentelures.

Les pates sont assez longues et minces; les jambes antérieures sont dentées latéralement; les intermédiatires et les postéricures ont quelques épines; les tarses sont longs, filiformes, composés de cincj articles presque égaux, dont le dernier est armé de deux crochets assez forts, longs, arqués et pointus.

On trouve ces insectes, en été, sur les fleurs et sur les trones des arbres; les femelles, qui sont pourvues d'une tarière, fréquentent les bois cariés pour y díposer leurs ocufs; leurs larves ressemblent à eelles des cétoines; elles out le corps mou, allongé, cylindrique, un peu aplati en des- 
sous; composé de douze anneaux, sur lesquels sont placés neuf stigmates de chaque cỏté; leur tète est écailleuse, munie de deux dents trìs fortes, et de deux antennules filiformes, composćes de cinq articles; leurs yeux sont cachés sous les enveloppes de la larve et de la nymphe; elles ont six pales écailleuses, placées sur les trois premiers anneaux.

Les larves vivent dans le bois mort, et dans les racines des arbres qu'elles percent et rongent. On ignore le temps qu'elles passent sous la forme de larves.

Ce genre ne contient que scize ou dix-luit espèces : on n'en trouve que quatre aux environs de Paris. Nous allons passer a leur description.

La Trichic ermite, Trichius eremita.

Elle a environ quatorze lignes de long; les antennes sont noirâtres; te chaperon est carré, rebordé ; le corselet a une élévation mansversale à sa partic antéricure, et deux Iongitudinales sur le milieu; l'écusson ese 
grand, triangulaire; les élytres sont un peu ? raboteuses; tout le corps, tant en dessis qu'en dessous, est d'un brun noirâtre bronzé; les pates sont de la même couleur ; les jambes antéricures ont trois dents latérales, les autres ont quelques épines.

On la trouve dans presque toute l'Europe, sur les troncs d'arbres cariés. La larve vit dans les trones des saules, des poiriers et de quelques autres arbres. Elle est rare aux environs de Paris.

\section{La Trichie noble, Trichius nobilis.}

Elle est une fois plus petite que la trichic ermite; elle est d'une belle coulcur verte brillante, doréc ou cuivreuse en dessus; les antennes sont noires; le chaperon est arrondi, échancré; le corselet est bordé, fincment pointillé; il a un enfoncement longitudinal sur le milicu; l'écusson est petit, en coeur; les élytres sont un peu raboteuses, plus courtes que l'abdomen; tout le dessous du corps est cuivreux et couvert d'un duret roussître, fin et serré; 
les côtés et l'extrémité de l'abdomen ont une rangée de taches blanches; les pates sont cuivreuses.

On la trouve en Europe, sur les fleurs. Elle n'est pas commune aux environs de Paris.

\section{La Trichie fasciée, Trichius fasciatus.}

Elle a environ cinq lignes de long; les antennes sont noires; la tête et le corselet sont noirs, entièrement couverts de poils roux; l'écusson est noir; les élytres sont jaunes, sans poils, avec chacune trois grandes taches noires qui forment trois bandes transversales interrompues; le dessous du corps est d'un noir bronzé, couvert d'un duvet jaunattre; les pates sont noires.

On la trouve en Europe, sur les fleurs. Elle est commune aux environs de Paris.

La Trichie lunulee, Trichius lunulatus.

Elle a environ cing lignes de long; les antennes sont noires; le chaperon est échancré; tout le corps est d'un bleu noirâtre lui- 
sant, convert d'un duvet roussattre très court; les élytres sont beaucoup plus courtes que l'abdomen, elles ont chacune deux petites lignes transversales, courtes, de couleur jaunâtre le long du bord extérieur, et quelques lignes longitudinales peu élevées; le dessous du corps est couvert de poils roussâtres; l'extrémité de l'aldomen a deux grandes taches oblongues, blanches; les pates sont d'un vert noirâtre.

On la trouve dans la Caroline.

\section{La Trichie delta, Trichius delta.}

Elle a environ quatre lignes de long; ses antennes sont brunes; le chaperon est échancré, noir, avec le bord jaunâtre ; la tête est noire, avee trois tacles jaunes; le corselet est noir, bordé de jaune tout autour : il a sur le milieu un triangle formé par des lignes jaunes; les élytres sont d'un jaune testacé, avec quelgues points noirs ; le dessous du corps est noir, entierement convert d'une poussière ćcaillcuse, grrise; les cuisses sont ferrugineuses; les jamibes et les tarses sont noirs, les postérieurs sont très longss. 
On la trouve à la Caroline, la Virrinie, et dans le Maryland.

\section{La Trichie théfiniptère, Trichius hemipterus.}

Elle est de la longueur de la précédente, mais moins large ; la tète est noire, chagrinée ; le corsclet est bordé, inérgal, chagriné, marqué de deux lignes longitudinales, ćlevées : il a quelques taches irrégulières, blanches; lesćlytres sont aplaties, beaucoup plas courtes que l'abdomen; elles ont quelques taches blanches; tout le corps est noir, plus ou moins couvert d'écailles blanchattres; l'abdomen de la femelle est terminé par une tarière longue, pointue, dentéc à sa partie supérieure; les jambes antéricures ont cing dentelures.

On la trouve dans presque toute l'Europe, sur les fleurs. La femelle dépose ses œufs dans les bois cariés. Cet insecte est commun aux envirous de Paris. 


\section{La Trichic canaliculéc, Trichius canaliculatus.}

Elle est de moitié plus petite que la précédente, à laquelle elle ressemble beaucoup; elle a les antennes brunes; la tête très inclinée; le corselet est fortement rebordé, et ses bords latéraux sont un peu en scie; il a un sillon longitudinal très profond sur le milieu, et deux lignes élevées; les élytres sont très courtes, un peu strićes; tout le corps est d'un brun marron, plus ou moins couvert de petites écailles ferrugineuses. L'abdomen de la femelle est terminć par une tarière assez longue et pointuc, sans dentelures; les jambes antérieures ont trois épines latérales.

On la trouve au cap de Bonne-Espérance, et à la Caroline.

\section{La Trichie de la châtaigne, Trichius} castanea.

G. Crémastocheile. Latr.

Cet insecte est tout noir ; lc premier article de ses antennes, celui de la base, est 
grand, large, d'une forme triangulairc; la lèvre inférieure occupe tout le dessous de la tète, et forme, par sa concavité, une sorte de bassin ou d'écuelle; le bord antéricur du chaperon se courbe et se replie autour de cette pièce.

Cet insecte se trouve dans l'Amérique septentrionale.

\section{LXXIXe GENRE. HEXODON.}

Caractères génériques. Antennes composées de onzc articles; le prenier gros, velu, renflé à l'extrémité; le second très petit, le troisième assez long, les trois derniers en unasse ovale, fevilletée. (uatre antennules filiformes; les antérieures de quatre articles, dont le premier est très petit, le dernier allongé; les postérieures courtes, composées de trois articles, dont le premier et le second sont égaux et coniques, le dernier est ovale, allongé. - Jambes antérieures dentées, - Corps arrondi, plat en dessons.

M. Olivien est le premier entomologiste qui ait décrit ces insectes; il lcur a donné le nom d'hexodon, mot qui, en grec, sisnifie six dents, parce que les matchoires de 
ces insectes ont six dents cornées très apparentes.

Les hexodons, selon cet auteur, ont quelques rapports avec les hannetons et les cétoines; mais ils different des ećtoines, parce qu'ils ont une lèvre supérieure et des mâchoires cornées; ils diffèrent des hannetons par leurs mâchoires, qui sont grandes et six-dentées, et par leurs antennes, qui sont: composćes de onze articles.

Les hexodons ont la tête beaucoup plus itroite que le corselet; les yeux arrondis $\mathrm{ct}$ pen saillans; la bouche composéc d'une livre supéricure, de deux mandibules cornóes, atrquées, presque dentées à leur exIrémité; de deux màchoires, dures, cornées, terminées par six dents, dont une scule a l'extrímité; d'une lèvre inféricure et de quatre antennules.

Le corselet est large, lérgèrement rebordí: sur les côtés, échancré antéricurement, un peu avancé postéricurement.

L'écusson est large et tries court ; les ćlyfres sont convexes, un peil rebordés stu les côtrís. 

Insectes.

Pl. Go.
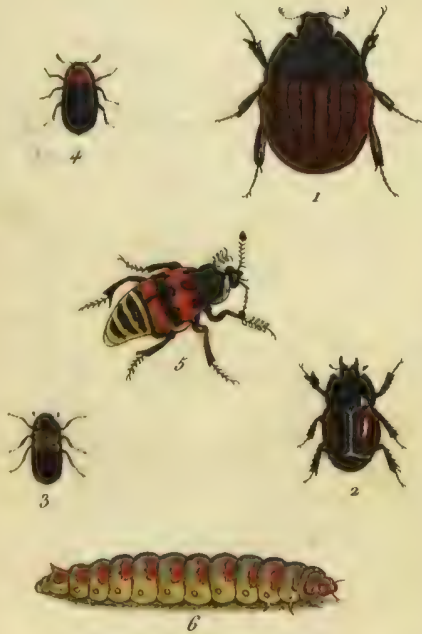

prescuere del.

Dedittien of feuly.

1. I'H. réticulè,

2.Lisc rciniforme.

3.Denu, du. Jared. t. Tet. des Bolets.

b. Nec fossoveur.

6. Sa I.arvé. 
Le corps est ovale, convexe en dessus, presque plat en dessous; les pates sont de longacur moyenne; les jambes antérieures ont trois dents latérales; les autres ont des poils courts et rudes; les tarses sont filiformes, composés de cinq articles, dont les quatre premiers sont un peu plus gros at leur extrémité, et terminés par trois on quatre épines.

Ces insectes se nourrissent des feuilles des arbres et des arbrisseaux. M. Olivier ne sait point s'ils sont aussi destructeurs que les hannetons, et s'ils multiplicnt autant. Leurs larves ne lui sont point counues; mais il croit qu'elles ressemblent à celles des hannetons, et qu'elles vivent dans la terre.

On ne connaît encore que deux esprèces de ce genre. Nous domnerons la description d'une de ces deux espèces.

\section{L'Hexodon réticulé, Trexodon reticulatum.}

Il est ovale, convexe en dessus, presque aplati en dessous; ses antemues sont noires; 
le premier article est poilu, la masse est ovale et feuilletéc; la tite et le corselet sont noirs; l'écusson est large, court et noirâtre ; les élytres sont cendrées, avec deux nervures longitudinales, élevées, réticulées et noirâtres; le dessous du corselet et de la poitrine est noirattre; l'ablomen est d'un brun ferrugineux; les pates sont noires; les jambes antérieures ont trois dents latérales; les autres ont des poils courts asse\% roides.

On le trouve a Madagascar.

\section{XX Xe GE, N R E.}

ESCARBOT.

Caructères génériques. Antennes coudées, en masse, composées de onze articles, dont le premicr très long, les autres courts et globaleux, les trois derniers en masse solicle, ovale. - Quatre antennules filiformes; les antérieures composées de quatre articles, dont le dernier obtus; les postérieures de trois. - Jambes antérieures dentées. - 'Této petite, un peu cachée dans le corselet.

I,INNí avait d'abord placé les escarbots avec les coccinclles, dont ils different par 
les autennes et la forme du corps. Il les a ensuite séparés, et en a fait un genre, sous le nom d'hister. M. Geoffroy a adopté ce genre de Linné, auquel il a donné le nom d'attclabus, et en français, escarbot. M. Olivier a conservé à ces insectes les noms que ces deux naturalistes leur ont donnés; ainsi les escarbots de cet anteur sont les histers de Linné, et les escarbots ou attelabus de M. Geoffroy.

La forme des antennes des escarbots suffit pour les distinguer de tous les insectes des genres précédens, parce que, quoique la masse qui les termine soit composéc de trois articles, ces articles ne sont point séparís comme ils le sont aux antennes des scarabées, des trox, des cétoines et des trichies; ils sont au contraire réunis, et forment une masse qui, à la vue simple, paraît être d'une seule pièce; de plus, les antennes des escarbots sont coudées et font un angle vers leur. milieu, et elles sont de la longueur de la tête.

Ia tite est tris petite : l'insecte la tient plus ou moins enfoncée sous le corselet. 
La bouche est composie d'une livve supéricure, de deux mandibules cornées, très dures, grandes, arquées, simples ou unidentées intérieurement; de deux mâchoires, d'une lève inférieure, et de quatre antennules.

Le corselet est grand, échancré antérieurement, presque droit postérieurement, légèrement bordé sur les côtés, et ordinairenent lisse en dessus.

L'écusson est triangulaire et trìs petit, quelquefois peu visible.

Les élytres sont plus courtes que l'abdomen, point bordées: elles couvrent deux ailes membraneuses, replices, dont l'insecte se sert lorsqu'il veut voler.

Les pates sont de longueur moyenne; les jambes sont courtes, aplaties; les antéricures ressemblent a celles des scarabées, elles ont quelques dents très marquées; les intermédiaires et les postérieures sont épineuses; les tarses sont filiformes, composés de cinq articles; le dernier est un peu plus long que les autres, et armé de deux petits crochets pointus. 
La larve de ces insectes n'est point comue; mais comme on trouve l'insecte parfait dans les charognes et les excrémens des animaux, on peut croire que leurs larves vivent dans ces matières. Quelques espèces cependant se trouvent sous les écorces des arbres morts. On voit courir les escarbots au printemps et en été, sur les sables et dans les chemins; dès qu'on les touche, ils cachent leurs antennes et leurs pates sous leur corps, et restent immobiles dans cette position, jusqu'ì ce qu'ils croient qu'il n'y a plus de danger pour cux, et ensuite ils se remettent en marche.

Ce genre est composé d'un assez grand nombre d'espices, dont on trouve la majeure partic en Europe, et aux environs de Paris.

L'Escarbot unicolor, Hister unicolor.

Il est enticrement d'un noir luisant; la tite est petite, lisse; les mandibules sont srandes, avancées; le corsclet cst lisse, avec deux lignes un peu enfoncées sur les cótés, 
et une le long du bord antéricur; les élytres ont trois stries longitudinales peu marquées le long du bord extérieur; les jambes antérieures ont plusicurs dents latérales; les autres sont armúes d'épines.

On le trouve dans presque toute l'Europe : il est commun aux environs de Paris.

\section{L'Escarbot quadrimaculé, Hister quadrimaculatus.}

Il a environ quatre lignes; il est d'un noir luisant; les élytres ont quelques stries peu marquées et deux taches d'un rouge brun, l'une à la base, et l'autre vers le milieu: cette dernic̀re est plus grande que l'autre; les jambes antérieures ont trois dents latérales.

On le trouve dans presque toute l'Europe: il est commun aux environs de Paris.

L'Escarbot réniforme, Hister reniformis.

Celui quion trouve aux environs de Paris "st ì peu près de la grandeu du prícédent; 
mais dans les départemens méridionaux de la France, il est deux ou trois fois plus grand; ses antennes sont de la longueur de la tête; les mandibules sont avancées; le corselet cst lisse; les élytres ont quelques stries longitudinales peu marquées, avec une tache réniforme d'un rouge brun; tout le corps est noir luisant; les jambes antéricures ont quelques dents latérales.

Il est rare aux environs de Paris, et tris coinmun dans les départemens méridionaux de la France.

\section{L'Escarbot brouzé, Hister ceneus.}

Il est beaucoup plus petit que l'hister unicolor; il est entièrement d'un noir bronzé, très brillant; le corselet est très finement pointillé sur les bords latéraux; les élytres sont finement pointillées; elles ont quelques stries à peine marquíes, et très courtes; les dentelures des jambes antéricures sont peu marquées.

On le trouve en France, en Angleterre: il est commun aux envitons de Paris. 
L'Escarbot déprimé, Hister depressus.

Il a une ligne et demie de long; il est noir, très brillant; le corps est aplati; les antennes sont noires, avec la masse ferrugineuse; les ćlytres ont quatre stries longitudinales; les jambes antérieures ont quatre dents latérales, les intermédiaires trois, et les postérieures deux.

On le trouve en Europe, sous l'écorce des arbres: il n'est pas rare aux environs de Paris, au commencement du printemps.

L'Escarbot globuleux, Hister globosus.

Cette espèce diffère beaucoup des précédentes; tout son corps est d'un noir terne; les antennes sont plus longues que la tète; le corselet est chagriné, avec quatre lignes longitudinales, élevées; les élytres sont presque aussi longues que l'abdomen, et profondément striées; Ies dentelures des jambes antérieures sont peu marquées.

On le tronve dans les départemens méri- 
dionaux de la France : il est rare aux environs de Paris : il habite les bouses.

\section{L'Escarbot sillonné, Hister sulcatus.}

Il ressemble beaucoup au précédent, mais il est plus petit; il n'a qu'une ligne de long; tout son corps est noir, globuleux; sa tête est très petite, entièrement cachée sous le corselet; le corselet et les élytres sont très profondément striées.

On le trouve aux environs de Paris, ordinairenent dans les fientes de cheval; dès qu'il entend le moindre bruit, il cache ses antennes et ses pates sous son corps; et comme il est très petit, il échappe aux recherches des entomologistes.

\section{L'Escarbot bimaculé, Hister bima- culatus.}

Il a environ deux lignes de long; le corps est noir, luisant; les élytres sont striées; elles ont chacune une tache d'un rouge brun, vers l'extrémité; les jambes antérieures ont cing ou six dents latérales. 
On le trouve dans presque toute l'Europe: il est commun aux environs de Paris.

\section{X X X I ${ }^{e}$ GENRE.}

DERMESTE.

Caractères génériques. Antennes courtes, en masse, composées de dix articles, dont le premier plus gros, les autres égaux, presque globuleux, les trois derniers en masse perfoliée, - Quatre antenoules filiformes, inégales; les antérieures composées de quatre articles égaux, les postérieares de trois. - Jambes simples sans dentelures.

LES dermestes ont les antennes plus Iongues que la tête; la masse qui les termine est assez grosse, et les trois articles qui la composent paraissent comme cnfilés par leur milieu. Ce caractère sert à les distinguer des tétratomes, dont la masse des antennes est de quatre articles.

Leur tête est petite, inclinée, arrondic, un peu enfoncée dans le corselet; les yeux sont petits, arrondis et saillans.

Ia bouche est composée d'une lèvre supéricure, de deux mandibules cornćes, un 
peu arquées, aiguës, armées intéricurement d'une dent peu saillante; de deux mâchoires; d'une lèvre inférieure, et de quatre antennules.

Le corselet est peu bordé, convexe, arrondi postérieurement, et un peu moins large que les élytres; l'écusson est petit, triangulaire.

Les élytres sont convexes, de la longueur de l'abdomen; elles recouvrent deux ailes membrancuses, repliées lorsque l'insecte n'en fait point usage pour voler.

Les pates sont de longueur moyenne; les jambes n'ont ni dents ni épines; les tarses sont filiformes, le dernicr article est un peu plus long que les autres; il est armé de deux petits crochets minces, très pointus.

Le corps est linéaire, un peu convexe en dessus et en dessous.

Depuis long-temps on connait les dermestes par les dégats que font leurs larves dans les collections d'histoire naturelle et les magasins de pelleteries; elles détruisent les viseaux, les quadrupèdes et les insectes desséchés; elles se nourrissent ordinairement 
de leurs cadavres, rongent les poils, la peau, la substance charnue, les parties nerveuses, et. n'y laissent que les os, qu'elles rongent même un peu; enfin, clles en font des sujuclettes parfaits. On trouve aussi ees larves dans les offices et les garde-manger, où elles rongent le lard et autres substances; il n'est pas facile de se garantir de ces insectes destructeurs, dont la petitesse de la larve la met a l'abri des recherches; mais, comme il n'y a dans la nature aucun animal qui n'ait son utilité, soit générale, soit particuliere, il semble que les dermestes soient destinés à détruire et à décomposer entièrement les cadavres des animaux, pour former de leurs débris un texreau qui, it son tour, sert d'aliment ì d'autres productions, surtout aux plantes. L'air et l'humidité ne parviennent ì faire cette décomposition que bien plus lentement. Ces insectes, aidés des boutcliers et des nécrophores, achèvent de ríduire à leurs premiers élémens les restes des calavres que les larves de quelques mouches ont laissés; car ces deruières larves ne mangent la chair que tandis qu'elle est molle, 
ct ne touchent point aux parties nerveıses et tendineuses.

Les larves des dermestes sont plus on moins velues; quelques unes ont, ì l'extrémité du corps, une touffe de poils, qui forme une espèce de pinceau; telles sont celles du dermeste du lard et celles du dermeste pelletier; leur corps est composé de douze anneaux; clles ont la tète écailleuse, armée de deux mandibules fortes; deux antennes, et quelques barbillons; six pates érailleuses, attachées aux trois premiers anneaux. Elles changent plusieurs fois de peau, pour passer à l'état de nymphe; elles ne s'enferment point dans une coque, elles cherchent seulement un endroit ćcarté; et peu de temps après cette métamorphose, elles deviennent insectes parfaits.

Les dermestes vivent peu de temps sous leur dernière forme; on les trouve ordinairement sur les fleurs; ceux qu'on rencontre sur les cadavres ne paraissent s'en rapprocher que pour y déposer leurs oufs; de même que les cscarbots ct quelques autres insectes, dès qu'on les touche, ils retitent

III, 
leurs antennes et leurs pates sous leur corps, restent sans mouvement, et paraissent morts. Souvent on ne parvient it les faire sortir de cet état d'inaction, qu'en les piquant ou en les exposant à une forte chaIeur ; alors ils se remettent sur leurs pates, et cherchent it s'enfuir.

Ce geure est composé d'une quarantaine d'espèces, dont une partic se trouve en Furope, et plusieurs aux environs de Paris. Nous allons en décrire quelques unes.

\section{Le Dermeste du lard, Dernestes lardarius.}

Il a environ trois lignes de long; les antcmes sont brunes; la tête ct le corselet noirs; les élytres sont noires; clles ont une large bande d'un roux cendró, depuis leur base jusque vers leur milieu, sur laquelle on voit quelpues points noirs; le dessous du corps et les pates sont noirs; la poitrine a quelyues poils d'un roux cendré.

If habite presque toute l'Furope : on le trouve souvent dans les maisons; sa larve 
est une des plus destructives de toutes calles de ce genre.

\section{Le Dermeste Souris, Dermestes murinus.}

Il est un peu plus petit que le précédent; sa tîte et son corselet sont noirs, couverts en quelques endroits de poils d'un roux cendré; les élytres sont noires, avec quelquues poils d'un gris cendré; l'écusson est couvert de poils de la méme couleur; tout le dessous du corps est blanc; les pates sont noires.

On le trouve dans presque toute l'Europe, sur les endavres.

\section{Le Dermeste Pelledier, Dermestes Pellio.}

Il est moins grand que le précédent ; il est oblong, noir, ou d'un beun noirattre; le corselet a quelquefois trois petits points blanchitres vers sa partie postérieure; les ilytres ont un point blane vers le milien; les pates sont noires. 
On le trouve dans presque toute l'Europe, sur les fleurs; sa larve se nourrit de toute sorte d'animaux desséchés.

Le Dermeste destructeur, Dermestes macellarius.

Il est un peu plus petit que le précédent; tout son corps est noir et luisant; ses pates sont d'un brun ferrugineux.

On le trouve en Europe : il est commun aux environs de Paris.

\section{Le Dermeste velouté, Dermestes}

tomentosus.

G. Cholève. Latr.

Il a environ deux lignes de long; Ics antennes sont brunes; la tẻte et le corselet bruns, couverts de poils jaunes; les yeux noirs; les élytres brunes, couvertes de poils jaunes; les pates sont brunes.

On le trouve aux environs de Paris, dans les bois vicux et pourris.

Le genre cholève est assez nombreux 
en espèces. M. Spence, natmaliste anglais, a publié une monographic de ce genre dans les transactions de la Société Limnéenne de Londres, tom. xx, pag. 123; il cn décrit dix-huit espèces : on en trouve plusieurs aux environs de Paris.

La Cholève roussatre, Choleva mufescens, est noire, avec les élytres et les pates grises; les élytres sont presque striécs; les antennes sont assez longues et grêles. On la trouve sous Ies ćcorces des arbres.

La Cuolève soyeuse, Cholera sericca, est noiratrc, avec un duvet soyeux; ses pates sont brunes, de mène que ses élytres.

\section{Le Dermeste ondé, Dermestes undatus.}

Cette jolic espèce est moins grande que le dermeste pelletier; ses antennes sont noires; le dernier article est allongé, terminé en pointe; la títe est noire; le corse. let noir, avec trois petites tache's blanches formées par des poils; les élytres sont noires, avec quelques points blaties et deux. lignes ondées de la méme couleur, formées 
par des poils; tout le dessous du corps et les pates sont noirs.

On le trouve an nord de l'Europe, en Angleterre, et aux environs de Paris, sur les fleurs.

\section{LXXXII ${ }^{\circ}$ GENRE. TÉTRATOME.}

Caractères génériques. Antennes en masse; les premiers articles petits, arrondis, les quatre derniers larges, aplatis. - Quatre antennules inégales; les antérieures plus longues, composćes de quatre articles, dont le dernicr allongé, en masse, ovale; les postérieures de trois articles. - Jambes simples, sans dentelures. - Corselet bordé.

Ces insectes n'ont été connus par aucun auteur. M. Fabricius est le premier qui les ait décrits; il leur a donné le nom de tétratomes, probablement à cause de leurs antenues, dont la masse est composée de quatre articles. Les tétratomes ont un peu de ressemblance avec les dermestes par la forme, mais elles en diffèrent par les antennes, colles des dermestes n'ayant lewr masse composice que de trois articles. 
Les antennes sont presque de la longueur du corselet, écartées à leur base, et insérées au-dessous des yeux.

La tête est petite, un peu enfoncéc sous le corselet; les yeux sont grands, arrondis, saillans de chaque cóté de la tête; la bouche cst composée d'une lèvre supéricure, de deux mandibules courtes, épaisses, cornées, terminées par une pointe aiguë; de deux mâchoires membraneuses, bifides; d'une lèvre inféricure, et de quatre antennules.

Le corselet est grand, convexe, rebordé; l'écusson est arrondi.

Les élytres sont convexes, de la longucur de l'abdomen; clles recouvrent deux ailes membraneuses, replićes quand l'insecte n'en fait point usage pour voler.

Les pates sont de longueur moyenne, les jambes simples, les tarses filiformes, le dernier un peu plus long, et armé de deux crochets. *

? On a recounu que ecs insectes avaient les quatre premiers tarses composés de cinq articles, et les derniers de quatre, ce qui les cloigue des dermestes et les rapproche des diapieres. 
Tout le corps est un peu allongé, convexe en dessus.

La larve des tétratomes n'est point connue. Le seul insecte parfait que nous connaissions se trouve aux environs de Paris, dans les bolets, et il est présumable que sa larve se nourrit de cette substance. Ce genre n'est composé que de trois espèces, qu'on trouve en Europe; nous décrirons celle des environs de Paris.

La Tétratome des bolets, Tetratoma fungorum.

Elle a environ deux lignes de long; ses antennes sont rousses à la base, avec la masse brune; la tête est noire, luisante; le corselet est testacé, luisant, fmement pointillé et bordé; les élytres sont noires, luisantes et pointillées; le dessous du corps est brun; les pates sont testacées.

On la trouve en Allemagne, et aux environs de Paris, dans les bolets. 


\section{GENRE.}

\section{NÉGROPHORE.}

Caractères génériques. Antennes en masse; premier article gros et assez long, les autres courts et presque globulenx; les quatre derniers très gros, aplatis, en masse perfoliée. - Quatre antennules égales, filiformes; les antéricures composées de quatre articles, dont le premier très court; les postérieures de trois, dont le premier plus long que les antres. - Corselet bordé, ăplati.

M. Fabricius a fait un grente de ces insectes, que Linné a placés parmi les boucliers, et MI. Geoffroy avec les dermestes. M. Olivier a adopté ce genre, auquel M. Fabricius a donné le nom de nécrophore, qui signifie fossoyeur, parce que ces insectes cachent dans la terre les petits animaux dont ils se nourrissent.

Les antennes des nécrophores les font aisément distinguer des dermestes et des bouclicrs. Nous avons vu que celles des dermestes sont terminées par une masse de trois articles: celles des necrophores sent 
terminées par quatre articles, qui forment une massc très grosse et presque arrondie, au lieu que les antennes des boucliers sont seulement un peu plus grosses a l'extrémité.

Les nécrophores ont les antennes de la longucur de la téte, insérées à sa partie antérieure; la téte un peu inclinéc, assez grande, moins large que le corselet; les yeux petits, point saillans; la bouche composée d'une lèvre supérieure, de detix mandibules cornées, arquées et pointues; de deux mâchoires formées de deux pièces plus courtes l'une que l'autre; d'une lèvre inférieure, et de quatre antennules.

Le corselet est rebordé tout autour, aplati en dessus, plus ou moins échancré antéricurement, arrondi sur les côtés; l'écusson est triangulaire.

Les élytres sont plus courtes que l'abdomen; elles couvrent deux ailes membraneuses, dont l'insecte fait usage pour voler.

Tout le corps est allongé ; l'abdomen est composé de six anncaux, et terminé en pointe; les derniers anneaux sont un peu inclinés. 
Les pates sont assez longues; les cuisses yrosses; les jambes antérieures courtes, armées d'une dent latérale très saillante, et d'une épine à leur extrémité; les autres ont aussi une ou plusieurs épines à leur cxtrémité; les tarses intermédiaires et les postérieurs sont filiformes; les antérieurs sont larges, aplatis, et garuis de poils en dessous.

On trouve les nécrophores sur les cadavre's en putréfaction; aussi ces insectes ont une odeur de charogne très forte, qu'ils conservent míme long-temps apre's leur mort, et qu'ils communiquent aux boîtes dans lespuelles on les renferme. Ils se nourrissent de ces matières dégoûtantes, qu'ils sentent de très loin. Lorsqu'ils rencontrent une taupe, ou une souris morte, plusieurs se réunissent pour l'enterrer, afin de la manger plus commodément; ils creusent la terre en commun, et mettent beaucoup d'adresse et d'activité dans ce travail. C'est aussi dans les cadavres qu'ils déposent leurs neufs, et que leurs larves vivent.

Ces larves sont longues, d'un blane gri- 
sâtre, avec la tête brune; leur corps est composé de douze anneaux, dont chacun est garni à sa partic supérieure d'une petite plaque écailleuse, d'un jaune rougeâtre; la plus grande partie de ces plaques ont plusieurs petites pointes; elles ont six pates écailleuses très courtes, attachées aux trois premicrs anneaux. Pour se changer en nymphes, ces larves s'enfoncent en terre, it plus d'un pied de profondeur; elles s'y forment une loge qu'elles enduisent de matic̀res gluantes, s'y changent en nymphes, et restent environ un mois sous cette forme, avant de devenir insectes parfaits.

Ce genre est composé d'une douzaine d'espèces, dont on trouve plusicurs aux environs de Paris, que nous décrirons.

\section{Le Nécrophore fossoyeur, Necrophoms vespillo.}

Il a environ dix lignes de long; ses antennes sont noires à la base, avec les trois derniers articles ferrugineux; la tète est noire; le corselet est noir, couvert de poils 
roux; les élytres sont noires, plus courtes que l'abdomen : elles ont deux bandes transversales ondées, d'un jame roux; le dessous du corps est noir, avec des poils roussitres fins et serrés sur la poitrine; les pates sont noires.

On le trouve dans presque toute l'Europe, sur les cadavres : il répand une odcur très fétide.

J'ai dans ma collection un individu $\mathrm{Je}$ cette espèce, qui n'a que quatre lignes de longueur : je l'ai trouvé aux environs de Paris.

\section{Le Nécrophore mortuaire, Necro- phorus mortuorum.}

Il est un peu plus petit que le précédent, auquel il ressemble beancoup : il n'en differe que par ses antennes, qui sont noires.

On le trouve à Paris; mais il est plus rare que le précédent. 


\section{Le Nécrophore germanique, Necro- phorus germanicus.}

Il est beaucoup plus grand que le fossoyeur; noir, avec une tache ferrugineuse ì la partic antérieure de lat tête; le corselet est fortement bordé : il a une ligne enfoncée sur le milieu; les élytres sont plus courtes que l'abdomen, tronquíes à leur extrémité, pointillées, avec trois lignes longitudinales peu marquées, et le bord extéricur recourbé et ferrugineux; le dessous du corps est noir, avec quelques poils ferrugineux vers la poitrine; les cuisses sont grosses; les jambes antérieures ont une dent trìs forte, et une épine à l'extrémité.

M. Olivier dit que ect insecte a la masse des antennes ferrugineuse; $j$ 'en ai plusicurs individus dans ma collection, qui ont tous les antennes noircs: c'est le necrophore inhumesur qui les a ferrugineuses.

On le trouve en Allemagne, sur les cadavres : il est assez rare aux environs de Paris. 


\section{Le Nécrophore inhumeur, Necro- phorus humator.}

Il est un peu moins grand que le précédent, entièrement noir, à l'exception de la masse des antennes, qui est ferrugineuse; le corselet a une ligne transversale, un sillon longitudinal sur le milieu, et une petite éminence de chaque côté de sa partie antérieure; les élytres sont pointillées, et elles ont chacune une ligne élevée peu marquée.

Il habite l'Allemagne, et les environs de Paris : on le trouve sur les cadavres. 


\section{GEINRE。}

\section{BOUCLITR.}

Caractères génćriques. Antennes en masse perfolice, un peu comprimées, composées de onze articles, le premier allongé, les autres plus courts et plus larges, le dernier ovale. - Quatre antennules inégales, filiformes; les antéricures un pen plus longues, composées de quatre articles, dont le premicr tres court et tres petit, et le second gros et coniquac; les postéricures de trois articles, le premier plus long que les autres. - Corselet et élytres bordés.

L.Es boucliers ont été nommés silphe par Iinne; MI. Geoffroy leur a domé en latiu le nom de peltis, et en francais celui de bouclier; M. Olivier a conservé à ces insectes les noms que ces deux naturalistes leur ont donnés.

Linné a placé beaucoup d'autres insectes avec les bouclices, mais les naturalistes qui ont écrit depuis lui les ont séparés, et en ont fait des genres dont nous donnerons les caractères.

On distingue les boucliers des nécropho- 
res, qui sont des silpha de Linné, par les antennes et la forme du corps.

Les antennes des boucliers sont moins longues que le corselet; le premier article est le plus long de tous; les autres sont presque érgux, et le dernier est ovale : elles sont insérées à la partic antérieurc de la tète, au-dessous des yeux.

La tìte est petite, étroite, allongée; quelquefois l'insecte la porte hotizontale, mais le plus souvent inclinéc, et une partie est cachée sous le corsclet; les yeux sont petits, arrondis, peu saillans; la bouche est composée d'une lèvre supérieure, de deux mandibules cornées, arquées, simples, un peu ciliées intérieurement; de deux matchoires comérs ì leur hase, presque membraneuses dans le reste de leur longueur, garnics de poils dans cette partic, et munies d'une dent cachie par ces poils; d'une livre inféricure, et de quatre antennules.

Le corselet est plus étroit que le corps, if est couvert par une platyue ćcailleuse, domı les bords sont plus ou moins grands et pre's- 
que aussi larges que les élytres: c'est cette pièce qui a fait donner à ces insectes le nom de bouclier; l'écusson est triangulaire.

Les élytres sont minces; dans quelques espèces elles sont plus courtes que l'abdomen : elles ont extérieurement un large bord relevé qui forme une espèce de gouttière, et en dessous une marge qui recouvre la poitrine et une partie des côtés de l'abdomen. Dans quelques espèces les ailes manquent entièrement, ou sont très courtes; dans d'autres elles sont replićes sous les élytres, et l'insecte paraît en faire peu d'usage; il se sert plus volontiers de ses jambes.

L'abdomen est large, conique it l'extrémité, divisé en six anneaux; l'insecte allonge souvent beaucoup les deux ou trois derniers, qui sont très mobiles.

Les pates sont de longueur moyenne; les euisses un peu renflées; les jambes aplaties, larges a l'cxtrémité, armées intérieurement de petites pointes roides et terminées par deux épines longues et droites; 
les tarses de la premic̀re paire ont les quatre premiers articles courts et larges; ceux des intermédiaires et des postérieures sont filiformes et presque égaux entre eux; le dernier article de tous les tarses est armé de deux crochets forts, recourbés, très pointus et écartés l'un de l'autre.

Les boucliers, de mène que les nécrophores, exhalent une odeur très forte et très désagréable; aussi vivent-ils comme ces insectes, des matières animales en putréfaction : on les trouve quelquefois courant dans les champs ou sur le sable, mais le plus ordinaircment sur les cadavres à demi pourris, ou dans les excrémens des animaux: ils y sont continuellement occupés it fouiller; ce sont ces matières qui leur communiquent la mauvaise odeur qu'ils répandent, car ceux qui ne font que de naître et qui n'en ont pas encore mangé, n'ont point l'odeur dégoùtante des autres. Quand on prend ces insectes, souvent on leur voit sortir par l'anus une goutte d'une liqueur noire, bourbeuse et puante, qu'on croit destinéc à hatter la putréfaction des chairs sur les- 
So MISTORHE NATUREXLE:

quelles ils la répandent, et â préparer la nourriture qui leur convient.

Les larves des boucliers vivent dans le fumier, la terre, et surtout dans les charognes: on les trouve souvent auprès de l'insecte parfait. Elles sont plus ou moins longues; leur corps est aplati, composé de donze anneaux; leur tète est écaillense, pctite, armée de dcux fortes mâchoires : elles ont deux antennes, six pates écailleuses courtes. On les voit courir pour aller chercher leur nourriture, quand elles ont consommé celle qui se trouvait à leur portée. Pour se changer en nymphe elles s'enfoncent dans la terre, et y subissent leur métamorphose.

On connaît un assez grand nombre d'espèces de ce genre.

Le Bouclier surinamois, Silpha surinamensis.

Il a environ dix lignes de long; il est noir; ses antennes sont noires; ses yeux bruns et saillans; le corselet est borde tout 
autour, il a une ligne longitudinale enfoncée sur Ie milicu; l'écusson est grand; les élytres sont plus longues que l'abdomen, aplaties, bordées, finement pointillées : elles ont trois lignes longitudinales élevées, et une bande transversale ferrugineuse vers l'extrémité; l'abdomen des mâles est terminé en pointe, et les cuisses postéricures sont très grosses.

On le trouve dans l'Amérique méridionale, à Cayenne et a Surinam.

Le Bouclier littoral, Silpha littoralis.

Il est un peu moins grand que le précédent, auquel il ressemble beaucoup; il est entièrement noir; les élytres sont moins longues que le corsclet; le corselet est arrondi, bordé, lisse et luisant; les élytres sont un pers plus courtes que l'abdomen, finement pointillées : elles ont trois lignes longitudinales élevées, avec une petite bosse vers l'extrémité ; l'abdomen est terminé en pointe; les cuisses postérieures du mâle sont très grosses. 
On le trouve dans les charognes et les ordures: il habite presque toute l'Europe ; on le trouve aux environs de Paris.

\section{Le Bouclier américain, Silpha ame- ricana.}

Il a environ huit lignes de long, et presque autant de largeur; il est noir, déprimé; ses yeux sont bruns; słs antennes sont de la longueur de la moitié du corselet; le corselet est jaune, avec une grande tache noire au milieu : il est échancré antérieurement, arrondi postérieurement; l'écusson est triangulaire, assez grand; les élytres sont beaucoup plus larges que l'abdomen, noires, raboteuses, avec trois lignes longitudinales peu élevées.

On le trouve dans l'Amúrique méridionale.

\section{Le Bouclier thoracique, Silpha tho- racica.}

Il a cnviron six lignes de long, et quatre: de large; il est noir, aplati; les autennes 
sont moins longues que le corselet; le corselet est grand, échancré antérieurement, arrondi sur les côtés, bordé, rabotenx, un peu élevé sur le milieu, d'une couleur de rouille luisante; les élytres sont d'un noir mat, inćgales, raboteuses, avec une ligne longitudinale élevéc.

Il habite l'Europe; il vit dans les champignons pourris : on le trouve dans les bois des environs de Paris.

I. Bouclier quadriponctué, Silpha quadripunctata.

Il est de la longueur du précédent, mais un peu moins large; son corps est noir, un peu luisant; les antennes sont presque aussi longues que le corselet; la tète est noire ; le corselet est rebordé d'un jaune fauve sur les côtés, noir sur le milieu; l'écusson est triangulaire, noir; les élytres sont d'un jaune fauve, pointillées : elles ont trois lignes longitudinales peu élevées, et deux points noirs, l'un à la base et l'autre vers le milieu; les pates sont noires. 
On le trouve dans presque toute l'Europe, et aux environs de Paris, sur les chènes.

\section{Le Bouclier obseur, Silpha obscura.}

Il a environ huit lignes de long; il est entièrement noir, luisant; le corsclet est grand, finement pointillé, rebordé, aplati sur les côtés, un pen élevé sur le milieu; les élytres sont pointillées, rebordées, formant une espèce de gouttière sur les côtés : elles ont trois lignes longitudinales élevées, très marquées.

\section{Le Bouclier piémontais, Silpha pedemontana.}

Ce bouclier varie pour la grandeur : celui qu'on trouve en Piémont a cinq lignes; celui des environs de Paris n'en a que trois; les antennes sont brunes, avec les trois derniers articles noirs; tout son corps est d'une couleur fauve obscure, un peu plus claire en dessous qu'en dessus; le corselet est inígal, raboteux : les inégalités sont formées par 
des touffes de poils noirs très courts, extrèmoment fins et serrés; les ćlytres sont pointillées : clles ont trois lignes longitudinales élevées, et uie petite hosse ver's le milieu; les pates sont de la méme couleur que le corps.

On le trouve en Piémont et aux environs de Paris.

\section{Le Bouclier sinué, Silpha simuala.}

Il a environ quatre lignes de long; les antennes sont plus courtes que le corselet; la tête et le corselet sont noirâtres, couverts de poils blanchatres très courts, qui les font paraître un peu argentens; on voit sur le corselet des points élevés, plus noirs que le reste ; les élytres ont trois lignes longitudinales élevées: clles sont un peu échaucrées près de l'extrémité, qui se termine en pointe mousse; le dessous du corps et les pates sont noirs.

On le trouve en Europe, dans les charognes, et aul cap de Bonne-lispérance. 
I.e Bouclier raboteux, Silpha rugosa.

Il est de la tiille du précédent; noir, avec un duvet d'un roux jaunâtre sur la tête; le corselet est tronqué en devant, un peu sinué au bord postéricur; il offre plusicurs petites aspérités ou parties un peu relevées; il est noir sur un fond d'un noir cendré et soyeux; les ćlytres ont trois lignnes élevées et longitudinales, avec de petites rides transversales; on voit une bosse sur la ligne extérieure, vers son extrúmité; le bout des d́lytres est un peu sinné.

Il est commun aux environs de Paris et dans toute la France.

\section{Le Bouclier lisse, Silpha lavigata.}

Il a environ six lignes de long et trois de large ; il est d'un noir un peu luisant, de forme ovale; les antennes sont moins longues que le corselet; celui-ci est finement pointillé, légèrement bordé; les élytres sont fortement pointillées, sans stries; elles ont un rebord assez grand, qui forme tout le long une espèce de gouttiere. 
On le trouve dans les forêts de l'Europe, principalement dans les lieux humides.

\section{GENRE.}

\section{NITIDULE.}

Caractères génériques. Antennes en masse; articles courts, presque éganx; les trois derniers très gros, aplatis, en masse perfoliće. - Quatre antennules égales, filiformes; les antéricures composées de quatre articles presque égaux, et les postérieures de trois, - Corselet et élytres un peu bordés.

Linné et Degéer ont placé les nitidules parmi les boucliers, et M. Geoffroy avec les dermestes. M. Fabricius les en a séparées, et en a formé un genre que M. Olivier a adopté.

Les nitidules se rapprochent des bouclices par la forme du corps; mais clles en different par les antennes, qui servent également à les distinguer des dermestes.

Les antennes des nitidules sont courtes, composées de onze articles, dont le premier est assez gros; les suivans sont petits, 
grenus et égaux; le huitième est un peu plus large; les trois derniers forment une masse grosse, ovale, presque arrondic; elles sont insérćes au-dessous des ycux.

La tête est petite, à moitić enfoncéc sous le corselet; les yeux sont petits, arrondis et saillans; la bouche est composée d'une lèvre supéricure, de deux mandibules cornées, arquuées, bidentées à leur extrímité; de deux mâchoires presque membraneuses, sans dents; d'une lèvre inféricure, et de quatre antennules filiformes.

Le corselet est presque aussi large que les dytres, un peu échancré antérieurement, coupé droit postérieurement et légèment hordé; l'écusson est triangulaire.

Les élytres sont dures, un peu convexes, de la longueur de l'abdomen, et légèrement bordées : elles recouvrent deux ailes membrancuses, dont l'insecte fait usage pour voler.

Les pates sont de longueur moyenne; les tarses sont filiformes, composés de cinq articles, dont les quatre premiers sont égaux, le dernier un peu plus long et renflé it 
BES NITIDULES.

l'extrémité, armé de deux crochets recourbés et aigus.

Les nitidules sont en général de forme ovale, un peu aplatie; mais quelques espèces sont un peu convexes en dessus : on les trouve dans les charognes, sur les cadavres desséchés, sous les écorces pourries des vicux arbres et sur les fleurs. Les espèces qui fréquentent les flcurs volent plus que celles qu'on trouve sous les écorces des arbres. Ces insectes sont assez petits, et leurs coulcurs ne sont point aussi brillantes que le nom générique que $M$. Fabricius leur a donné peut le faire croire.

Leurs larves ressemblent à celles des boucliers : elles ont le corps aplati, composé de douze anneaux, terminés latéralement par un angle assez aigu; le dernier annean, comme celui des larves des boucliers, a deux petits appendices coniques; elles ont six pates ćailleuses, attachíes aux trois premiers anncaux. Parvenues à leur accroissement, elles s'enfoncent très profondément en terre, pour subir lenr métamorphose.

I.e genre nitidule est composé d'un assez 
grand nombre d'espèces : on les trouve presque toutes aux environs de Paris. Nous en déerirons quelques unes.

\section{La Nitidule bordée, Nitidula mar- ginata.}

Elle a environ trois lignes de long; ses antennes sont d'un brun ferrugineux; la téte est ferrugineuse, elle a deux petites parties avancées en forme d'oreilles, au-dessus des antennes; le corselet est ferrugineux sur les côtés, brun sur le milieu; les élytres sont brunes, avec les bords latéraux ferrugineux et quelques taches ferrugincuses : elles ont plusieurs stries longitudinales peu marquées; le dessous du corps et les pates sont d'un brun ferrugincux.

On la trouve en Italie et aux environs de Paris, sur les fleurs.

\section{La Nitidule bipustuléc, Nitidula bipustulata.}

lille a cuviron deux lignes; les antenues somt noires; le corps est noir, preu luisant; 
le corselet est large, bordé ; les ćlytres ont chacune un point rouge sur le milieu; le dessous du corps est d'un noir un peu brun; les pates sont brunes.

On la trouve aux environs de Paris, sur les charognes.

\section{La Nitidule bigarréc, Nitidula variegata.}

Elle varie par la grandeur; clle a ordinairement une ligne et demie de long: ses antennes sont ferruyineuses; tout le corps est panaché de noir et de jaune; les élytres sont un peu sillonnées; le dessous du corps est brun; les pates sont ferrugineuses.

On la trouve en Europe, et aux environs de Paris, sur les cadavres et sous les écorces.

La Nitidule obscure, Nitidula obscurct.

Elle a quelquefois deux lignes de long , souvent elle est plus petife; ses antennes sont brunes, avec la masse noire; la bonche 
est brune ; tout le corps est noir, point luisant; les pates sont ferrugincuses.

Flle labite l'Europe. On la trouve aux environs de Paris, dans les mêmes endroits qque la précédente.

La Nitidule sinuée, Nitidula flexuosa.

Flle a environ deux lignes et demie de long; les antennes sont fauves, avec la masse noire; la tite est noire; le corselet est noir, avec les bords latéraux jaunes'; les élytres sont moins longues que l'aludomen, noires, avec chacune deux taches jaunes, dont une ì la base, et l'atutre vers le milieu, prìs de la suture; le dessous du corps est noir; les pates sent d'un jaune fauve.

On la trouve dans les départemens méridionaux de la lirance et aux environs de Paris.

\section{La Nitidule variée, Nitidula varia.}

Elle a environ deux lignes et demic ; ses antennes sont ferrugineuses; la téte est brune; le corselet est ferruçineux, arec un 
peu de brun sur le milieu; les élytres sont ferrugineuses, mólangées d'un peu de brun noirâtre; le dessous du corps est d'un brun noir ; les pates sont ferrugineuses.

On la trouve en Allemagne et aux environs de Paris.

\section{La Nitidule Colon, Nitidula Colon.}

Elle a environ une ligne et demie de long; les antennes sont ferrugineuses; la téte, le corselet et les élytres sont ferrugineux. On voit sur le corselet deux points enfoncés, et sur les élytres quelques taches d'un brum noiratre; le dessous du corps est noir ; les pates sont d'un brun ferrugineux.

On la trouve en Europe; elle est commune aux environs de Paris.

\section{La Nitidule discoide, Nitidula dis- coidea.}

Elle est à preu près de la grandeur de la précédente; ses antennes sont fauves, avec la masse noire; le corselet est d'un brum noiratre, avec les bords ferrugineux; les 
ćlytres sont d'un jaune fauve sur le milieu, avec les bords et l'extrémité noirs; le dessous du corps est noir; les pates sont brunes.

On la trouve en $\Lambda$ ngleterre et aux environs de Paris, sur les charognes.

La Nitidule estivale, Nitidula astiva.

Elle est de la grandeur de la précédente : les antennes sont ferrugineuses, avec l'extrémité de la masse brune; la tête, le corselet, les élytres et les pates sont de couleur ferrugineuse, sans taches; le dessus du corps et le's yeux sont noirs.

On la trouve aux environs de Paris et en Viurope, sur les fleurs.

\section{Ía Nitidule pédiculaire, Nitidula pedicularia.}

Elle est noire, ovale; la masse de ses antcmes est grosse, ovale, un peu comprimée; le corselet et les élytres sont un peu bordés et chagrinés; Ies pates sont noires.

On la trouve en Furope, sur les fleurs; dle est commune aux environs de Paris. 


\section{J XXXVI GENRE.}

\section{BY H R IIES.}

Caractìres Ǵnériques. Antennes courtes, en masse; articles courts et grenus; les six dernicrs en masse perfolice, aplatis, et grossissant insensiblement.

- Quatre antennules égales, presque en masse; le dernier article ovale et plus gros; les antéricures composées de quatre articles, et les postérieures de trois. - Jambes comprimées.

LrNNÉ a placé ces insectus avec les dermestes, et ensuite avec les anthrìnes. M. Geoffroy en a fait un genre aucuel il a donne le nom de cistèle. Mais M. Tabricius et MI. Olivier, en adoptant le genre établi par M. Geoffroy, ont conservé à ces insectes le nom de byrthus, que Jinné leur avait donnć pou les distinguer des anthrìnes. L.es byrrhes ont quelques rapports avec les authrines et les sphéridies, mais on les distingue par la forme des antennes. Celles des anthrines sont terminées par une masse ovale, assez grosse, qui paraît solide; et celles des sphéridies ont une masse composée de quatre 
articles distincts; au lieu que celles des byrrhes, quoiqu'elles soient plus grosses à leur extrémité qu'à leur origine, ne forment point une masse très sensible.

Leurs antennes sont moins longues que le corselet, composíes de onze articles, dont le premier est plus gros, et les autres vont cn grossissant jusqu'à l'extrémité; les cinq on six derniers sont aplatis et comme cnfilés par leur milicu; le dernier est arrondi à son extrémitć.

La tìte est petite, inclinée, cachée en partic sous le corselet; les yeux sont petits, ovales, peu saillans; la bouche est composée d'une livre supérieure, de deux mandihules très dures, arquées, terminées par deux petites dents; de deux mâchoires divisées en deux pièces; d'une lève inféricure, et de quatre antentules égales, presque en masse.

Le corselet est arrondi à sa partic supciricure, conique, sans rebords, et postérieurement aussi large que les élytres; l'écusson est très petit.

I.es élytres sont dures, convexes, point 
bordées, de la longueur de l'abdomen; elles recouvrent deux ailes membrancuses, repliées.

Les pates sont de longucur moyenne; les jambes sont un peu arquées et comprimées; chaque cuisse a une rainure dans lacuelle l'insecte place quelquefois la jambe, et chaque jambe a également une rainure qui sert à contenir le tarse; de sorte que sonvent ces insectes paraissent avoir les pates mutilées, alors qu'elles ne sont que cachíes et replicies; les tarses sont filiformes; les quatre prenices articles sont cour's et égaux; le dernier est presque aussi long que tous les autres, arqué et renflé ì l'extrémité; il est armé de deux crochets arqués et pointus.

Les byrrhes sont convexes en dessus, et un peu moins en dessons; ils paraissent lourds; on les trouve dans les endroits secs et sablonneux, et sur les bords des chemins; ils font rarement usage de Ieurs ailes; des qu'on les touche, ils retirent promptement: leurs antennes et leurs pates sous leur corps; chaçue piece de colles-ci se place dans les rainures deatinées it les contenir, et, dans IIr. 
cette position, les byrrhes ressemblent ì des graines hémisphériq̨ues.

Les larves de ces insectes ne sont point connucs; mais, d'après les rapports qui se trouvent entre eux et les anthrènes, il serait possible que leurs larves vécussent de mème que celles de ces insectes.

Ce genre est composé de peu d'espèces; on les trouve toutes aux environs de Paris; nous en décrirons quelques unes.

\section{Le Byrrhe pilule, Byrrhus pilula.}

Il a environ cinq lignes de long; il est de forme ovale; ses antennes sont noires; la tête et le corselet sont noirs, couverts d'un duvet jaunâtre très court; les élytres sont de la mème couleur et également couvertes d'un duvet jaunàtre; elles ont trois ou quatre lignes longitudinales formées par des poils très courts et très fins, alternativement noirs et roussâtres; le dessous du corps et les pates sont noirs.

On le tronve dans presque toute l'Europe, sur les bords des chemins, et dans 


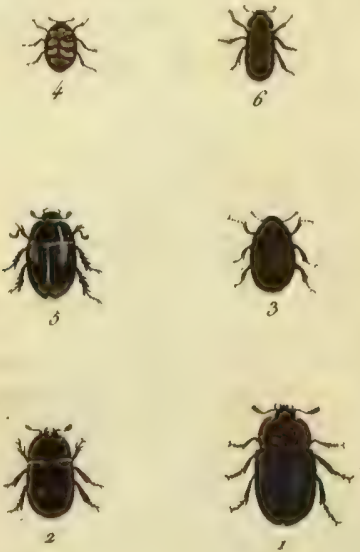

Rarabiand del.

Soletlion Sculp.

1. Bous thoracigue

2. Vit bordice.

5. Bure pilule. t. Ant destrucus.

S. Sphe scaraboide.

6. Vril maryustéc. 
les endroits secs et sablonneux; il est quelquefois tout noir, parce que les poils qui couvrent le dessus de son corps ont été enlevés par le frottement.

\section{Le Byrrhe fascié, Byrrhus fasciatus.}

Il est plus petit que le précédent, de mime forme; tout le corps est noir, un peu luisant en dessous; les élytres et le corselet. sont couverts de poils courts qui le font paraître velouté; le corselet a quelques poils roussâtres; les élytres ont une bande transversale ondée, peu marquée, forméc par des poils d'un fauve foncé.

On le trouve en Allemaizne, en Hollande, et aux cnvirons de Paris, sur les bords des chemins et dans les endroits sablonneux.

Le Byrrhe fasciculé, Byirhus fascicularis.

G. Nosodendron. LیTR.

It est de moitic plus petit que le byrrhe fascie; il est noir, ovale; ses antemes sont bruncs; tout son corps est noir, tant en 
dessus qu'en dessous; la tète et le corselet sont lisses et finement pointillés; les élytres sont pointillés; elles ont plusicurs rangies de poils rassemblés par faisceaux; les pates sont brunes; les jambes sont très larges et aplaties, principalement les antirieures.

On le trouve, au printemps, aux environs de Paris, sous les ulcères des ormes. Souvent ces insectes y sont rassemblés en très grande quantité.

\section{Le Byrihe bronzé, Byrrluss eneus.}

Il a cnviron une ligne et demic de long; ses antennes sont noires; le dessous du corps et les pates sont noirs, luisans; tout le dessus du corps est d'un vert bronzé luisant; les élytres et le corselet sont finement pointillés.

On le trouve à Upsal, dans les endroits sablonneux des forets: il est rare aux environs de Paris. 


\section{Le-Byrrhe noir, Byrrhus ater.}

Il est un peu plus petit que le byrrhe pilule; il est d'un noir velonté en dessus, et d'un noir luisant en dessous; les tlytres ont quelques lignes longitudinales, formées par des poils d'un noir foncé, très fins et très serrés.

On le trouve en Allemagne et aux chvirons de Paris.

A la suite du genre Byrrhe, viennent se placer les genres suivans, dont les caractères ont déjà été exposés t. n, pagè 232 .

\section{G. Eumis. Latr.}

\section{L'Elmis de Maugé, Elmis Maugetii.}

Cette espece est très petite, noiratre et matc en dessus, cendrce en dessous. Le's antennes sont d'un lorun ferrugineux; les yeux sont noirs; te disegue du corsclet est élevé, comme encadré par une arite de chaque côté, ct le milicu du bord postéricur relevé inégalement; les ilytres ont 
chacune trois cottes longitudinales, plus remarquables, sans y comprendrc le bord relevé de la suture; chaque sillon a deux rangs de points disposés en lignes; les pates sont brunes, particulièrement leurs tarses; 12 moitié inféricure des cuisses est cendrée.

On trouve cet insecte aux environs de Paris. Feu Maugé en a trouvé douze individus dans un ruisseau, sous une pierre, près de Fontainebleau.

G. Macronyeux. Latr.

Le Macronyque à quatre tubercules, Macronyclus quadrituberculatus.

Il est noir, un peu bronzi; les antemnes sont roussâtres; le bord antéricur du corselet et des élytres est pâle ou jaunattre; le corselet a, entre le inilieu et le bord postérieur, des petites éminences disposées sur une ligne transversale; les élytres ont des stries longitudinales formées de points enfoncés.

On le trouve en Allemagne. 


\section{G. GÉonisse, Lat:}

Le Géorisse Pygmée, Georissus

$$
\text { Pygmaus. }
$$

Cet insecte est très petit, noir; son corps est court, renflé, avec la tête très inclinée et cachée sous le corselet; ses pates ne sont pas contractiles; les jambes sont étroites et presque linéaires.

Cette espece se trouve en France et en Allemagne; clle fréquente les lieux humides, comme les précédens.

\section{X X X V I I ${ }^{\circ}$ GE N R E.}

\section{ANTIRENE.}

Caractères génériques. Antennes courtes, en uasse; articles presque égaux, les trois derniers en masse solide un peu comprimée. - Quatre antennules cylindriques, inégales; les antérieures un peu plus longues, composées de quatre articles, ct les postérieures de trois. - Corps ovale, presque arrondi.

LiNkÉ a d'abord placé ees insectes avec les eoccinclles, et cnsuite avec les dermestes; M. Geoffroy en a faic un grenre, auquel il a 
donné le nom d'anthrène, et ce genre a été adopté par MI. Fabricius et par M. Olivier.

Les antennes des anthrènes sont un peu plus longues que ta tète, composées de onze articles, dont le premier est plus gros que les suivans, qui sont courts et arrondis; les trois dernicrs forment une masse ovale, assez grosse, qui paraît solide; elles sont insérées dans une cavité latérale, placée de chaque côté et en dessous du corselet, dans laquelle l'insecte les retire quelquefois.

La tète est très petite, inclinée, cachíe en partic par le corselet; la bouche est composée d'une lèvre supérieure, de deux mandibules cornées, un peu arquíes el pointues ì leur extrémité; de deux michoires très petites; d'une levre inférieure et de quatre antennules.

Le corps est de forme ovale, presque arrondi; mais ce qui distingue ces insectes des byrrhes et des sphéridies, avec lesquels ils ont quelques rapports, c'est qu’ils sont aplatis en dessus et convexes en dessons; leur corselet n'a point de rebord; il est itroit antérieurement et postéricurement; 
il est presque anssi large que les élytres; celles-ci sont de la longueur de l'abdomen; elles recouvrent deux ailes membraneuses, dont l'insecte fait souvent usage pour voler.

Les pates sont courtes, les anthrènes les tiement sourent appliquées contre le corps; les tarses sont composés de cinq articles, dont le dernier est plus long que les autres, et armé de deux petits crochets pointus.

Les anthrines sont de petits insectes quion trouve sur les fleurs, occupés it sucer la liqueur mielleuse qu'elles contienuent; ils sont de couleur noire en dessous; la tète, le corselet et les élytres sont converts de petites écailles coloríes, qui rendent ees insectes très jolis; mais te moindre frottement les leur enlève, et alors ils paraissent. entièrement noirs. On les trouve aussi dans les maisons; ils y viennent pour déposer leurs oufs dans les fourrures et sur les cadavres desséchés des animaux; les larves font beaucoup de tort aux collections, en rongeant les peaux des animaux príparís, dont elles font tomber les poils et les plumes; elles rérluisent aussi en poussière les corps des 
insectes renfermés dans des boîtes, et souvent on ne s'apercoit des ravages qu'elles font que quand il est trop tard pour y remédier; cnfin, ces larves sont un vrai fléau pour les possesseurs de cabinets d'histoire naturelle.

Ces larves sont assez petites, puisque, lorsqu'elles ont pris tout lcur accroisscment, elles n'ont qu'environ deux lignes; elles ont le corps court, gros et velu; les poils sont en plus grande quantité sur les côtés et au derrière que partout ailleurs; leur corps est composé de douze anneaux, dont les trois premiers donnent naissance it six pates écailleuses; il est couvert d'une peau membrancuse et flexible; la tète est petite, arrondie et écailleuse, garnie de deux petites antennes, composées de trois articles, et de deux dents écailleuses assez fortes; les pates sont assez longues et divisées en trois pic̀ces garnies de poils, et terminćes par un crochet arqué; tous les poils qui couvrent la téte et le corps de la larve de l'anthrène destructeur, sont hérissés dans toute leur étendue de pointes courtes en 
forme d'épines, comme les poils des chenilles velues, et ceux qui se trouvent sur les côtés sont dísposés par faisceaux; mais ce que ces larves ont de plus remarquable, ce sont six aigrettes de poils longs, placées sur le dernier anneau, dont trois de chaque côté couchées sur l'extrémité du corps, et une semblable aigrette sur chaque côté des neuvième, dixième et onzième anneaux. Degéer, qui a examiné ces poils au microseope, dit qu'ils sont composés d'une suite de petites parties coniques, dont la pointe est dirigéc vers l'origine dı puil, et cette pointe est extrèmement déliće; chaque poil est terminé par une grosse masse allongée, conique, dont la pointe se trouve dans un seus contraire à celle des parties de la tige; lorsqu'on inquiète ces larves, elles redressent leurs poils, comme les porcs-épics redressent leurs piquans; clles ont l'extrémité du corps terminée par une espèce de queue formée par deux paquets de poils beaucoup plus longs que tous les autres; ces poils sont simples, mais mobiles comme ceux qui sont épineux. 
On trouve ees larves dans les maisons pendant presque toutes les snisons de l'annie. Elles cherehent de tous côtŕs de quoi se nowrix; dès qu'elles rencontrent une mouche sèche, ou d'antres insectes, ou des matières animales, elles s'y attachent et les mangent: elles passent l'hiver dans l'état de larves ou sous celui de nymplies, et l'insecte parfait se montre ordinaitement au printemps. Ia larve change plusieurs fois de peau, mais elle ne quitte point entièrement la derniere quand elle passe al l'état de nymphe; la peau ne fait que se fendre le longr du dos, depuis la trite jusque vers l'extrimité du corps, et l'ouverture laisse ì découvert une grande partie de la nymphe, gui reste dans la peau de la larve jussfùì ce qu'elle prenne la forme d'insecte parfait. Ces nymphes n'offient rien de remarquable, mais on distinguc sur elles toutes les parties que doit avoir l'insecte at l'état de perfection; il se débarrasse de son cuveloppe de nymphe ruelpues jumes après quela larve at subila métamorphose. Degéer a olserve que cestarves sont sujettes à nourrir 
des larves d'ichnemmons dans letr corps; il est sorti de celles quili a élevées, des petits ichneumons noirs à paleb roussâtres.

Ce grenre est composci de cinq ou six espèces; on les trouve toutes aux environs de Paris. Nous allons passer a la description de quelques unes.

\section{I'Anthrène brodé, Anthrenus pim- pinella.}

Il a environ une ligne et demie de long : ses antemnes sont noires, sa tète est noive, sans taches; le corsclet est noir, avec un pen, de ferrugineux; les clytres sont noires, avec un peu de ferrugineux a la base, et une large bande blanchatre, un peu ondée, vers le milieu; le dessous du corps est cendré.

On le trouve en Europe, sur les fleurs : sa larve vit dans les cadavres desséchés; cet insecte est commun aux environs de Paris.

L'Anthrène destructeur, Anthrenus muscorum.

Il est un peu plus petit que le précédent; III. 
les antennes et la téte sont noires; le corselet est couvert d'une poussière ferrugineuse et grisitre; les élytres ont trois bandes ondies, grises, et un peu de ferrugineux; le dessous du corps est d'un gris cendré.

On le trouve en Europe, sur les fleurs; il est très commun aux environs de Paris: sa larve fait beaucoup de ravages dans les cabinets d'histoire naturelle. Tous les moyens qu'on a employés pour la détruire sont insuffisans : les fumigations de tabac, la vapeur de soufre, le camphre et les préparations arsénicales l'éloignent, mais la font rarement périr, parce que ces vapeurs pénètrent difficilement dans le corps de l'animal où cette larve est renfermée. Le meilleur moyen pour s'en garantir est d'avoir des armoires ou des boîtes qui ferment très bien, afin de l'empícher d'y pénétrer.

L'Anthrène fascié, Anthrenus verbasci.

Il est couvert en dessus d'écailles d'un roux jaunâtre; le dessous du corps, les côtés du corselet, le milicu de son bord 
postérieur, sont gris; les élytres ont trois bandes de cette couleur; les pates sont noires.

On le trouve aux environs de Paris et dans toute la France; il est commun sur Ics fleurs.

\section{L'Anthrène hérissé, Anthrenus hirtus.}

Il est noir, avec le corselet et les ćlytres pubescens.

On le trouve aux environs de Paris.

$\Lambda$ la suite de cegenre vient se placer celui que M. Fabricius a établi sous le nom de

\section{Chélonare, Chelonatium.}

Les caractères de ce genre sont des plus tranchés (voye tome $\mathrm{xI}$, p. 231 ); ce sont des insectes très rares dans les collections, peu connus, et dont on n'a décrit que deux espèces.

La Chélonaire de Bauvois, Chelonariume Bauvoisi, Latn. Ch. alrum, FABn.

Elle est longue de près de deux lignes, 
noire, luisante, avec les pates antéricures d'un brun foncé.

M. Palisot Bauvois l'a trouvée dans l'ìe de Saint-Domingue.

\section{GENRE.}

\section{SPHÉRIDIE.}

Caractères génériques. Antennes courtes, en masse; articles éganx, presque arrondis; les quatre derniers plus gros, en masse perfoliée; le dervice plus petit et ovale. - Quatre antennules inégales, filiformes; les antérieures composées de quatre articles, les postérieures de trois. - Jambes épineuses. - Corps ovale, presque hémisphérique.

'Tous les auteurs qui ont écrit avant M. Fabricius, ont placé ces insectes, les uns avec les dermestes, les autres avee les escarbots, et quelques autres avec les scatrabées. M. Fabricius les en a séparés, et a formé de ces insectes un genre anquel il a donné le nom de spharidium, d̀ cause de leur forme, qui est arrondic, ovale, prescue hémisphérique; et M. Olivicr a adopte ce genre. 
Les sphéridies diffèrent des insectes parmi lesquels on les avait placés, et dont nous avons parlé, par la forme des antennes et par celle des pates.

Les antennes des sphéridies sont courtes, composées de onze articles, dont le premicr est long, le second petit, les suivans peu distincts; les quatre derniers forment une masse oblongue, perfoliée; et le dernier est comme enchâssć dans l'avant-dernier.

La tète est arrondic, inclinée, enfoncéc dans une échancrure qui se trouve à la partic antérieure du corselet; les yeux sont peu saillans; la bouche est composée d'une lève supérieure, de deux mandibules courtes, cornées, arquécs, pointues a l'extrémité; de deux mâchoires courtes, membrancuses et bifides; d'unc lèvre inférieure, et de quatre antennules iniegales.

Le corselet est grand, convexe, échancré antérieurement; l'ćcusson est allongé, triangulaire; les élytres sont convexes, de la longueur de l'abdomen; elles convent deux ailes membraneuses, dont l'insecte se sert assez souvent pour voler. 
Les pates sont de longueur moyenue; les cuisses sont larges, aplaties et épincuses dans toute leur longueur; les tarses sont filiformes; le dernier article est armé de deux crochets assez minces et très pointus. Dans quelques espèces, l'un des deux sexes a les tarses antéricurs beaucoup plus courts; le dernier article gros et terminé par deux crochets d'inćgale grandeur.

On trouve les sphéridies dans les bouses et les fientes des animaux; mais leurs larves sont inconnues; cependant il est présumable qu'elles se nourrissent des matières fécales dans lesquelles on trouve l'insecte parfait.

Ce genre est composé de vingt-cing ì trente espèces, dont on trouve la moitié aux environs de Paris. Nous allons passer à leur description.

Lc Sphéridic scaraboïde, Spharidium scarabrooides.

Il a environ trois lignes de long; il est de forme ovale, lisse, noir; les élytres ont chacune dcux taches ferrugincuses, l'une à 
la base, et l'autre plus grande et plus pâte it l'extrémité; les pates sont d'un brun ferrugincux; les jambes sont épineuses.

Il habite l'Europe; on le trouve aux environs de Paris, dans les bouses.

\section{Le Sphéridie marginé, Spharidium} marginatum.

Il est un peu moins grand que le précédent, noir, luisant; le corsclet et les ćlytres ont leurs bords légèrement ferrugineux; les pates sont ferrugineuses; les jambes épineuses dans toute leur longucur.

On le trouve aux cnvirons de Paris et en Allemagne, dans les bouses.

\section{Le Sphéridie mélanocéphale, Sphari- dium melanocephahum.}

Il a une ligne de long; les antennes sont noires; la tète et le corselet sont noirs, lisses et luisans; Ics élytres sont d'un brun marron, luisantes, un peu stricies; le dessous du corps est noir; les pates sont brunes; les jambes ćpincuses. 
On le trouve en Europe, dans les bois; il est commun aux environs de paris.

\section{Le Sphéridie ruficolle, Spharidium ruficolle.}

Il est de la grandeur du précédent; ses antennes sont rougeâtres; tout le corps est luisant, tant en dessus qu'en dessous; la tìte est noire; le corselet est rongeàtre ; les élytres et le dessous du corps sont noirs; les pates sont rougeâtres, et les jambes épineuses.

Il est rare aux environs de Paris.

\section{Le Sphéridie atome, Spharidium} atomarium.

Il n'a pas une ligne de long; son corps est lisse, noir, tant en dessus qu'en dessons; les élytres ont des stries hien marquées, dans lesquelles sont des points enfoncés; l'extrémité des élytres est ferruginense; les pates sont fauves.

Il habite l'curope : on le trouve aux environs de Paris, dans fe's bouse's. 


\section{Le Sphéridie jaune, Spharidium luteum.}

Il a pris de deux lignes de long; les antennes sont brunes; tout le corps, tant eu dessus qu'en dessous, est d'un jaune ferrugineux, point luisant; les yeux sont noirs; le corsclet et les élytres sont finement pointillés; les pates sont de la méme coulcur que le corps.

On le trouve aux environs de Paris.

\section{X X X IX GENRE.}

\section{VRILLETTE.}

Caractères génćriques. Antennes filiformes, légèrement en masse; les trois derniers articles un peu plus gros et plus longs, presque ovales, amincis d̀ leur base. - Quatre antennules égales, terminées en masse; les antérieures composées de quatre articles, et les postérieures de trois. Tète enfoncée dans le corselet. - Corselet convexe, un peu bordé.

M. Grorfnoy est te premier qui ait faic un genre de cesinsectes, auxquels il a domme 
le nom de vrillettes, parce qu'ils font des trous ronds dans le bois, comme ferait une vrille. Linné les avait d'abord placés avec les dermestes; mais ensuite il les en a sciparés, en a fait un genre, et lui a donné le nom de ptinus. M. Fabricius a adopté le genre établi par M. Geoffroy, et a changé son nom latin de byrrhus, pour lui donner celui d'anobium. Mais M. Olivier a conservé ì ce genre le nom latin anobium, et le nom français de vrillette.

J.es vrillettes ont quelques rapports avec les dermestes; mais leurs antennes sont plus longues, et la masse qui les termine est moins grosse, ce qui sert à les distinguer de ces insectes. Elles se rapprochent davantage des ptines par la forme du corps, dont elles differrent aussi par les antennes : celles des ptines sont filiformes, et composées d'articles égaux.

Les antennes des vrillettes sont ordinairement de la longueur du corselet, composées de onze articles, dont le premier est plus gros; les suivans sont presque égaux ; les trois derniers beaucoup plus allongés, 
et un peu plus gros que les autres; elles sont insérćes au-dessous des yeux.

La tête est petite, inclinée, presque entièrement cachée par le corselet; Ies yentx sont arrondis, saillans; la bouche est composée d'une lèvre supérieure, de deux mandibules courtes, cornées, terminées par trois dents aiguës; de deux mâchoires membraneuses, bifides à leur extrémité; d'une lèvre inféricure, et de quatre antennules égales.

Le corselet est convexe, rebordé, de la largeur des élytres; l'écusson est petit, arrondi ; les élytres sont convexes, légèrcment bordées, de la longueur de l'abdomen : elles recouvrent deux ailes membraneuses, repliées quand l'insecte n'en fait point usage pour voler; la forme du corps est allongéc, un peu cylindriqque.

Les pates sont de longueur moyenne; les jambes simples, et les tarses composís de cinf articles presque égaux, larges, aplatis ; le dernier est armé de deux crochets aigus.

On trouve les vrillettes au printemps, dans les maisons: on les roit se promener 
sur les fenétres et le long des boiseries: clles ne se font pas remarquer par leurs couleurs: elles sont brunes, et point du tout brillantes; de mème que les dermestes, les byrrhes, et quelques autres insectes, des qu'on les touche, elles retirent leur téte sous leur corselet, appliquent exactement les jambes contre les cuisses, cachent leurs antennes entre la tète et les rebords inférieurs du corselet, et restent très long-temps dans cette attitude, sans faire le moindre mouvement, de sorte qu'elles paraissent mortes. Si l'on en croit Degéer, ni le feu, ni l'eau, ni aucune espèce de torture n'est capable de les tirer de cet état d'engourdissement apparent, nide leur faire donner le moindre signe de vie; mais aussitòt qu'on les laisse tranquilles, peu à peu elles commencent à se remuer, et se remettent à marcher, mais lentement, et avec une espèce d'indolence. Elles font rarement usage de leurs ailes, quoiqu'elles soient assez fortes, ct heaucoup plus longues que les ćlytres.

La larve de ces insectes ressemble à un petit ver blanc; son corps est mou, allongé; 
sa líte est brune et écaillcuse : olle est armée de deux matchoires en forme de pinces, très fortes et tranchantes. Elle en fait usage pour ronger les vieux meubles de bois vermoulu, dans lesquels elle vit, et dont elle se nourrit. Elle rend ensuite ce bois par petits grains très fins, qui forment une poussière quion aperçoit au-dessous de l'endroit où clle est renfermée. En prenant sa nourriture, cette larve se creuse un logement dans lequel elle est à l'abri. Parvenue au terme de son aceroissement, elle tapisse de quelques fils de soie le fond du trou qu'elle habite, s'y change en nymphe, et n'en sort que sous la forme d'insecte parfait. Ces larves n'habitent pas seulement les maisons, on les trouve aussi dans les campagnes, où elles attaquent les arbres vivans et les bois secs. Il y on a une espèce qui travaille sur une matière moins dure : le pain, la farine, et la colle faite avec la farine, lui servent d'alimens. Si on laisse traîner loug-temps dans un tiroir des pains ì eacheter, on les trouvera déchirés et mis cu pieces par es petit insecte, qui y forme III. 
des sillons et des canaux, comme les autres espèces de vrillettes en font dans le bois.

Les insectes de ce genre offrent un petit phénomène qui mérite de fixer l'attention. Il arrive quelquefois, lorsqu'on est seul dans une chambre, et parfaitement tranequille, d'entendre un petit bruit régulier, souvent continué assez long-temps, ct semblable au mouvement d'une montre. Quelques personnes l'ont attribué à une araignée, d'autres à l'hemerobius pulsatorius de M. Fabricius. M. Geoffroy l'attribue à une espèce de villette, qui frappe à coups redoublés le vieux bois, pour le percer et s'y loger. M. Olivier, qui s'est assuré que le bruit vient de l'intérieur du bois, croit qu'il est plutôt produit par la larve que par l'insecte parfait, parce que cet insecte, qui a les mâchoires moins fortes que sa larve, ne pourrait percer le bois, dans lequel, selon cet auteur, il n'a aucun besoin de rentrer après en ètre sorti, puisqu'il dépose ses œufs dans les fentes et les crevasses qui se trouvent it la surface du bois. L'observation de M. Olivicr peut être juste; mais si les larves des 
vrillettes produisent le bruit qu'il a entendu dans l'intérieur du bois, il n'en est pas moins vrai que l'insecte parfait en fait aussi entendre an-dehors; car il nous est arrivé plusicurs fois de surprendre la vrillette marquetée, vrillette savoyarde de Gcoffroy, frappant à coups redoublés avec sa tète sur le plafond. Cherchait-elle à y déposer ses neufs? c'est ce que nous ignorons; ou plutôt ze serait-ce pas un moyen employé par la femelle pour inviter le mảle à se rendre auprès d'elle, afin de s'occuper de la propagation de leur espièce? Il n'y a que le hasard ou des observations suivies qui puissent lever les doutes à cet égard.

Ce geure est composé d'une quinzaine d'espèces : on les trouve presque toutes aux environs de Paris. Nons en décrirons quelques unes.

La Vrillette marquetée, Anobium tessellatum.

Elle a près de quatre lignes de long; les antennes sont brunes, de la longueur du 


\section{4 HISTOIRE NATURELLE}

corselet; le corps est brun; le corsclet et les ćlytres ont des poils qui forment des taches peu marquées dans quelques endroits; le corselet est un peu bordé; les pates sont de la conleur, du corps.

On la trouve en France, sur le bois vermoulu.

\section{La Vrillette marron, Anobium castaneum.}

Elle a deux lignes et demie de long; les antennes sont presque de la longueur du corselet; elle est entièrement de couleur brune foncée, sans taches; ses yeux sont noirs; son corselet est bordé; il a une petite ligne enfoncée sur le milieu; ses élytres sont striées, et les stries sont pointillées.

On la tronve aux environs de Paris, dans l'intérieur des arbres.

\section{La Vrillette molle, Anobium molle.}

Elle a trois lignes de long; elle est d'un brun obscur; ses antennes sont plus longues que le corselet; le corselet est lisse, convexe, 
bordé; il a une ligne longitudinale, enfoncíe sur le milieu; les ćlytres sont lisses.

On la trouve en Europe.

La Vrillette striće, Anobium striatum.

Elle a une ligne et demie de long; tout le corps est d'un brun grisâtre; les antennes sont fauves, de la longueur du corselet; Je corselet est élevé, un peu comprimé; il a une ligne longitudinale cnfoncéc sur le milieu; les élytres sont striées, et les stries sont: pointillées.

On la trouve en Furope, dans les maisons : elle altague les charpentes et les boiseries.

\section{La Vrillette brune, Anobium bruneum.}

Elle a environ trois lignes de long; ses antennes sont testacćes, de la longueur du corselet; tout le corps est chattain; le cor- selet est un peu élevé, et marqué d'une ligne enfoncée; les ćlytres sont légèrement striées, avec des points enfoncés, peu marqqués; 
l'abdomen et les pates sont d'un brun ferrugineux.

On la trouve aux envifons de Paris.

La Vrillette opiniâtre, Anobium pertinax.

Elle est de la grandeur de la précédente; ses antennes sont un peu plus longues que le corsclet; sa couleur est d'un brun obscur noiritre; le corselet est élevé, convexe; il a deux petites ćlévations et une ligne longitudinale enfoncéc au milicu : on voit sur ses bords postérieurs une petite tache fauve formée par des poils; les élytres sont légerement strićes, et les stries ont des points enfoncés peu marqués; le dessous du corps est noirattre, cendré ct luisant; les pates sont noires.

On Ia trouve en Europe.

\section{La Vrillette de la farine, Anobium paniccum.}

File est moins grande que la précédente; les autennes sont de la longueur du corselet; 
elle est d'un brun rougeâtre, luisant; les ycux sont noirs; le corselet est un peu élevé et rebordé; les élytres sont striées.

On la trouve en Europe. Sa larve se nourrit de substance farineuse : si elle trouve du pain très sec, elle s'y forme une coque, s'y change en nymphe, et en sort au bout de quelque temps sous la forme d'insecte parfait.

\section{La Vrillette de Dresde, Anobium Dresdensis.}

\section{G. Dorcatome. Laxk.}

Cet insecte a moins d'une ligne de long; il est noir, presque aussi large que long, arrondi; les antennes finissent brusquement par trois articles plus grands et dont les deux avant-derniers sont en forme de dents de scie.

On le trouve rarement aux environs de Paris, dans les bois, sur les écorces d'arbres. 


\section{La Vrillette du bolet, Anobium boleti.}

\section{G. Cis. JגaTn.}

Elle est longue de deux lignes; son corps est d'un brun châtain, assez luisant, irrégulièrement et fincment pointillé; ses élytres sont un peu rugueuses; ses antennes et ses pates sont d'une couleur moins foncće, presque testacée.

On la trouve aux environs de Paris, dans les bolets et sous les écorces où il y a des champignons.

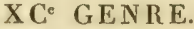

\section{PTINE.}

Caractères génériques. Autennes longues, filiformes; articles presque éganx, un peu comiques. Quatre antennules égales, filiformes; les antérieures compośes de qnatre articles, et les postérieures de trois. - Corselet relevé en bosse.

Lrnnt: a placé ces insectes parmi les vril. lettes. M. Geoffroy en a fait tü genre, anduel il a domé is nom latin de bru- 
clutes, en français bruche. M. I'abricius et M. Olivier, en adoptant le genre établi par M. Geoffroy, lui ont conservé le nom de ptinus, que Linné a donné a ces insectes réunis aux vrillettes.

Il est très facile de distinguer les ptines des vrillettes par les antennes et la forme du corselet.

Les ptines ont les antennes plus longues que la moitié du corps, filiformes, composées de onze articles, dont le premier est un peu plus gros que les autres; les suivans sont presque égraux; le dernier est plus allongé; elles sont insérées it la partic antérieure de la tète, et un pen rapprochées at leur base.

La tête est petite, inclinće, un peu enfoncíe sous le corselet; les yeux sont arrondis et un peu saillans; la bouche est composée d'une lèvre supérieure, de deux mandibules cornées, arquées, avec une dent vers le milieu de leur partie intérieure; de deux mâthoires mombraneuses; d'une lève inférieure, et de quatre antenmules filiformes. 
Le corselet est plus étroit que les élytres, renflé, bossu, arrondi et muni de quelqques tubercules.

Les élytres sont convexes, de la longueur de l'ablomen; elles couvrent deux ailes membraneuses, dont l'insecte fait usage pour voler: quelques especes en sont dépourvucs, d'autres les ont très courtes.

Les pates sont longues; les cuisses sont un peu renflées; les jambes sont minces; les tarses composés d'articles presque égaux; le dernier, un peu plus long que les autres, est armé de deux crochets pointus.

Ces insectes sont assez petits : on les trouve dans les maisons, principalement dans les endroits peu habités, tels que les greniers, parmi le foin et les tas de feuilles siches. Leurs larves ont six pates : elles ont le corps cylindrique, un peu velu; leur títe est écailleuse, armée de deux petites mâchoires: elles se nourrissent de feuilles sèches et d'animaux desséchés. Ainsi ces larves font beaucoup de tort aux herliers et aux collections. Pour se changer on nymphe, elles font une coque d'un tissu fin, soyeux 



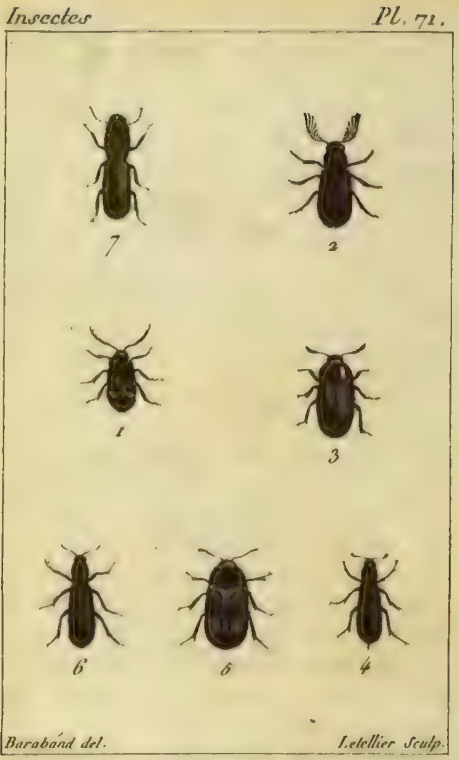

1. Pi. Impérisl.

2.Pul pectinicorne.

5.1 ps a autenues nouces

f.Jyc. Canalicule. j. Mfi. quadrimaculé.

6. Ilyp - nation.

7. 'Trog.toritider. 
ct très blanc, dans laquelle elles s'enfoncent.

L'insecte parfait ressemble à beaucoup d'autres dont nous avons parlé, par la manière dont il retire ses antennes et ses pates contre son corps dès qu'on le touche, et il reste immobile jusqu'à ce qu'on cesse de le tourmenter.

Ce genre est composé de dix à douze espèces : on les trouve presque toutes aux cnvirons de París. Nous allons passer à la description de quelques unes.

\section{Le Ptine impérial, Ptinus imperialis.}

Il a plus de deux lignes de long; ses antennes sont brunes, presque aussi longues que le corps; le corselet est brun, caréné en dessus: il a une tache blanche de chaque côté; l'écusson est blanc; les élytres sont brunes, avec plusieurs taches blanches ondées; le dessous du corps est cendré; les pates sont ferrugineuses.

Il habite l'Europe : on le trouve aux environs de Paris, sur le bois mort. 


\section{Le Ptine volcur, Ptinus fur.}

Il a une ligne et demic de long; les antennes sont presque aussi longues que le corps; sa tète est large, un peu aplatie; le corsclet est arrondi, obscur, avec quatre tubercules élevés et des touffes de poils blanchâtres sur les côtés; l'écusson est blanchâtre; les élytres sont convexes, striées, et les stries sont pointillées; elles ont deux bandes transversales blanches, formées par des poils, qui s'enlèvent par le frottement; le dessous du corps et les pate's sont testacés; tout le dessus de l'insecte est brun.

Il habite l'Europe; on le trouve aux environs de Paris : il détruit les plantes et les animaux que l'on conserve daus les cabinets.

\section{Le Ptine larron, Ptinus latro.}

Il est de la grandeur du précédent, auquel il ressemble: ses antennes sont aussi longues que le corps; il est de conleur fauve, avec les yeux noirs; le corselet a deux tubercules élevés; l'écusson est arrondi; les 
élytres sont sans taches, striées, ft les stries sont pointillées; les pates sont fauves.

On le trouve en Europe.

Le Pline germain, Ptinus germanus.

Il est de la grandeur du précédent; les antennes sont brunes, de la longueur du corps; la tête est brune; les yeux sont noirs; le corselet est brun, couvert d'un duvet cendré, avec quatre tubercules élevés; lés élytres sont brunes, couvertes d'un léger duvet cendré; clles ont des stries formécs par des points; le dessous du corps et les pates sont d'un brun moins foncé que les élytres et le corselet.

On le trouve en Allemagne et aux 'nvirons de Paris.

\section{Le Ptine testace, Ptimus testaceus.}

Il est un peu plus petit que le ptine voleur : tout le corps est testacé, tant en dessus qu'en dessous, sans taches; les antenues sont de la Iongueur du corps; les yeux sont noirs; le corselet a quatre tubercules élevís ; 
les élytres sont légèrement couvertes d'un duvet court, elles ont des stries formées par des points.

On le trouve aux environs de Paris.

Le Ptine scotias, Ptinus scotias. G. Gibbium, Latr.

Il diffère des autres par la forme du corps; il a une ligne et demic de long: ses antennes sont moins longues que le corps, testacíes, couvertes d'un duvet cendré; elles sont insérées au-devant de la tête dans une petite cavité; la tète et le corselet sont d'un brun foncé luisant; les élytres sont renflées, réunies, lisses, d'un brun rouge très luisant; les pates sont longues, couvertes d'un duvet cendré.

On le trouve en Europe; il est moins commun que les espèces précédentes aux environs de Paris : il habitc les maisons.

Le Ptine palpeur, Ptinus palpalis. G. Mastige. Larr.

Cet insecte est long de plus d'une ligne 
et demic ; son corps est tout noir, et un peu soycux; la tête et le corselet sont beaucoup plus étroits que les élytres; les antennes sont filiformes, longues, très coudées; leurs deux premiers articles, et surtout le radical, sont très allongés; les autres sont courts, ct ont la forme de cônes allongés, et le terminal, ou onzième, a une forme ovale oblongue; les palpes maxillaires sont très grands, avancés, et finissent par une massuc ovale, composée des deux dernicrs articles; le corselet a presque la figure d'un cœur tronqué postéricurement; l'abdomen cst ovalaire, et enveloppé par les élytres, qui sont soudées, et fortement pointillées; les pates sunt longues et gréles.

On trouve cet insecte en Espagne et en Portugal; il se tient à terre sous les pierres et les débris de végćtaux. 


\section{GENRE.}

\section{P'TILIN.}

Caractères génériques. Antennes pectinées d'an seul coté, composées de onze articles, dont le premier et le second sont simples, les autres terminés laziralement par un long appendice. - Quatre antennnles filiformes, inégales; les antérieures un peu plus longues, de quatre articles, le premier petit, le second et le troisième coniques, le dernier allongé, pointu; les postérieures composées de trois, dont le premier est petit, le second conique, le deraier allongé. - Corps convexe, cylindrique. - Tète un pea enfoncée dans le cosselet.

LINNÉ a placé le seul insecte qui compose ce genre avec les dermestes. M. Geoffroy, en établissant ce genre, lui a donné le nom latin de ptilinus, en français panache, it cause des antennes de eet insecte; son genre était composé ele deux especes, que M. Olivier a séparées; et it a fait un genre de l'autre espèce, anquel il a donnć le nom de drille.

Ses antennes sont plus longues que le cor- 
selet; le premier et le second articles sont simples; les suivans ont un appendice très long; elles sont insérées au-devant des yeux, assez distantes a leur base.

La tête est petite, arrondie, inclinée, un peu enfoncéc suus le corselet; les yeux sont arrondis, saillans; la bouche est composée d'une lìvre supéricure, de deux mandibules courtes, un peu arquées, bidentées à l'extrémité; de deux mâchoires membraneuses, d'une lèvre inféricure, et de quatre antennules.

Le corselet est arrondi, convexe, un peu bordé; l'écusson est petit, arrondi.

Les ćlytres sont de la longueur de l'abdomen, un peu convexes; elles recouvrent deux ailes membraneuses, repliées ruand l'insecte n'en fait point usage pour voler.

Les pates sont de longueur moyenne; les tarses sont filiformes; le dernier article est armé de deux petits crochets.

Le corps est de forme allongée, cylindrique.

La larve de cet insecte se loge dans ic bois mort, de mene que celle des vril- 
lettes; elle y forme des petits trous ronds ct profonds; elle y subit ses mćtamorphoses, et n'en sort que pour volex. On trouve l'insecte parfait dans les maisons; on le voit marcher lentement sur les vitres et le long des boiseries.

Le Ptilin pectinicorne, Ptilinus pectinicornis.

Il a près de deux lignes de long : il est entièrement d'un brun marron foncé; les antennes sont à peu près aussi longues que la moitić du corps; les ycux sont noirs; le corselet est convexe, un peu bordé; les élytres ont des stries formées par des points peu enfoncés; les pates et les antennes sont d'un brun plus pâle que le reste du corps.

J,es antennes de la femelle sont filiformes, m scie; clle est plus grosse que le mâle.

On le trouve au nord de l'Europe et aux environs de Paris, sur le bois mort. 


\section{XCIJ' GENRE.}

I P S.

Caractèrs génériques. Antenues droites, en masse; articles presque sphériques et iganux, les trois derniers julus gros, aplatis et perfoliés, le dernier arrondi it sa pointe. - Quatre antennules très courtes, igales, filiformes; les antéricures composiées de quatre articles, le premier petit, le second et le troisième arrondis, le dernier ovale; les posterienres de trois articles presque ígaux, le dernier ovale, un pen renflé. - Corps allongé. - Premier article des turses tries court, et plus petit que les antres.

Les ips ont été placés par plusieurs auteurs dans différens genres. M. Fabricius les en a séparés. Dans les premiers ouvrages de cet atuteur, ce genre était composé de quelques silphes de Linné, et de quelques dermestes de M. Geoffroy. M. Olivier a adopté ec geure ćtabli par M. Fabricius; mais depuis que M. Olivier a écrit, M. Fabricius a séparć plusicus insectes du geare jps, et en a formé plusicuss autres. Comme es genres sont assez généralement adoptés, 
nous donnerons les caracteres qui les distinguent, et nous décrirons quelques espèces des insectes qui les composent.

Les ips ont les antennes plus longues que la tête, composées de onze articles, dont les trois derniers sont en masse perfoliće, un peu aplatie; elles sont insérées au-dessous des yeux, et distantes à leur base.

La tête est assez grande, ovale, un peu aplatie, peu enfoncée sous le corselet; les yeux sont arrondis, pen saillans; la bouche est composée d'une lèvre supérieure; de deux mandibules cornées, arquées, simples et pointues; de deux màchoires presque membraneuses, bifides; d'une lèvre inférieure et de quatre antennules.

Le corselet est de la largeur des élytres, un peu convexe et très peu bordé ; l'écusson est triangulaire.

Les élytres sont convexes, de la longueur de l'abdomen, hordées; elles recouvrent deux ailes membrancuses, replićes quand l'insecte n'en fait point usage.

I.es pates somt de longueur moyeme; les cuisses un peu renflécs, comprimées; les 
jambes sont simples, un peu comprimées; les tarses sont composés de cinq articles; les quatre premiers sont assez larges, le dernicr est cylindrique et armé de deux petits crochets.

Ces insectes sont de forme allongée, convexe, lisse; on les trouve, en été, sous l'écorce du bois mort et dans les vieux bolets; après en ètre sortis, ils y rentrent pour y déposer leurs ocufs.

La larve des ips est petite, allongée, bianchâtre; sa tête est brune, écailleuse : elle vit dans lé bois mort et les bolets qu'elle réduit en poussière; elle se change en nymphe dans l'endroit où elle a vécu, et n'en sort que sous la forme d'insecte parfait.

Ce genre contient une quinzaine d'espèces; presque toutes habitent l'Europe: on en trouve peu aux environs de Paris. Nous en décrirons quelques unes. 
L'Ips à élytres noires, Ips nigripennis.

G. Nitidule. Laxr.

Cet insecte est l'érotyle russe de M. Olivier; il a deux lignes et demie de long; les antennes sont noires, de la longueur du corselet; la tête et le corselet sont d'un rouge jaunâtre luisant; le corsclet est convexe, un peu bordé; les élytres sont lisses, convexes, un peu bordées d'un noir luisant, avec des stries peu marquées, formées par de petits points enfoncés; le dessous du corps et les pates sont d'un rouge jaunâtrc, luisant; les yeux sont noirs.

Il habite l'Europe : on le trouve aux environs de Paris, sur le bois mort.

L'Ips rufipède, Ips rufipes.

G. Nitidule. Latr.

Il est moins grand que le précédent, auquel il ressemble beaucoup : il a les antennes, la líte, le corselet et les prates d'un 
rouge jaunatirc; le corselet est convexe, bordé, luisant; les élytres sont noires, luisantes, un peu bordées; elles ont des stries peu marquées, formées par de petits points enfoncés; le dessous du corps est noir.

On le trouve en Norwége et aux environs de Paris, dans les bolets.

\section{L'Ips quadripustulé, Ips quadripus-} tulata.

\section{G, Nitidule, LATr.}

Il est à peu près de la longueur de l'ips à dlytres noires, mais moins large; il est allongé, cylindrique : ses antennes sont brunes, moins longues que le corselet; la tête est noire, luisante; le corsclet est noir, luisant, tris convexe en dessus, un peu aplati sur les côtés; les élytres sont d'un noir luisant, lisses, un peu bordées, convexes; elles ont chacune deux taches d'un rouge jaunitte, l'une vers le bord, l'autre vers l'extrémitć; le dessous du corps et les pates sont d'un noir luisant. 
On le trouve au nord de l'Europe et aux environs de Paris.

\section{CII I GENRE. \\ L Y C T E.}

Caractères génériques. Antennes terminées par ane masse solide composée de deux ou trois articles. - Quatre antennules filiformes, très courtes. Corps allongé, déprimé; corselet souvent étroit.

CF genre a été établi par M. Fabrieius; une partic des insectes qui le composent appartient au genre ips de M. Olivier. On distingue les lyctes des ips par la forme du corps et par les antennes: les ips sont de forme un peu ovale, tandis que les lyctes ont le corps allongé et cylindrique.

Les lyctes ont les antennes moins longues que le corselet, composies de onze articles, dont le premier est un peu plus gros; les suivans sont courts, grenus et igaux; les trois derniers forment une masse solide arrondie; elles sont insérées atı-dessous des ycux, et distantes à leur basc. 
La téte est grande, ovalc, un peu aplatic, un peu enfoncíc sous le corselet; les yeux sont arrondis, saillans; la bouche est composéc d'une lèvre supérieure, de deux mandibules cornées, courtes, un peu arqquées; de deux mâchoires membrancuses, bifides; d'une lève inférieure, et de quatre antennules.

Le corselet est allongé, aplati; l'écusson est très petit; les élytres sont de la longueur de l'abdomen, hordćes; elles couvrent deux ailes membraneuses.

Les pates sont courtes; dans quelques espèces les cuisses sont un peu comprimées; les tarses sont filiformes, composés de cinq articles, dont le dernier est armé de deux crochets aigus. ${ }^{1}$

Le corps est allongé, un peu déprimé, lisse. Les lyctes sont des insectes assez petits, de couleur brune ou noirâtre, point luisante. On les trouve dans les bois morts,

' Un examen plus attentif a fait reconnaitre à M. Latreille que les tarses de ces insectes n'avaient que quatrc articles; il les a placés dans la section des tétranères.

III. 
sous les écorces et dans les bolets. Nous nc connaissons point leurs larves, mais il paraît qu'elles vivent dans les endroits où l'on trouve l'insecte parfait.

Ce genre est composé d'une douzaine d'espèces. On les trouve presque toutes en Europe, et plusieurs aux environs de Paris. Nous en décrirons quelques unes.

\section{Le Lycte poli, Lyctus politus.}

Il a environ une ligne et demie de long: il a les antennes ferrugineuses, un peu plus Iongues que la tête; il est entièrement noir; le corselet est lisse, point bordé; les élytres ont des stries peu marquées, formécs par de petits points peu enfoncés; les pates sont. ferrugineuses.

Il habite l'Europe: on le trouve aux environs de Paris, dans les bolets.

Le Lycte canaliculé, Lyctus canali- . culatus.

Il a un peu plus de deux lignes : il est entierament brum; les aniennes sont de lia 
longucur de la moitié du corselet; les yeux sont noirs; le corselet est aplati, bordé; il a un sillon assez profond sur le milicu; les élytres sont striées, et les stries sont ponctuées.

Il habite l'Europe: on le trouve aux environs de Paris, sous les écorces des arbres.

\section{Le Lyete crénelé, Lyctus crenatus.}

\section{G. Bitome. LATR.}

Il est de la grandeur du lycte poli : il est brun; les antennes sont moins longues que le corselet; le corselet est aplati, inégal, raboteux, bordé; les élytres sont striées et ponctuées, brunes, avec deux grandes taches ferrugincuses, l'une à la base, l'autre vers l'extrémité; les pates sont ferrugineuses.

Cette espece se trouve à Paris. On rencontre aussi quelquefois le bitome rugicolle, bitome rugicollis, qui est plus petit, d'un brun obscur, avec quatre lignes longitudinales élevées, sur le corselot et sur les élytres: celles-ciont de plus des stries ponctućes. 


\section{C I V ${ }^{\circ}$ G E N R E.}

\section{MY CF́TOPHAGE.}

Caractères génériques. Antennes courtes, grossissant insensiblement; les derniers articles perfoliés. - Quatre antennules inígales; les antérieures composées de quatre articles, dont le dernicr plus gros; les postérieures de trois articles presque égaux. - Corps oblong. - Tète petite.

Lrs mycétophages sont décrits dans les premiers ouvrages de M. Fabricius sous l: nom d'ips. Dans son dernier ouvrage, cet auteur ayant donnć le nom d'ips à d'autres insectes, a nommé ceux-ci mycétophages. Il paraît qu'aucun d'eux n'a èté décrit par M. Olivier, puisque dans la synonymic M. Fabricius ne cite point cet entomologiste.

Les mycétophages ont les antennes presque aussi longues que le corselet, composíes de onze articles, qui vont en grossissant insensiblement depuis la base justju'au sommet; les quatre ou cing derniers forment 
une masse perfoliéc; elles sont insérées atudessous des yeux, et distante's à leur base.

I al tète est petite, inclinice, arrondie, un peu enfoncée sous le corselet; les yeux sont petits, globuleux et saillans; la bouche est composée d'une lève supéricure, de denx mandibules cornées, courtes, arquécs, pointues à leur extrémité; de deux mâchoires membraneuses, unidentées; d'une lèvre infúricure, et de quatre antennules inézzales.

I.e corselet est plus large que long, arrondi et échancré antérieurement, et postéricurement de la míme largeur que le corps, légèrement bordé sur les cótés ; l'écusson est triangulaire.

I.es ćlytres sont aussi longues que l'ab. domen; elles recouvrent denx ailes membraneuses, replices.

I.es pates sont courtes; les cuisses sont comprimées; les tarses filiformes, composés te eing articles inégaux, le dernicr est armé de deux petits crochets pointus. '

- Ces iusectes ont seulement quatre anticles aux rarses; ils fout partic des tétramères. 
Les mycétopliagres sont de petits insectes ale forme oblongue: on les trouve at printemps, et eu été, daus les bulets et sous les icores des vieux arbres.

Nous ne connaissons point la larve de ces insectes; mais il est viasemblable qu'elle vit dans les bolets et dans les trones pourris des arbres.

Ce genre est composé d'une quinzaine d'espices: on les trouve presque toutes en Europe. Nous en dierirons quelgues unes.

I. Mycétophage quadrimaculé, MYycetophagus quardrimaculatus.

Il at environ deux lignes et demie de long; ses antennes sont noires; la téte et le corselet sont noirs, sans taches; les élytres sont noires, strices: clles ont deux taches rouges presque carries, l'une vers la base, l'autre vers l'extrémité; le dessous du corps et les pates sont noirs.

Il habite l'juroje : on le trouve aux envirous de Paris, daus les bolets, quelyue fois sur les arjores. 
Le Mycitophage multiponctui, $M_{3}$ ceiopthagus multipunctatus.

Il est moins grand que le précedent; il at les antennes Inunes; la téte et le corselet noirs, sans taches; les idytres noires, strices, avec des points de couleur rousse, et à la base une tache de méme couleur; les pates sont brunes.

On le trouve en Suisse el aux cnvirous de Paris, dans les bolcts.

\section{Le Mycétophage atome, Mycetophagras atomarius.}

Il a une demi-ligne de long; il a les antemes noires; la tite et le corselet noirs, sins taclies; les flytres noires, avec les bords lateraux fauves, deux lignes transversales formées par des taches, l'une vers la base, et l'autre vers l'extrémité, et deux points de la méme conleur sur le milieu: Ales sont finement pointillées et strićes; les pates sont noires. 
On le frouve an nord de l'Europe ct aux environs de Paris, dans les bolets.

Ic Mycétophage fulvicolle, Mycetophagus fulvicollis.

Il est de la grandeur du mycétophage multiponetué; noir, avec la tète et le corselet fauves; les élytres strićes et pointillées, noires, avec une tache fauve a la base; le dessous du corps, les pates et les antennes fauves.

On le tronve en Aliemagne et aux environs de Paris, dans les vieux clampignons.

Le Mycétophage chàtain, MYycetophagus castaneus.

G. Agyrte. LaxR.

Cet insecte ayant cing articles à tous les tarses, a été placé par M. Intreille à côté des boucliers; il a un pen plus d'une ligne de long; tout son corps est d'un châtain clair.

Il est rare aux environs de Paris. 
Le Mycétophage brun, MYcetophagus

\section{piceus.}

Il est un pen plus grand que le précédent; les antennes sont brunes; la tite est noire; le corselet est noir, avec deux points enfoncés le long du bord postéricur; les élytres sont strićes, et les stries ont des points enfoncés; clles ont deux lignes transversales fauves, l'une à la base, et l'autre vers l'extrémité; lc dessous du corps est noir; les pates sont fauves; tout le corps est un peu déprimé.

On le trouve en Allemagne et aux environs de Paris, sous les écorces des arbres.

Le Mycétophage bifascié, Mycetophagits bifasciatus.

Il a près d'une ligne de long; les antennes sont plus longues que le corsclet, de couleur ferrugineuse; la tête et le corselet sont luisans, d'une couleur ferrugineuse; les ćlytres sont noires, avec deux bandes transversales, et l'extrémité ferrugineuse : clles sont striées, 
T54 HISTOIRE NATURELDE

et les stries ont des points enfoncés; le dessous du corps et les pates sont luisans, d'une couleur ferrugineuse.

On le trouve au nord de l'Kurope et aux environs de Paris.

Le Mycétophage dermestoïde, MYycetophagus dermestoüdes.

G. Eustroplee. LaxR.

Il est brun, avec l'abdomen et les pates lestacés.

On le trouve en Allemagne dans les bolets, et aux environs de Paris.

A la suite des mycétopltages, M. Latreille place (Rigne Animal) le gemre suivant :

G. Agathidie.

(Voyez les Caractères, tome II, page 27 I.)

L' $\Lambda$ gathidie à élytres noires, Agathidium nigripenne.

Il n'a pas plus d'une demi-ligne de long; il est rougeattre; ses antennes sont brunes, ct son abolomen est noir, ainsi que ses élytres.

On le trouve en Styrie. 
L'Agathidie globuleux, Agathidium globulosum.

Il est plus petit que le précédent, noir, avec les álytres, les pieds et l'abdomen fauves.

Il se trouve aux environs de Paris.

\section{$\mathrm{XCV}^{\mathrm{e}} \mathrm{G} \mathrm{ENRE}$.}

\section{IIYPOPHLEEE.}

Caractèrcs génériques. Antennes droites, plus grosses vers l'extrémité, en raasse perfolićc. - Quatre antennules presque filiformes, égales; les anterieures composées de quatre articles, les postérienres de trois, le dernier un peu plus gros que les autres. - Corps allongé, cylindrique.

UNE partic des insectes qui composent ce gente, sont des ips de M. Olivier. Mr. Fabricius les en a séparés, les a réunis a quelques autres espèces, et en a forme: un genre sous le nom d'hypophlée. Les ips de ces deux autcurs ne sont point les mèmes insectes. On trouve dans ecux de M. Fabricins des niti- 
dules et un érotyle de Mr. Olivier, et l'on ne trouve dans les ips de M. Olivier aucun insecte décrit par M. Fabricius, on cet auteur n'a pas cité cité par M. Olivier dans la synonymic.

Nous avons cru devoir adopter le genre hypophlée, ainsi que les genres lycte ct mycétophage, établis par MI. Fabricius, parce que les insectes qui les composent ont des formes qui les distinguent les uns des autres, et ces caractères nous ont paru plus faciles à saisir que ceux que présentent les parties de la bouche d'insectes aussi petits.

Les hypophlées ont les antennes moniliformes, moins longues que le corselet, composées de onze articles; le premier asse\% gros, les deux ou trois suivans tris petits, à peine distincts, les six ou sept derniers beaucoup plus gros, arrondis, le dernier un peu aplati, terminé en pointe mousse; elles sont insérées au-dessous des yeux, et distantes à leur base.

La tète est ovale, avancée, moins large que le corselet, sous lequel elle est un peu cnfoncée; les yeux sont globulenx, saillans, 
DES FYPOPULÉIS.

placés de chaque côté de la tête; la bouche est composéc d'une lìve supéricure, de deux mandibules cornées, arquées, simples, pointues à leur extrémité; de deux mâchoires membraneuses, d'une lèvre inférieure et de quatre antennules presque filiformes.

Le corselet est allongé, presque cylindrique, un peu convexe, légèrement bordé sur les côtés, plus étroit que les élytres ì sa partic postérieure; l'écusson est petit, arrondi.

Les élytres sont un peu convexes, de la longueur de l'abdomen; elles enveloppent un peu les côtés du eorps, et recouvrent deux ailes membraneuses, repliées.

Les pates sont courtes; les cuisses sont comprimées; les tarses sont filiformes, composés de cinc articles, dont le dernier est armé de deux petits crochets pointus. '

Le corps est allongé, cylindrique. On trouve les hypophlíes au printemps, et en été, sous les écorces de différens arbres. Les

' Cos insectes n'ont que quatre articles aux tarses; ils appartiennent à la section des tétramères.

III. 
larves de ces insectes ne sont point connues; mais il est présumable qu'elles vivent dans les troncs des arbres cariés.

Ce genre est composé de six espèces, qui tontes habitent l'Europe. On en trouve plusieurs aux environs de Paris. Nous les décrirons.

\section{L'Hypophlée marron, Hypophlaus castaneus.}

Il a près de trois lignes de long, et une demi-ligne de large ; il est d'un brun luisant, sans taches; les antennes ont les sept derniers articles plus gros que les autres; le corsclet est finement pointillé; les élytres ont des stries très peu marquées, formées par de petits points peu enfoncés.

On le trouve aux environs de Paris, sous les écorces des arbres.

L’Hypophlée déprimé, IIypophlaus depressus.

Il est de moitić plus petit que le précédent; d'un brun ferrugineux; le corselet est lisse; 
les élytres ont des stries formúes par des points enfoncés; les antennes sont moins longues que le corselet.

On le trouve aux environs de Paris, sous les ćcorces des arbres.

\section{L'Hypophlée bicolor, Mypophlaus bicolor.}

Il est de la grandeur du précédent : les antennes sont rougeâtres, moins longues que le corselet; Ja tête et le corselet sont rougeàtres, lisses; les yeux sont noirs; les élytres sont noires, avec la base rougeâtre; clles sont luisantes et finement pointillées; le dessous du corps et les pates sont rougeâtres; l'extrémité de l'abdomen est noire.

On le trouve aux cnvirons de Paris, sous l'écorce des arbres. 


\section{GENRE. TROGOSSITE.}

C'aractères génériques. Antennes courtes, composées de onze articles, le premier gros, les suivans gronus, les trois derviers distiucts, un pen en masse. - Quatre antennules presque égales; les antévieures comprosées de quatre articles, le premier très court, les denx suivans éganx et coniques, le dernier très gros; les postérieures de trois articles, le premier petit, le dernier assez gros. Corps allongé, légèrement déprimé.

LE seul insecte de ce genre qui ait été connu par Linné et par M. Geoffroy, a été placé par le premier avec les ténébrions, et par le second avec les lucanes. M. Fabricius en a décrit une autro espèce, et l'a aussi placce avec les lucanes. Mais Mr. Olivier n'ayant trouvé à res insectes aucun des caractères des ténćbrions, ni des lucanes, en a fait un genre, et lui a donné le nom de trogossite, qui signifie rongeur de grains, parce que la larve d'une des espéces attarue et ronge les grains dans les départemens méridionaux de la France. 
I.es trogossites diffèrent des ténébrions par le nombre des articles des tarses, ce qui suffit pour les séparer de ces insectes, et ils different des lucanes par les parties de la bouche et les antennes. Celles des lucanes sont coudées, en masse lamelléc; au lieu que celles des trogossites sont droites et terminées par une masse composíe de trois atlicles un peu plus gros que les autres.

Les antemes sont un peu plus longues que la tète, insérées à sa partic antéricure près la base des mandibules.

La tète est assez grande, un peu aplatic, portée en avant, et presque atussi large que le corselet; les yeux sont un peu allongés et point saillans; la bouche est composéc d'une lèvresupérieure, de deux mandibules, grandes, cornées, dures, arquées et dentécs tout le lon:r de leur partic interne; de deux mitchoires presque cornées, unidentées it lcur base; d'une lìve inférieure et de quatre antennules presque égales.

Le corselet est allongé, un peu déprimé, bordé, plus large antéricurement que postéricurement, et séparé des clytres par un 
étranglement assez long; l'écusson est triangulairc, très petit.

Les élytres sont très dures, de la longueur de l'abdomen; elles recouvrent deux ailes membraneuses, repliées.

Les pates sont courtes; les cuisses un peu comprimées ; les tarses composés de cinq articles, le premicr est très court, les trois suivans sont égaux, velus en dessous, le dernier est plus long, arqué et terminć pardeux crochets. ${ }^{1}$

Tout le corps est allongé, un peu déprimé.

Nous trouvons dans l'Entomologic de M. Olivier, que depuis long-temps, dans les départemens méridionaux de la France, on connaît la larve d'une des espèces de ce genre sous le nom de cadelle; elle cause beaucoup de dommage aux grains qui sont xenfermés dans les greniers, dont clle mange et gâte une bien plus grande quantité que les larves des charançons et des teignes; elle

'M. Latrcille et tous les entomologistes ont placé ces insectes dans la section des tétramères. 
ne se renferme pas, comme ces larves, dans l'intéricur du grain, mais elle l'attaque audehors. C'est vers la fin de l'hiver, qu'clle a acquis tout son accroissement, qu'elle fait le plus de ravages. Parvenue à toute sa grosseur, elle a environ huit lignes de long et à peu près une ligne de large; son corps est blanchitre, composé de douze anneaux hérissés de poils clair-semés, courts, assez roides; la tète est noire, dure, écailleuse, armée de deux mandibules arquées, tranchantes, cornées, très dures; le dernier anneau est terminé par deux crochets cornés, trìs durs; elle a six pates écaillenses, courtes, attacluécs aux trois premiers anneaux. $\Lambda u$ commencement du printemps, elle quitte les tas de blé, s'enfonce dans la terre ou la poussièrc, pour y subir si métamorphose. L'insecte parfait se montre au printemps, et pendant tout l'été. On ne trouve point cette larve au nord de la France, mais elle est très abondante dans le midi.

On a remarqué que l'insecte parfait n'allaque jamais le blé : on en a renfermé plusicurs cuscmble dans un vase où il y arait 
de ce grain, ils n'y ont point touché, et ont plutôt cherché à se dévorer entre cux. On les a tronvés le lendemain privés d'antennes et de pates. On en rencontre souvent sur le Jlé, cherchant à dévorer des teignes et it perpétuer leur espèce. On trouve Ie trogossite bleu et le trogossite mauritaniquue dans le vieux pain, dont ils dévorent tonte la mie. On trouve aussi ce dernier, mort, dans le pain fait à Paris, où il paraìt qu'il est apporté dans la farinc.

Ce genre est composé de six it huit espèeses. Nous en décrirons quelques unes.

Le Trogossite mauritanique, Trogossita maurilanica.

Il a environ quatre lignes et demie de long : il est d'un brun noirâtre, plus foncé. en dessus qu'en dessous; les antennes sont. un peu plus longues que lat tite; la tite et le corselet sont pointillés; le corselet est un peu bordé, il a quatre petites dents avancées, dont une de charque côté de sa partie antérienre, et une moins marquée de cha- 
que cíté de sa partic postérieure; les élytres sont strićes, et entre chaque strie on aperçoit des petits proints enfoncés; les pates sout de la mème couleur que le dessous du corps.

On le trouve a Alger et dans les départemens méridionaux de la France. On le trouve aussi quelquefois à Paris dans le pain. C'est la larve de eerte espèce qui est connue dans le midi de la France sous le nom de catdelle, et qui attaque les grains. Nous renvoyons aux généralités de ce genre, pour voir ee que nous en avons dit.

\section{Le T'rogossite verditre, Trogrossita virescens.}

Il a six lignes de long : il est d'un vert bronzć, brillant, tant en dessus qu'en dessous; les antennes sont noires, de la longucur du corselet, un peu velues; les trois derniers articles sont un peu plus gros que les autres; les mandibules sont noires, assez grandes; la tite et le corsclet sont pointillés; cclui-ci est un peu bordé; les élytres ont des points enfoneés qui forment des 
strics peu marquécs; les pates sont d'un vert bronzé, plus foncé que le dessus du corps.

On le trouve ì la Caroline.

Le Trogossite ferrugineux, Trogossita ferruginea.

G. Diapìre, LATR.

Il a près de quatre lignes de long; il est un peu moins allongé que les précédens; de conleur ferrugineuse, tant en dessus qu'en dessous; les antennes sont un pet plus longues que la tête; la tête et le corselet sont finement pointillés; celui-ci est un peu bordé; les élytres sont strićes, et on aperçoit dans les stries des points enfonćs; les pates sont de la couleur du corps; les cuisses sont assez grosses, un peu comprimées.

On le trouve à la Caroline. 


\section{Le Trogossite sillonné, Trogossita sulcata.}

G. Colydium. Latr.

Il a environ trois lignes et demic : il est entièrement de couleur ferrugincuse, luisant; les antennes sont un peu plus longues que la tête; les yeux sont noirs, saillans; le corsclet est bordé, il a trois lignes longitudinales enfoncées sur le milieu; les élytres sont légèrement striées, et l'on apercoit entre les stries des petits points enfoncés; les pates sont de la coulcur du corps; les cuisses sont un peu comprimées.

On le trouve aux environs de Paris, sous les écorces des arbres cariés.

Le Trogossite strié, Trogossita striata.

Il a près de ciny lignes de long: il est noir, un peu luisant; les antennes sont un peu plus longues que la téte; le corselet est pointillé, bordé, un peu coupé postérieurement; les élytres ont des stries assez profondes, et deux rangées de points enfoncés 
entre chaque stric; les pates sont noires, courtes; les jambes antérieures ont quelques dents latérales un peu marquées.

On le trouve au Sénégal et à la Caroline.

Les genres suivans, la plupart établis par M. Latreille, doivent être placés près des trogrossites.

G. MÉrRYX.

(Voyez les Caractères, tome rr, page 272.)

La Méryx rugucuse, Meryx rugosa.

Cet insecte est long de près de cinq lignes; son corps est d'un brun noirâtre, allongé et ćtroit; ses yeux sont proćminens; son corselet est plus étroit que les élytres, presque carré, un peu rétréci en arrière; il a un sillon longitudinal aı milieu; les élytres ont deux lignes élevées, longitudinales, crénclíes, avec des points enfoncés.

On le trouve dans les Indes orieutales.

G. Latridis.

(Voyez les Caractères, tome 11, page 27z.) 


\section{Le Latridie transversal, Latridius} transversalis.

Il n'a pas une demi-ligne de long; son corps est testacé; ses élytres sont plus pâles et striées; son corselet est rebordé, avec unenfoncement transversal postérieurement.

On le trouve aux environs de Paris, sur les bois morts.

\section{Le Latridie enfoncé, Latridius impressus.}

Il est plus petit que le précédent, brun, avec le corselet arrondi, ayant un enfoncement à sa partie supérieure; les élytres sont pubescentes et pointillces.

Il est commun à Paris, dans les maisons et sur le bois.

\section{G. Silvain.}

(Voyez les Caractères, tome II, page 272.) 


\section{Le Silvain unidenté, Silvanus uniden- tatus.}

Il a une ligne de long; son corps est étroit, déprimé, et d'une couleur testacéc sans taches; sa tête est triangulaire; ses antennes sont en massue de trois articles; les articles de la base sont égraux, et presque globuleux, jusqu'au huitième; le corselet est allongé, presque carré, rétréci insensiblement en arrière; il est fortement pointillé, avec une dent avancéc de chaque côté; les élytres sont fortement pointillées.

On trouve cc petit insecte aux environs de Paris, sous l'écorce des arbres. 


\section{CVII ${ }^{*}$ GENRE.}

\section{SCAPHIDIE.}

Caractères génériques. Antennes composées de ouze articles, les six premiers minces, allongés, les cinq deruiers en masse allongèe, perfoliée. Quatre antennules inégales, filiformes; les antérieures composées de quatre articles, dont le premier petit, les autres coniques, le dernier allongé, terminé en pointe; les postéricares plus courtes, de trois articles, le premier est petit, le second conique, le dernier presque ovale. - Tête petite, un peu enfoncée dans le corselet,

M. Olivier est le premier qui ait fait un genre de ces insectes; il leur a donné le nom de scaphidic, qui signific barque ou bateau, parce qu'ils sont de forme ovale, convexes, et terminés en pointe par les deux bouts.

M. Fabricius, dans ses premniers ouvrages, a placé la seule espèce qu'il connut alors avec les sphéridies; et dans son dernicr ouvrage, il a adopté le genre de M. Olivier. Limné en a placé une autre espèce avec les boucliers; mais les scaphidies different tel- 
lement des insectes de ces deux grenres, par la forme du corps et par les antennes, qu'il est très facile de les distinguer.

I.es scaphiclies ont les antenńcs presque aussi longues que le corsclet, minces à leur base, en masse perfolice à leur sommet; elles sont insérées à la partie supérienre et antéricure de la téte, au-dessous des yeux, rapprochécs ì leur insertion.

La tète est trìs petite, un pea enfoncéc sous le corselet; les yeux sont petits, arrondis, peu saillans; la bouche est composée d'une lèvre supéricure, de deux mandibules cornées, courtes, arquées, bidentées à leur extrémitć; de deux mâchoires moitié cornées, moitić membraneuses, bifides a leur extrémité; d'une lisre inféricure, et de quatre antennules filiformes.

Ie corselet est convexe, un peu bordé, plus étroit à sa partic antéricure qu’à sa partic postéricure; l'ćcusson est très petit.

Les ellytres sont très dures, convexes, plus courtes que l'abdomen, et tronquíes it leur extrémité; le dessous du corps est convexe; l'abdomen est large ì sa base, et ter- 
miné en pointe; il est plus long que les élytres.

Les pates sont assez longues, minces; les tarses sont filiformes, composés de cinq articles, les quatre premiers sont égaux, le dernier est un peu plus long, et armé de deux crochets assez forts.

On trouve les scaphidies pendant le printemps, ct en été, sous le chapeau de diverses espèces de champignons : une espèce se trouve dans l'agraric. La larve de ces insectes est inconnue.

Ce genre n'est composé que de quatre espèces : on en trouve trois aux envicons de Paris; l'autre habite la Nouvelle-IIollande. Nous les décrirons.

Le Seaphidie quadrimaculé, Scaphidium quadrimaculatum.

Il a environ trois lignes de long; il est d'un noir luisant; les antennes sont moins longues que le corselet, minces, terminées en masse perfoliéc; la tête est petite, noire; le corselet est noir, finement pointillé; les 
ćlytres sont noires, plus courtes que l'abdomen, pointillées, avec une strie près de la suture, et deux taches ronges, une ì la base, et l'autre plus petite à l'extrémité; les pates sont noires.

On le trouve aux environs de Paris; il n'est pas commun.

Le Scaphidie immaculé, Scaphidium immaculatum.

Il est de la grandeur du précédent; d'un noir luisant sans taches; les antennes sont moins longues que le corselet, un peu velues; le corselet est lisse, finement pointillé; les élytres sont plus courtes que l'abdomen; elles ont plusienrs stries formées par des points enfoncés, et úne autre sans points près de la suture; l'abdomen est terminé en pointe; les pates sont minces; les jambes postérieures sont un peu arquées.

On le trouve aux environs de Paris, sous l's champignons: il cst moins rare que le précédent. 


\section{Le Seaphidie agaricine, Scaphidium}

\section{agaricinum.}

Il a une demi-ligne de long; les antennes sont fauves; il cst d'un noir luisant; la títe et le corselet sont lisses; les élytres sont lisses, plus courtes que l'abdomen; elles ont une strie peu marquée de chaque cóté de la suture; les pates sont rougeâtres.

Il habite l'Europe : on le trouve aux environs de Paris, sur les agaries.

\section{GENRE. \\ MÉLYRE.}

Caractères génériques. Antennes filifornes, un peus en scie, presque de la longueur da corselet, composées de onze articles; le premicr assez gros, Ic. second petit, le troisième allongé, les autres égaux. - Qaatre antennules filiformes, inégales; les antérieures un peu plus longues, composées de quatre articles; les postérieures courles, de trois articles. - Tếte avancée, un pen inclinée.

Cx genre a été établi par M. Fabricius. cet auteur n'a décrit que deux espèces: 
mais M1. Olivier, en adoptant le genre melyre, y a ajouté plusieurs autres insectes gue M. Fabricius avait placés dans différens genres.

Les mélyres ont les antennes un peu plus courtes que le corselet, en scic depuis le yuatrième article jusqu'au dixième; le dernier article est de forme ovale; elles sont insérúes de charue côté de la partie antéricure de la tête, au-dessous des yeux.

La tète est avancéc, un peu inclinće; les yeux sont arrondis, saillans; la bouche est composée d'une lèvre supérieure, de deux mandibules cornées, arquices, pointues à l'extrímité; de deux mâchoires cornées, divisíes en deux parties inćgales; d'une lève inférieure, et de quatre antennules ineigales, filiformes.

Le corselet est arrondi, bordé; l'écusson est petit, arrondi ; les élytres sont bordées, chagrinées, de la longueur de l'aldomen; elles recoivent deux ailes membraneuses, replićes.

Les pates sont de longueur moyenne, un jeu velues; les tarses sont filiformes, com- 
posés de cinq articles, dont le dernier est plus long que les autres, et terminé par deux crochets assez forts.

Tont le corps est plus ou moins allongé, et plus ou moins couvert d'un léger duvet. On trouve communément ces insectes pendant la plus grande partie du printemps, et en été, sur les fleurs composées et sur les fleurs en ombelles; ils volent avec assez d'agilité; quelques espèces ont des couleurs brillantes. Quoique les mélyres soient assez communs, lcurs larves ne sont point connues; mais on croit qu'elles se cachent et vivent dans la terre.

Ce genre est composé de scize à dix-huit espèces : plusicurs habitent l'Europe. Nous en décrirons quelques unes.

\section{Le Mélyre vert, Melyris viridis.}

Il a environ cinq lignes de long; les antennes sont noires, moins longues que le corselet, un peu en scie; la tète est chagrinéc; le corselet est d'un vert noirâtre, cliagriné, raboteux, bordé, avec une ligne longitu- 
dinale enfoncée sur le milieu; les élytres ont des points très enfoncés qui les font paraître raboteuses; elles ont trois lignes longitudinales élevées, et sont de couleur verteluisante, quelquefois bleue; le dessous du corps et les pates sont de la mème couleur que les élytres; Ies tarses sont noirs.

Il est commun au cap de Bonne-Espérance: on le trouve sur les fleurs.

Le Mélyre bleuâtre, Melyris cyaneus.

$$
\text { G. Dasgle. Latr. }
$$

Il a environ trois lignes et demie de long; sa forme est allongée; ses antennes sont presque aussi longues que le corselet, un peu en scie, d'un noir verdâtre à la base; tout le corps est velu, d'un vert plus ou moins foncé ; le corselet est pointillé, bordé; les élytres sont fortement pointillées; le dessous du corps est très luisant; les pates sont vertes; les tarses noirs.

On le trouve aux environs de Paris, sur les fleurs. Il est trìs commun dans les départemens méridionaux de la France. 
Le Mélyre atre, Melyris ater.

$$
\text { G. Dasyte. Latr. }
$$

Il a environ quatre lignes et demie de long : il est noir, velu; les antennes sont en scic, presque aussi longues que le corselet ; le corselet est bordé; les élytres sont pointillées; les pates sont velues. Dans l'un des deux sexes, le premier article des tarses antérieurs et postéricurs est allongé, un peu arqué, et muni à sa base d'un appendice long, arqué, qui paraît sortir de l'cxtrémité de la jambe.

On le trouve dans les départemens méridionaux de la France, à la fin du printemps et au commencement de l'été, sur les plantes graminées.

Le Mélyre plombé, Melyris plumbeus.

$$
\text { G. Dasyle. Latr. }
$$

Il a environ deux lignes et demic de long; il est bronzé, un peu velu; les antennes sont un peu plus longues que le corselet, 
légèrement en scic; le corselet est bordé ; les ćlytres sont flexibles, pointillées; les pates sont d'un noir bronzé.

On le trouve aux environs de Paris, sur les fleurs.

\section{Le Mélyre floral, Melyris florulis.}

$$
\text { G. Dasyte. Latr. }
$$

Il est un peu plus grand que le précédent; il est noir luisant, légèrement velu; les àntennes sont trìs en scie, plus longues que le corselet; le corselet et les ćlytres sont pointillés.

On le trouve aux environs de Paris, sur les fleurs. 


\section{GENRE.}

\section{TILLE.}

Caractères génériques. Antennes en scie, composées de onze articles, le premier un pen renflé. Quatre antennules inégales; les antérieures filiformes, composées de quatre articles, le premier petit, les deux suivans coniques, le dernier un peu plus gros, presque cyliadrique; les postérieures de trois articles, le premier et le second très petits, arrondis, le dernier très grand, sécuriforme. - Corps allongé.

ON ne connaît encore que deux espèces de tille. Un de ces deux insectes a été connu par Linné et par M. Fabricius. Le premier l'a placé avec les chrysomèles, et M. Fabricius avec les lagries. Cet insecte n'ayant aucun des caractères qui distinguent les clirysomèles et les lagries, dont il diffère d'ailleurs par le nombre des articles des tarses, M. Olivier en a fait un genre. Les tilles ont quelques rapports avec les mélyres; mais on les distingue de ceux-ci par les antennules postérieures.

III. 
Les antennes sont presque aussi longues yue la moitié du corps, le premier article est un peu renflé, le second est petit et arrondi, les autres sont en scic; elles sont insérées à la partic latérale antéricure de la léte, au-devant des yeux.

La tête est de la largeur du corselet; les yeux sont arrondis; la bouche est composée d'une lèvresupérieure, de deux mandibules courtes, cornées, arquées, pointues, unidentées; de deux mâchoires membrancuses, bifides, dont les divisions sont inégales; d'une lèvre inférieure, et de quatre antennules inégales.

Le corselet est presque cylindrique, plus étroit que les élytres; l'écusson est très petit; les élytres sont de la longueur de l'abdomen : elles reconvrent deux ailes memJ)raneuses, replićes.

I.es pates sont de longuenr moyenne; les tarses sont composés de cinq articles courts, assez larges; le dernier est armé de deux petits crochets pointus.

On trouve ces insectes sur les plantes et les fleurs : ils se nourrissent dn suc 

Insecter.

Pl. 72.
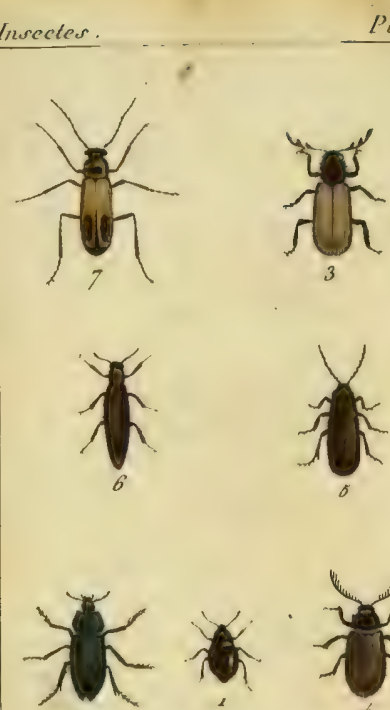

2
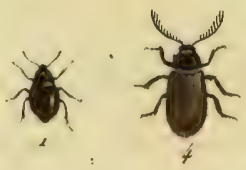

Baraband del.

Letellier Sculp.

1. Scap quadrimaculé. 2. Mél vert.

5. Vil. Serraticorne. f. Dril jaunâue.
5. Onal Sucural.

6. Lv. Naval.

7. 'íléph bimasuke. 
miclleux qu'elles contiennent; leur larve est inconnue.

N'ayant point ces insectes sous les yeux, nous prendrous leur description daus l'ouvrage de IM. Olivier.

\section{Le Tille allonge, Tillus elongatus.}

Le corps est noir, allongé, un peu velu ; les antennes sont filiformes, un peu en seic, presque de la longueur de la moitié du corps; le corsclet est rougeâtre, cylindrique, à peu près de la largeur de la tète.

Il se trouve en Allemagne et en Angteterre, sur les fleurs.

Le Tille serraticorne, Tillus serraticornis.

$$
\text { G. Énoplie. Laxa. }
$$

II ressemble au précédent; mais il est une fois plus petit; les antennes sont noires, filiformes à leur base, terminces par trois articles Ires grands, en scie; le corps est noir, un peu velu; lesćlytres sont testacées.

On le trouve en Italie. 


\section{Ce GEN R E.}

\section{R I L E.}

Caractères génériques. Antennes pectinées, composćes de onze articles, le premier court, un peu renflé; le second très petit, arrondi; le troisième triangulaire; les autres presque égaux, et pectinés d'un senl còté. - Quatre antennules inégales; les antérieures plus longues, composées de quatro articles, dont lo premier est plus petit, les autres insensiblement plus gros; les postérieures de trois articles, velus, presque égaux. - Tête courte, presque aussi large que lo corselet.

M. Geoffroy a placé le soul insecte qui compose ce gente, avec les ptilins. Comme cet insecte n'a de rapport avec les ptilins que par les antennes, qu'il en diffère par la forme du corps et par les parties de la bouche, MI. Olivier l'en a sćparé, et en a fait un genre auquel il a donné le nom de drile, d'un mot grec qui sert à désigner une espèce d'insecte ou de ver entièrement inconnu.

Les antennes sont de la longueur de la moitié des élytres, pectinées d'an seul côté, 
insćrées à la partic antérieure latérale de la tête, au-dessous des yeux.

La téte est de la largeur du corselet, inclinćc; les yeux sont arrondis, saillans; la bouche est composéc d'une lèvre supérieure, de deux mandibules cornées, avancées, arquices, pointues, unidentées; de deux mâchoires cornées à leur base, membraneuses et arrondies à l'extrémité; d'unc lèvre inférieure, et de quatre antennules inégales.

Le corselet est bordé, presque aussi large que les élytres; l'écusson est petit, triangulaire; les élytres sont bordées, flexibles, de la longueur de l'abdomen : elles recouvrent deux ailes membraneuses et replices.

Les pates sont de longueur moyenne; les tarses sont filiformes, les quatre premiers articles sont égaux, le dernier un peu plus long, et terminé par deux petits crochets.

Le corps est un peu allongé, déprimé. On trouve le drile dans toute la France, sur les fleurs : il est assez commun dans les déparlemens méridionatux, et aux environs de Paris. Il vole assez lígérement d'une fleur à l'autre. 


\section{Le Drile jaunâtre, Drilus flavescens.}

Il a environ trois lignes et demie de long; tout le corps est un peu velu; les antennes, la tète et le corselet sont de coulcur brune; les élytres sont flexibles, ponctuces, d'un jaune plus ou moins obscur; te dessous du corps et les pates sont bruns.

On ne connaît que depuis peu les niétamorphoses du drile jaunatre; sa larve vit en parasite dans la coquille de l'helix $\mathrm{uc}^{-}$ moralis, dont elle mange l'habitant; aptès avoir passé à l'état de nymphe dans cetle. coquille, il en sort a l'état parfait. La femelle est toujours aptère, et au moins six fois plus grosse que le mâle. Ices Mémoires de MM. Mielzinski, Desmarest et Audouin, insérés dans les Annales des Sciences nuturelles, présentent des détails curieux sur les moeurs et l'anatomie de cet insecte.

On commait denx autres espèces de ce fenre; elles sont d'Turope, mais tries tares. 


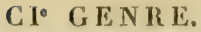

\section{OMALISE.}

Caractères géníriques. Antennes filiformes, articles prestue cylindriques, le second et le troisicme prestque globuleux. - Quatre antennules incigales, filiformes; les antérieures un pen plus longues, composées de quatre articles, dout le premirr est trés petit, à peine apparent, le second et le troisieme sont coniques, le dermier est gros et ovale; les postérieures de trois, premier article petit, les denx autres presque égaux. - Corstlet un peu aplati, teruiné postéveurement en deux angles aigus.

M. Georirox a donné à ec genre le nom d'omalise, qui veut dire aplati, it canse de la forme plate du corselet, et des élytres de la seule espéce qu'il connaissait.

Liomalise se rapproche un peu des lycus par la forme, mais il en differe par ses antennes, qui sont filiformes; celles des lycus sont comprimées, plus ou moins en scic.

I.es antemes sont ripprocheres it leur hase, plus longues que le eorselet, et in. 
sćrées à la partic antérieure de la tète, un pen au-dessous des yeux.

La téte est plus étroite que le corselet; les yeux sont arrondis, saillans; la bouche est composée d'une lèvre supérieure, de deux mandibules cornées, longues, minces, arquées, terminées en pointe aiguë; de deux mâchoites cornées à leur base, membraneuses à l'extrémité, d'une lìvro inféricure, et de quatre antennules inégales.

Le corselet est moins large que les élyires, presque carré, un peu aplati, rebordé; les angles postérieurs se terminent en pointes longues et aiguës; l'écusson est assez grand, arrondi.

Les élytres sont dures, aplaties, de la longueur de l'abdomen : elles recouvrent deux ailes nembraneuses, replićes.

Les pates sont de longueur moyeme, simples; les tarses sont filiformes, composés de cing articles presque égaux, le dernier est terminć par deux petits crochets pointus.

Tout le corps est de forme allongéce, un peu aplatic. On le trouve pendant l'été sur les plantes : il vole avec beaucoup d'agi- 
lité, mais il fait rarement usage de ses ailes: il se laisse tomber lorsqu'on vent le prendre, et se cache sous les herbes. Sa larve est inconnue.

\section{L'Omalise sutural, Omalisus suturalis.}

Il a près de trois lignes de long et une demi-ligne de large; tout le corps est noir, léprimé; les antennes sont noires, plus longues que le corselet; le corselet a ses deux angles postérienrs terminés en pointes aiguës; les élytres sont striées, et les stries sont pointillies; elles sont d'un rouge brun, avec une bande noire sur le milieu, tout le long de la suture : cette bande est, plus large da la base que près de l'extrémité; les pates sont noires.

On le trouve dans toute la France : il n'est pas commun aux environs de Paris. 


\section{G E N R E.}

\section{LYMEXYLON.}

Caractères génériques. Antenues filiformes, composćes de onze articles, dont les trois premiers sont un peu plns petits que les antres, les suivans sont preşue cylindriques et éganx, le dernier est terminé en pointe allongce, mousse; elles sont légèrement en scie dans quelques espèces. Quatre autennules inćgales; les antérieures beancoup plus longues, grossissant insensiblement, composées de quatre articles, dont le premier petit, le dernier gros ct eyliudrique; les postérieures filiformes, de trois articles, le premier petit, les autres égaux. - Tarses filiformes; corps allongé.

M. Fabrocius est le premier auteur qui ait fait un genre de ces insectes. Des deux espèces que Linné a connues, il a placé l'une avec les cantharides, et l'autre avec les méloés, dont les lymexylons diffèrent par le nombre des articles des tarses et par les antennes. M. Olivier a adopté ce genre établi par M. Jiabricius.

Les lymexylons ont les antennes filifor- 
mes, ou ligerement en scie, moins longrues que le corsclet; elles sont insérées a la par-tie antéricure de la tôte, au-dessous des yeux.

La téte est presque aussi large que le corselet, arrondie, trís inclinéc; les yeux sont arrondis, saillans; la bouche est composée d'une lévre sipérieure, de deux mandibules courtes, cornécs, peu arquées, presque dentées intérieurement; de deux michoires courles, presque membrancuses, divisées en deux, ì division inćgale; l'extéricure est plus grande, arrondic; l'intéricure est termince en pointe: d'une lève infévieure, et de quatre antennules inégales.

Le corselet est presque aussi large que les Ćlytres, peu bordé; l'écusson est petit, arrondi; les élytres sont flexibles, de la longnueur de l'ablomen; elles couvrent deux ailes membraneuses, replices.

Les pates sont minees, de longuteur moyenne; les tarses sont filiformes, composés de cing articles, dont le premier est le plus loug, les autres presque égaux, le dernicr est armé de deux crochets pointus. 
Tout le corps est de forme allongée, presque linéaire.

La larve des Iymexylons n'est pas connue; mais on sait qu'elle vit dans l'intérieur du bois, et qu'elle fait beaucoup de tort aux arbres. Ceux qui sont attaqués par ces larves, par celles des lucanes, des eapricornes ct des leptures, languissent et finissent par périr. On trouve l'insecte parfait, en été, sur le bois mort ou sur le tronc des arbres, on la femelle va déposer ses coufs.

Ce genre est composé de cinq ou six espices : elles habitent le nord de l'Europe ; l'on n'en trouve qu'une aux environs de Paris. Nous allons passer it la description de quelques uns de ces insectes.

\section{Le Lymexylon dermestoïde, I $y$ - mexylon dermestoides.}

G. Hylecote. LAxR.

Il a cnviron quatre lignes et demic de long; il est allongé, linéaire; ses antennes sont moins longues que le corselet, obscures et fauves à leur base; les deux premiers 
articles sont arrondis, les cinq suivans sont un peu en scie, les autres sont petits et arrondis; la tète est fauve; les yeux sont noirs; le corselet est fauve, un peu bordé; les élytres sont d'un fauve un peu plus foncé; elles ont quelques lignes élevées peu marquécs; le dessous du corps et les pates sont fauves; on voit un peu de noir à la poitrine.

Le mâle de cette espèce a été décrit par les auteurs, sous le nom de lymexylon printanier (Iymexylon marci) : il est ì peu près de la grandeur du précćdent; ses antennes sont filiformes, presque en scie et plus courtes que le corselet; la tète et le corselet sont noirs; les élytres sont noiritres; le dessons du corps est noir, avec l'extrémité de l'abdomen fauve; les pates sont fauves, avec les cuisses postérieures obscures.

On le trouve en Sucde, en Allemagne et dans le nord de la France.

Le Lymexylon barbu, Lymexylon barbatum.

Il a environ cinq lignes de long; ses anIII. 
tennes sont brunes, moins longues que le corselet; il est entic̀rement noir, légèrement. couvert d'un duvet fauve luisant; les pates sont brunes.

On le trouve en Allemagne, sur le bois mort.

\section{Le Lymexylon naval, Lymexylon navale.}

Il est de la longueur du précédent, mais plus étroit; les antennes sont brunes, moins longues que le corselet; la tête est très pelite, inclinée, noire; lc corselet est étroit, allongć, d'un jaune fauve, avec le bord extérieur et l'extrémité noirâtres; le dessous du corps et les pates sont fatives.

On le trouve au nord de l'Europe et aux environs de Paris, sur le bois mort.

\section{Le Lymexylon raccourci, Lymexylon abreviatum.}

G. Atractocìre. LATR.

Ce singulier insecte a les élytres courtes, comme cela se voit dans les staphylins ou 
DES LYMEXYLONS.

daus les molorques; elles sont obtuses et échancrées en dedans; sa tète et son corselet sont noirâtres, avec une ligne longitudinale jaunátre.

On le trouve en Afrique; M. Palisot de Bauvois l'a trouvé dans le royaume d'Oware.

Le genre Cupès vient se placer près des lymexylons; on en connaît plusieurs espèces; la plus commune est

Le Cupès à tête jaune, Cupes capitata.

Il est long de quatre lignes; sa tète est d'un jaune roussittre; ellc est avancée, ne rentre pas dans le corselet, et a une forme triangulaire; les antennes sont plus longues que la tête et le corselet, cylindriques et droites ; ses palpes sont ćgaux, ct terminés par un article tronqué; les yeux sont petits, et assez saillans; le corselet est plane, court, plus large que long, et noir; les élytres sont rugueuses, sillonnćcs et aussi longues que l'abdomen; les pieds sont courts, comprimes, et noirs, avec les tarses roussittres, 
On trouve cette espèce dans l' $\Lambda$ mérique septentrionale.

\section{I G E N R E. TELEPHORE.}

Caractères génériques. $\Delta$ nteunes filiformes; articles cylindriques, égaux, le second beaucoup plus court. - Quatre anteunules inégales; les antírieures un peu plus longues, composées de quatre articles, le premier petit, les deux suivans coniques, le dernier grand, sécuriforme; les postéricures de trois articles, le dernier article dilaté, comprimé, triangulaire, en forme de hache. Còtés du ventre plissés et à papilles. - Corselet plat, légèrement borlé.

Linnź a donné le nom de cantharides aux insectes qui composent ce genre, et M. Groffroy celui de cicindeles, afin de les distinguer de la cantharide des boutigues, qui depuis long-temps est connue en médecine. Ces insectes ne peuvent étre confondus avec la cautharide, dont ils different non seulement par plusicurs parties, mais encore par le nombe d'articles qui composent les tarses. Schocffer et Degéer les ont nommés 
téléphores, et en ont fait un genre qui a été adopté par les auteurs qui ont écrit depuis cux.

Les téléphores ont les antennes presque aussi longues que le corps, composées de onze articles, le premier est plus gros, les autres sont égaux; elles sont insérées à la partie antérieure de la tète, entre les yeux.

La téte est un peu aplatic, l'insecte la porte inclinéc lorsqu'il est en repos; les yeux sont petits, arrondis et saillans; la bouche est composée d'une lèvre supérieure, de deux mandibules avancées, cornées, simples, minces, pointues; de deux máchoires membraneuses, bifides, à divisions igales et rapprochées; d'une lèvre inférieure, et de quatre antennules presque égalès.

Le corselet est aplati en dessus, arrondi sur les côtés, Jebordé, et presque aussi large que les élytres; l'écusson est petit, peu apparent; les élytres sont molles, très flexibles, ordinairement de la longueur de I'abdomen; elles couvrent deux ailes membraneuses, replićes. 
Les pates sont assez grandes; les cuisses ont un appendice ovale à leur base; les tarses sont filiformes, de cinq articles, dont le premier est le plus long, le quatrieme est large, bilobé, le dernier est armé de deux crochets longs et pointus.

Le corps est allongé, un peu aplati, assez mou. On les trouve, en été, dans les prairies, sur les plantes et sur les fleurs : ils courent très vite. Selon Degéer, quelques téléphores sont carnassiers, ils se nourrissent d'autres insectes, et n'épargnent pas méme ceux de leur espèce. Cet observateur a vu une femelle renverser un mâle, lui ouvrir le ventre avec ses matchoiros et le ronger. Ces insectes volent avec facilité et promptitude, surtont lorsque le soleil brille. Dans l'accouplement, qui a licu au commencement de l'été, sur les plantes, le mâle est placé sur le dos de la femelle; mais il a besoin d'user de précaution pour l'approcher; car il arrive souvent qu'elle le reçoit fort mal, et it court les risques d'ètre dévoré.

Les larves des téléphores sont d'un noir mat velouté; elles ont la títe ap̧latic, ćcail- 
leuse, garnie de deux petites antennes, de deux fortes dents at de quatre antenunles. Le corps est un peu aplati en dessous, composé de douze anneaux, comme celui des chenilles, et couvert d'unc peau membraneuse ; aux trois premiers annerax sont attachies trois paires de pates écailleuses, assez longues, divisées en trois articles, et terminées par un crochet peu courbé; elles sont de coulcur brune, ainsi que les antennes. On remarque au-dessous de la tite une grande cavité, dans laquelle la lèvre inférieure est placie ; les quatre antemules tiennent à cette lève, qui est mobile; la larve la remue continuellement en marchant, de meme que les antennules, et semble se servir de toutes ces partics pour toucher les objets qu'elle rencontre. Ce que la tète de cette larve offre de plus remarquable, ee sont les deux graudes dents placées à sit partie antérieure; ces dents, qui sont dures et écaillenses, ont une petite dentelure au eoite intéricur, et sont courbées et croisces au-devant de la téle. Ie corps a, de chaque cóté des anneaux, des plis ou rides longitudi 
nales; l'anus, qui est placé au-dessous du dernier, a une espèce de rebord qui forme un mamelon, avec un enfoncement au milieu; sa larve, en marchant, applique ce mamelon contre le plan de position, et s'en sert comme d'une septième pate.

Ces larves vivent dans la terre, dont l'humidité leur est nécessaire; on peut les élever en leur fournissant souvent de la terre fraîche et humide, elles s'y enfoncent aussitôt. Ainsi cachées dans la terre, il semble que ces larves ne doivent se nourrir que de racines; mais, d'après les expériences de Degéer, il paraît qu'elles sont carnassières, et se nourrissent, au besoin, des individus de leur espèce, ainsi que des vers de terre.

La larve du téléphore ardoisé, que Degéer a cu occasion d'observer, parvenue au terme de son accroissement, a caviron un pouce de longneur, et moins de deux lignes de largeur. Vers la fin de mai ces larves se changent en nymphes dans le miliet de la terre, sans faire de corpue; elles sont longues de près de six lignes, un peu courbées en are, 
d'un rouge très pâle; on distingue sur elles toutes les parties que doit avoir l'insecte parfait. Le ventre cst divisé en anneaux et terminé par deux petites pointes. $\Lambda \mathrm{u}$ mois de juin ces insectes quittent leur peau de nymphe, et se montrent sous leur dernière forme.

Nous rapporterons une observation à laquelle ces larves ont donné lieu. On trouve dans les auteurs, qu'on a vu quelquefois des ver's et d'autres insectes tomber avec la neige. Degéer a été témoin d'un semblable phénomènc. En 17/9, après un très grand froid qui se fit sentir en Suède, il y eut un dégel accompagné de neige qui tomba en abondance. On aperçut alors avec étonnement que les chemins, les prairies, les montagnes et mème la glace d'un lac, étaient couverts d'une si grande quantité d'insectes vivans, mèlés avec la neige, qu’on pouvait en ramasser à pleines mains : ces insectes étaient des araignées, des scarabées, des staphilins, des chenilles, et surtout des larves de téléphores. Comme tous ces insectes ont pendant l'hiver leur habitation sous terre, et qu'ils ne la quittent point dans une saison 
aussi rude, Degéer ne put douter qu'ils ne fussent tombés avec la neige : il chercha à expliquer comment cet événement avait pu arriver. Aprís avoir observé que la chute de ces insectes avait été précédéc et accompagnée d'une violente tempète, qui avait abattu et déraciné dans les forêts de la Suède un très grand nombre de pins et de sapins, il remarqua avec raison, que les racines de ces arbres, qui occupent un très grand espace de terrain, avaient été par conséquent enlevées, et avec elles la terre et tous les insectes qui y étaient contenus; que ces animaux, emportés par la violence du vent, avaient été quelque temp̧s soutenus en l'air, et étaient enfin retombés avec la neige à différentes distances de leur première habitation, ce qui explique la chute de ces insectes.

Ce genre est composé d'une trentaine d'espèces; presque toutes habitent l'Europe. Nous allons passer à la description de quelques uns de ces insectes. 


\section{Le Téléphore ardoisé, Telephorus fuscus.}

Il a environ sept lignes de long et plus d'une ligne de largeur; ses antennes sont noires et fauves à la base; la tête est noire; le corselet est large, aplati, rebordé, fauve, avec une grande tache noire au milieu; les dytres sont noirîtres, flexibles; le dessous du corps est noirâtre, avec les côtés et l'extrémité de l'abdomen fauves; les pates sont noirâtres; les cuisses intermédiaires ont une tache fauve. .

On le trouve dans toute l'Europe; il est. trìs commun au printemps.

\section{Le Téléphore livide, Telephorus lividus.}

Il est à peu près de la grandeur du précédent : ses antennes sont noirâtres, testacées à leur base; tout le corps est de couleur testacée pále; les yeux sont noirs; le corselet est bordé, il a une impression longitudinale sur le milieu; les élytres sont 
204

HISTOIRF, NATURELI.P.

flexibles, sans taches; le dessous du corps est noirâtre, avec les côtés, l'extrémité de l'abdomen et les pates fauves.

On le trouve dans toute l'Europe; il est très commun au printemps.

Le Téléphore obscur, Telephorus obscurus.

Il a environ quatre lignes de long; les antennes sont fauves; la tête est noire à sa partie postérieure, et fauve à sa partie anlérieure; le corselet est large, bordé, fauve, avec une grande tache noirátre sur le milicu; les élytres sont noirâtres, flexibles; le dessous du corps est fauve, noirâtre à la poitrine; les pates sont fauves, avec les tarses obscurs.

On lé trouve dans toute l'Europe.

Le Téléphore mélanure, Telephorus melanurus.

Il est de la grandeur du précédent; les antennes sont noirâtres, avec le premier anneau fauve; l'insecte vivant est d'un rouge 
fauve, mort il est d'une couleur testacie; il a les yeux et l'extrémité des élytres noirs; les pates sont faures, les tarses noiratres. On le troure dans toute l'Europe.

Le Téléphore bimaculé, Telephorus bimaculatus.

Il est de la grandeur du téléphore livide, mais il est un jeu plus déprimé; les antcunes sont noires; la tite est noire; le corsclet fauve, avec une grande tache noire au milicu; l'écusson est noir; les élytres sont fauves; elles ont chacune une grande tache oblongue, noire vers l'extrímité; le dessous du corps est noir, avec des bandes fauves sur les anneaux de V'alidomen; les pates sont noires.

(On le tronve dans l'Amerique septentrionale, la Caroline, la Géorsie, la Virginie:

\section{Lo Tálíphore pâle, Telephorus pallidus.}

Il a environ deux lignes et demie de long: III. 
ses antennes sont fauves à la base, noirâtres à l'extrémité; la tête, le corselet et le dessous du corps sont noirs; les élytres sont flexibles, testacées, sans taches; les pates sont testacées.

On le trouve dans toute l'Europe.

Le Téléphore bimoucheté, Telephorus biguttatus.

G. Malthine, JAXR.

Il a près de trois lignes de long; les antennes sont noirâtres, fauves à la base; la tête est noire, avec la partic antéricure testacée; le corselet est testacé, avec une tache noire sur le milieu; les ćlytres sont plus courtes que l'abdomen, yrises, avec l'extrémité jaune; le dessous du corps ct les pates sont d'un jaune testacé.

On le trouve aux environs de Paris, sur les saules et les chênes. 


\section{Le Téléphore nain, Telephorus minutus.}

\section{G. Malthine, Laxr.}

Il ressemble au précédent par la forme, mais il est un peu plus petit; il est d'un jaune pâle; les antennes sont de la longueur du corps, noiritres; la tète est noire; le corselet est patle, avec une tache noire sur le milieu; les ćlytres sont moins longues que l'abdomen, d'un jaune testacé pâle, avec l'extrémitć jaune; le dessous du corps et les pates sont d'un jaune testacé pâle.

On le trouve aux environs de Paris. 


\section{GENRE.}

\section{A L A CHIE.}

Caractères génćriques. Antennes filiformes, pres que en scie; le premier article gros et arroudi. Quatre antennules inégales, filiformes; les anti. sireures un peu plus longnues, compuosées sle quatre articles, le premicr petit, les deux antres coni ques, le dernien sélacé; les postévieures de trois articles, le premier petit, le second conique, le dernier sétacé. - Vésicules cachées de chaque cûté de la poitrine et du ventre.

LINNÉ a platcé ce's inscetes avec les eantharides; M. Geoffroy et Degéer avec les téléphores, auxquels le premier a domé le nom de cicindèles. M. Fabricius en a fait un gente qui a été adopté par MI. Olivicr.

Les malachies ont quclepues mpports avee les téléphores; de mème que ces insectes, ils ont le corps très mou, mais ils en différent par les parties de la bouche et par les antennes.

Les malachies ont les antennes de la lon- 
gueur de la moitic du corps, composées de onze articles, dont le premier est gros, le second court, les autres un peu triangulaires; les mâles de quelgues especes ont les trois ou quatre premiers articles dilatés, de grandeur incigale; elles sont insérées ì la partic antérieure de la tète, entre les yeux.

La téte est de la largeur du corselet; les yeux sont arrondis, saillans; la bouche est composéc d'une lèvre supérienre, de denx mandibules cornées, avancées, arquérs, III) peu fendues à leur extrémité; de deux machoires membraneuses, arrondies, bifides, et rlont la division extérieure plus grande; d'une live inférieure, et de quatre auteu nules inégales.

Ic corselet est presque aussi large gue les élytres, aplati, hordé, arroudi sur les côtés; l'écusson est petit, arrondi; les ćlytres sont flexibles, de la longueur de l'al)domen; elles recouvrent denx aile's membrancuses, replices quand l'insecte n'on fait point usage pour voler.

I.es pates sont de moyenne longueur, minces; les tarses sont filiformes; le premier 
article est un peu plus long que les autres, et terminé par deux crochets. Tout le corps est un peu allongé.

Les malachies sont assez communs: on les trouve ordinairement, au printemps et en été, sur les fleurs. Selon quelques auteurs, ils sont carnassiers et se nourrissent d'autres insectes. Leurs habitudes sont semblables à celles des téléphores; mais une singularité qui mérite d'étre remarquée, c’est que les malachies ont de chaque côté deux vésicules rouges, charnues, iırrégulières, et à plusieurs pointes, qui partent du côté du ventre et du corselet, un peu en dessous, et que l'insecte fait enfler et désenfler à volonté. Ces espèces d'appendices ont étés appelés par quelques amateurs d'histoire naturelle, des cocardes. Si on prive ces insectes d'une ou de toutes ces vésicules, ils ne paraissent ni moins agiles ni moins vifs. On ignore l'usage de ces parties singulières: quelque hasard heureux, ou des observations suivies, pourront peut-c̀tre un jour fairc connaître de quelle utilité elles sont à l'insecte. Lat larve est inconnue. M. Olivier croit qu'elle 
vit dans le bois, parce qu'il a souvent trouvé dans les chantiers l'insecte parfait nouvellement sorti de sa dépouille de nymphe.

Ce genre est composé d'unc vingtaine d'espèces, qui habitent l'Europe; on les trouve presque toutes aux environs de Paris. Nous en décrirons quelques unes.

Le Malachie bronzé, Malachius aneus.

Il a environ quatre lignes de long; les antennes sont noires; la tête est d'un vert bronzé, jaune à sa partie antérieure; le corselet est d'un vert bronzé, un peu velu; les ćlytres sont d'un beau rouge, avec la hase et une partie de la suture d'un vert bronzé; le dessous du corps et les pates sont d'un vert bronzé ; tout le corps est luisant.

Il habite l'Europe; on le trouve aux environs de Paris, sur les fleurs.

\section{Le Malachie bipustule, Malactius}

\section{bipustulatus.}

Il est un peu moins grand que le précédent; les antennes sont noires, avec les pre- 
miers articles dilatés dans le mâle; ces articles sont jaunes; tout le corps est un peu velu, d'un vert luisant bronze; l'extrémite des élytres est rouere; la bouche est jauuc.

Il habite l'Europe; on le trouve aux environs de Paris, sur les fleurs.

\section{Le Malachie élégant, Malachius elegans.}

Il est moins grand que le précédent; les antennes sont noires; la tite est d'un vert bronzé, avec la bouclie jaune; tout le cotps cst d'un vert un peu bronzé, queliuefois bleuatre; les ćlytres sont couvertes de poils noirutres, elles ont un point jaune ì l'exIrémité; les pates sont bronzées.

On le trouve aux environs de Paris, sur les fleurs.

\section{Le Malachie marginelle, Malachius} marginellus.

Il a près de trois lignes de longr; les antennes sont noires; la tète est d'un vert hronzé, avec la bouche jaune; le corselet 
est vert, avee les bords latéraux rouges; les elytres sont vertes, avec l'extrémité rouge; elles sont arrondies et dentées it leur extrémité; le dessous du corps ct les pates sont d'uu vert bronzé.

Il est très commun en Europe; on le Irouve aux environs de Paris, sur les fleurs.

\section{Ite Malachie pulicaire, Malachius}

\section{pulicarius.}

Il a une ligne et demic de long; les anfeumes sont assez longues, fauves; la tite est noire; le corselet est fauve, avec un grande tache noire sur le milieu; les élytres sont noires, luisantes, avee l'extrémité rougeatre; les pates sont noiritres.

Il habite l'Europe; on le trouve aux environs de Paris, sur les fleurs.

\section{Malachie thoracigue, Malachius thoracicus.}

Il est de la grandeur du pécédent, auguel il ressemble pour la forme; mais il en dif- 
fère par son corselet, qui est entièrement rouge.

On le trouve aux environs de Paris, sur les fleurs.

\section{Le Malachie fascié, Malachius fas- ciatus.}

Il est de la grandeur du malachie thoracique; les antennes sont courtes, à peine aussi longues que le corselet; la tête et le corselet sont d'un noir verdâtre, luisant; les élytres sont d'un noir luisant, avec deux bandes rouges, l'une à la base, l'autre à l'extrémité; le dessous du corps et les pates sont noirs; les cótés de l'abdomen sont rouges.

On le trouve aux environs de Paris, sur les fleurs.

\section{Le Malachie équestre, Malachius equestris.}

Il est de la grandeur du précédent; les antennes sont presque en scie, de la longueur du corselet, noires, avec les premiers 
articles fauves; la tête et le corsclet sont lisses, d'un noir bronzé; les élytres sont rouges, avec une grande tache noire au-delà du milieu, ct une de même couleur, de forme triangulaire, autour de l'écusson; le dessous du corps et les pates postérieures sont d'un noir bronzé; les quatre pates antérieures sont jaunes, avec la base des cuisses noire.

On le trouve aux environs de Paris, et en Italie, sur les fleurs.

\section{V・ G E N R E.}

\section{LAMPYRE.}

Caractères génériques. Antennes filiformes, simples, ou en srie, ou pectinées, composées de onze articles presque égaux. - Quatre antennules inégales, filiformes; les antérieures un pea plus longues, composées de quatre axticles, le premier petit, le dernier gros, terminé en pointe; les postérieures conrtes, de trois articles, le premier petit, le dernier assez gros. - Corselet grand, aplati, cachant la tête par un large rebord.

CES insectes sont connus vulgairement sous le nom de vers luisans; les Latins leur 
ont donne le nom de lampyris, en français lampyre, it cause de la propriéts singulière que yuelques espices de ce genre ont de répande pendant la nuit une lumière phosphorique. Jinné les a placés avec les cantharides, les lycus, les téléphores et les malachics. M. Geoffroy, en les séparant des cantharides, etc., les a confondus avee les lycus. Mais M. Fabricius ayant reconmu it ces insectes des caractìres qui les distinguent de tous les insectes avec lesquels ils ont itc placés, en a fait un geure, et il a ćtí adopti: par M. Olivier.

Les lampyres ont les antennes filiformes plus ou moins longues; le premier artich est un peu plus gros, le sceond est plus petit; les autres sont prescuce égaux et cylin driques; elles sont rapprocliées à leur hase. ot insérées à la partie antérieure de la téte, un pes au-dessous des yeux. Quclques espices les out en scie, on un pen pectinérs.

La títe est cacliéc sous le large bord du corselet; les yeux sont arrondis, saillans; la bouche est composée de deux mandibules tris pelites, comées, arquies et pointucs; 
de derix michoires courtes, membraneuses, divisées en deux parties inígales; d'une lérre inféricure, et de quatre antennules inégales. La lèvre supérieure manque.

Le corselet est aplati, demi-circulaire, arrondi antérieurement, droit postérieurement, ou comme coupé transversalement: il couvre entièrement la tète : il est presque anssi large que les ćlytres; l'écusson est petit, arrondi.

Les élytres sont aplaties, coriacées, un jeu flexibles, de la longueur de l'abdomen dans le plus grand nombre des espices, beaucoup plus courtes dans d'autres; elles recouvrent deux ailes membraneuses, replices, um peu plus longues que l'abdomen. Les femelles n'ont ni ailes ni élytres.

Les pates sont courtes; les tarses sont composés de cinq articles: les trois premiers sont presque éganx, le quatrième est bilobé, le dernier est armé de deux petits ongles crochus.

Le corps est allongé, aplati; les anneaux de l'abdomen forment autant de plis sur les IIr. 
cótés, ou des espècés de papilles molles, anguleuses.

Tous les insectes qui répandent de la lumière, ont dủ fixer l'attention des observateurs de la nature. Aussi les lampyres'sontils connus depuis très long-temps. On leur a donnć le nom de vers luisans, parce que les femclles, qu'on rencontre le plus ordinairement, sont dépourvues d'ailes, et toutes les femelles brillent pendant la nuit. Quelques mâles sont privés de la propriétć de luire. La partic lumineuse des lampyres luisans est placée an-dessous des deux ou trois derniers anneaux de l'abdomen; ce sont des taches jaunes, d'où part, dans l'obscurité, une lumière très vive, d'un blanc verdâtre ou bleuâtx'e, comme le sont toutes les lumières phosphoriques. Cette lumière, selon quelques auteurs, ne dépend point de l'influence d'aucunc cause extcrne, mais uniquement de la volonté de l'insecte.

On tronve les lampyres, en été, après le coucher du soleil, dans les prairies, au bord des chemins, et près des buissons. Dans les 
pays où ces insectes sont très communs, pendant les nuits paisibles de la belle saison, les mâles voltigent dans l'air, qu'ils semblent remplir d'étincelles de feu, et les femelles, qui, pendant le jour, restent cachćes sous l'herbe, se décèlent le soir par la lueur éclatante qu'elles répandent dans l'obscurité. Pendant que ces insectes sont en liberté, leur lueur est très régulière : une fois en notre pouvoir, ils brillent très irrégulièrement, ou ne brillent plus. Lorsqu'on les inquiète, ils répandent une lueur fréquente: ćtant placés sur le dos, ils luisent presque sans interruption, en faisant des efforts continuels pour se retourner.

La matière lumineuse de ces insectes a excité la curiosité de plusieurs savans; elle a été l'objet de plusicurs expérienes, qui ont fourni des observations très intiressantes, que nous allons rapporter. M. Forster ayant annoncé que la lumière des vers luisans étail si forte et si continue dans le gaz oxiggène, (qu'il pouvait y lire facilement, M. Beckerhem, en vérifiant ce fait, al trouvé que ces insectes vivent très long-temps danr 
le vide et dans différens gaz, excepté dans les gaz acides, nitreux, muriatiques et sulfureux, dans lesquels ils meurent en moins de onze minutes;

Qu'ils n'ont jamais diminué la bonté des gaz clans lesquels ils ont vécu, quel que soit le temps qu'ils y aient demeuré ; qu'au contraire, le gaz hydrogène est devenu détonant par le síjour de ces animaux, et que plusicurs gaz essayés avant et après, ont paru itre amćliorés;

Que dans quelques gaz que fussent ces vers, la lumicre n'a jamais paru augmenter;

Que cette lumière est produite par des petits corps lumineux, que l'insecte peut recouvrir d'une membrane;

Qu'après avoir óté ces points lumincux du corps de l'insecte, sans l'endommager, it a continué de vivre sans laisser reparaitre de lumière;

Que ces points lumineux, ôtés de l'insecte vivant, et exposés à l'action de plusicurs gaz, y ont produit de la lumière pendant des temps differens; d'oit l'auteur parait croire que la duréce est plus grande dans le 
gaz oxigène que dans les autres. Annales de Chimis, tome xv, page 19 .

Les expériences faites par le docteur Carradori, sur le lampyre italique, lui ont fourni les observations suivantes : Ces inscctes, selon cet autcur, brillent ì volonté dans chaque point de leur ventre; ce qui lui prouve qu'ils ont la faculté de mouvoir toutes les parties de ce viscère, indépendamment l'une de l'autre.

Ils peuvent aussi rendre leur phosphorescence plus ou moins vive, et la prolónger aussi long-temps qu'ils veulent.

La faculté d'étinceler ne cesse pas, 'selon cet auteur, par l'incision ou le déchirement du ventre. MI. Carradori a vu une partic du ventre séparée du reste du corps, qui ćtait presque éteinte, devenir tout a coup lumineuse pendant quuclques secondes, et ensuite s'étcindre insensiblement. Quelquefois, il it vu une semblable portion coupée, passer subitement du plus beau brillant à une extinction totale, et reprendre ensuite sa premiere lueur. MI. Carradori attribue ec plic- 
nomène ì un reste d'irritabilité, ou à urr stimulus produit par l'air.

Une légère compression ôte aux lampyres leur faculté de luire. L'auteur n'est pas éloigné de croire que le mécanisme par lequel ils cachent leur lumière, s'exécute par une retraite de leur substance phosphorique dans une membrane ou tunique particulière; cette membrane est composíe de deux pièces unies ensemble. Le phosphore qu'elle contient ressemble à une pâte qui a l'odeur de l'ail, et peu de saveur, et elle sort de ce réecptacle par la plus légère presiion.

La matière phosphorique expriméc, perd en peu d'heures sa splendeur, et se trouve convertie en une matière blanche et sìche. Un morceau du ventre phosphorique, mis dans l'huile, n'a lui que faiblement, et s'est bientôt éteint; dans l'eau, un semblable morceau a lui avec la même vivacité que dans l'air, et plus long-temps. Le phosphore de ces insectes luit également dans le vide barométrique. L'auteur pense que la lumière phosphorique des lampyres est propre et innéc dans ces insectes, comme: 
plusicurs autres productions sont propres it d'autres animaux, et il a recomnu juc la phosphoresecence est unc propriétí indépendante de la vie de ces insectes, et qu'elle tient plutôt à l'état de mollesse de la substance phosphorique. Le desséchement suspend la lueur : le ramollissement dans l'eau la fait renaitre, mais seulement après un temps de dessiccation donné. Réaumur et Spallanzani ont observé la mème chose à l'egard des plıolades et des méduses.

En plongeant alternativement des lampyres dans l'eau tiède et froide, ils luisent arec vivacité duns la première, et s'éteignent dans la dernière. Dans l'eau chaude, la lucur disparaît peu à peu : enfin, le docteur Carradori a éprouvé, sur les lampyres et leur phosphore, l'action des différens liquides salins et spiritueux, dans lesquels ils se sont comportés de la mème manière que les autres animaux phosphoriques. Ces dernières expériences lui ont jrouvé que la matière phosphorique des. Jampyres n'éprouve d'action dissolvante que de la part de l'enu. 
Toutes les observations faites sur ces insectes prouvent quils peuvent répandre de la lumière à volonté. Degéer ayant renfermé dans un poudrier un lampyre femelle, ot l'ayant observé pendant plusieurs nuits de suite, il a remarqué que la première nuit il était très lumineux, et la lumière avait tant d'éclat, qu'elle éclairait une partic da poudrier; en déplaçant ce poudrier, la lumière cessa tout à coup, et ne reparut plus; mais la nuit suivante, la mème lumière se fit voir. On peut se procurer un très joli spectacle, en plaçant dans un pondrier plusicurs de ces lampyres; ils luisent alors tous ì la fois, et la lumière, qui s'étend à une assez grancie distance, éclaire tous les environs. On ne se lasse point de voir ce beau phénomène, produit par un véritable phospliore naturel. On peut garder ainsi ces lampyres pendant quinze ou vingt jours, en mettant un petit gazon dans le poudrier, et en ayant soin de l'arroser, parce que ces insectes aiment les licux humides. On ne les rencontre guère sur les terrains secs. En gardant ces insectes, on 
s'aperçoit de jour en jour que l'éclat de leur lumière s'affaiblit, et ils finissent par luire tris peu; ce qui prouve qu'ils souffrent, lorsqu'ils sont renfermés, ou que le grand air leur est nécessaire pour renouveler leur maticre phosphorique.

On ne connaît en France que deux espèces de lampyres: on en trouve une plus grande quantité dans les pays chauds, et ces insectes y sont plus grands; mais leurs conleurs ne sont ni vives, ni très varićes. Au-delit des Alpes, le lampyre italique, ou la Incióle, y est beaucoup plus multiplié que notre cspèce commune; il y répand aussi une lumicre plus vive et plus constante. Ces insectes commencent ì paraître après le coucher du soleil. Bientôt l'ár en est rempli, la terre en est jonchée. Pendant le jour, les femelles gardent un profond repos : ce n'est qu'd l'approche de la nuit qu'elles se mettent en mouvement; elles marchent trés lentement, et avancent comme par secousses; mais les mâles sont très agiles. Les lampyres sont d'un naturel tris pacifi- 
que, ct sont incapables de nuire; aussi les parties de leur bouche sont très petites.

Les femelles des lampyres d'Europe, observées par Degéer, pondent un très grand nombre d'œufs, sur le gazon, ou sur l'herbe où elles vivent. Ces œufs sont assez grands, de forme ronde, d'un jaune citron; ils sont conduits d'une matière visqueuse, jaune, qui sert ì les fixer sur la plante; leur coque n'est qu'une peau molle et flexible, de sorte qu'on les écrase au moindre attouchement.

La larve, longue d'environ un pouce, et large de trois lignes, a beaucoup de ressemblance avec la femelle, qui elle-mème ressemble à un ver hexapode. Cette larve a six pates écailleuses placées sur les trois premicrs anneaux; le corps, divisć en douze parties annulaires, a plus de largeur au nilien, et diminue insensiblement vers le derrière, qui est comme tronqué, ou coupé transversalement; le premier anneau, auquel la tête est attachée, est arrondi par- . devant, et son bord postérieur est coupe Iransversalement en ligne droite; Ie second 
et le troisiène ammeau ont a peu près la figure d'un carré long; mais le quatrieme et les suivans, jusqu'au pénultième inclısivement, sont moins longs, et peuvent reatrer l'un dans l'autre, ce qui fait que la larve peut allonger et raccourcir le corps a volonté, ses anneaux étant unis ensemble par une membrane ou peau flexible. Quand la larve étend cette membrane, le corps s'allonge, et les anneaux s'écartent les uns des autres; au contraire le raccourcissement de la mème membrane fait le raccourcissement du corps : les anneaux glissent alors en partic les uns sur les autres. Cette conformation, qui rend le corps tris souple, lui permet de se courber de toute façon. Le contour de ces anneaux est irrégulier et angulaire; ils sont couverts en dessus d'une plaque horizontale, plus ou moins dure, qui, de chaque côté du bord postérieur, forme une pointe saillante sur les neuf derniers anneaux, mais plus arrondie sur les trois premiers. He chaque côté dn dessous des huit dernicrs anneaux, en cxceptant le dernier, on voit uue plaque co- 
riace, brtune, formant une pointe angulaire, de sorte que chaque côté du corps est garni de dets rangs de scmblables pointes, dont l'entre-deux est membraneux, et d'un brun plus clair que le dessus du corps; mais la plạque du pénultième anneau est d'un blanc verdâtre. Enfin, au milicu du dessous du corps, les mêmes huit anneaux ont chacun une pièce irrégulière, écailleuse, presque noire, qui se termine en deux pointes saillantes, garnies d'un poil roide; elles sont plus longues sur les derniers que sur les premiers de ces anneaux; les trois premiers ont aussi entre les pates quelques pièces écailleuses, et la peau qui couvre le dessous est membrancuse et un peu ridée; le dessus du corps est d'un brun obscur, presque noir et mat; mais les angles postéricurs des anneaux sont d'un jaune livide; le dessous des huit premiers, excepté les plaques écailleuses, est d'un blanc jaunâtre; mais les neuvième, dixième et onzième sont d'un blanc verdâtre, et c'est de cet endroit que part la lumière que la larve fait paraître dans l'obscurité, ou c'est là qu'est placéc la 
matière phosphorique qui la produit. L'anneau qui termine le corps est brun et dur au toncher; il forme deux pointes, garmies it leur extrémité d'un poil roide; cet anneau a une fente transversale, qui est l'ouverture de l'anus. Sur toutes les parties qui sont écailleuses, on voit, à l'aide de la loupe, un grand nombre de très petits poils, mais qui n'empèchent pas la larve de parnitre rase; clle a dix-huit stigmates en forme de petites taches, d'un brun clair, percés au milicu, et placés de mème que ceux des chenilles.

I.e tîte est très petite, de forme ovalc, de couleur brune; quand on prend la larve dans la main, elle la retire entièrement sous le premier anneau; clle est attachíe au corps par une espèce de cou membraneux, qui est la partie dans laquelle clle rentre quand la larve la vent cacher; clle a deux petites antennes assez gresses, coniques, couttes, divisées en trois articles, et de couleur brune, placíes vers les côtés; la bouche est arméc de deux longues dents écaillenses, minces, courberes ot très poin- 
tues, qui se rencontrent par leurs pointes; au-dessous de ces dents, il y a une petite partie en forme de lèvre inférieure, garnic de six petites pièces coniques, semblables aux barbillons des chenilles et antres insectes; les pates sont assez longues, écailleuses, et de couleur brune, divisées chacune en trois partics, jointes par une membrane flexible et blanchâtre, et terminées par deux petits crochets; ${ }^{3}$ elles ont quelques poils courts.

Cette larve marche fort lentement; à chaque pas elle raccourcit le ventre, le recourbe en dessous en appuyant le bout contre le plan de position, et ensuite elle se pousse en avant avec les pates; la forme de ses dents pourrait la faire soupçonner carnassière; mais elle vit d'herbes et des feuilles de différentes plantes; elle devient faible et languissante, quand on la laisse manquer de terre humide; dès qu'on la touche, elle retire la téte, et reste longtemps immobile.

Quand les insectes ont ì se transformer en nymphes, ordinairement la peau se fend 
ou se brise sur le milieu de lat téte et du dos, et laisse une ouverture suffisante pour donner passage it tout le corps; mais cette larve ne se défait point ainsi de sa peau; celle-ci se fend dans tonte l'étendue des trois premiers anncaux; le dessus de ces anneaux se détache tout-à-fait du dessous; la pean de la teite reste attachée à celle de la moitié inférieure du premier anneau, et, ce qui est. particulier, e'est qu'elle n'est pas fenduc, mais très entière; la larve tire la títe de la peau qui la couvrait, d̀ peu près de la mème manière fu'on tire la main hors d'ume bourse; les denx fentes latérales, ou la séparation du dessus des anneaux avec le dessous, donnent une ouverture tris spacieuse a l'insecte pour sortir de la vicille peaı, et il en vient aisément à bout, en contractant et en allongeant les anneaux du corps alternativement; la nouvelle peau dont il est alors couvert est d'une couleur hien différente de celle de la vieille; le des sus est d'un rouge pâle, et le dessous du cripes est d'un jaune pitle; pen apres, le dessus du eorps devient d'un brun pite, les 
còtés rougeitres, et le dessous d'un blanc jaune; la tête et les pates sont d'un gris verdâtre.

Dès que la larve est dégagée entièrement de sa peau, elle courbe le corps en are, et se trouve dans l'état d'une véritable nymphe; mais on la voit encorc remuer et allonger la téte, les antennes ct les pates assez lentement; le corps a aussi quelques mouvemens. Quoique cette nymplie ait beaucoup de ressemblance avec la larve, on remarque cependant que la tete, les pates et les antennes ont beaucoup changé; que ces parties sont plus grosses, et n'ont qu'un mouvement lent et difficile; on ne trouve plus à la tète ces deux dents aiguës, mais deux barbillons courts et gros, qui les remplacent; on voit ensuite cesser le mouvement de la tète, des antennes et des pates; chacune de ces parties se place le long du corps comme dans les autres nymplies, avec cette différence qu'elles n'y sont pas aussi exactement appliquées. Le seul signe de vie que dome la nymplie, éest de courber de limps en temps son ventre en are, de le 
redresser ensuite, et de lui donuer des inflexions de côté et d'autre. Le cor'ps est divisé en douze anncaux; la tête est baisséc en dessous, et appliquée contre le dessous du corselet ou du premier anneau, dans lequel clle est un peu enfoncée; les antennes sont divisées en plusieurs articles; les pates sont grosses, arrondies ì l'extrémité, et ne sont point pourvues de crochets; au lieu de deux pointes qui se trouvaient à l'extrémité du dernier anneau, on y en observe alors huit, posées tout autour de l'anneau, au milieu desquelles on voit deux tubercules charnus, qui ont un petit mamelon au bout, et qui sont placés dans un petit enfonecment. Dès que la nymphe a quitté sa peau de larve, on lui voit répandre une lumière trìs vive et très brillante, qui a une teinte d'un beau vert; on a remarqué que quand on touchait au vase où elle était renferméc, clle faisait paraitre une lumière très éclatante, qui ensuite diminuait peu à peu, jusq̨u' disparâtuce entièrement, ce qui fait croire que la nymphe a aussi la faculté de luire quand elle veut. 
Les observations de Degéer prouvent que le lampyre femelle luit dans l'état de larve et dans celui de nymphe, comme dans l'état d'insecte parfait; ce qui fait voir que la nature ne l'a pas douće de cette faculté, principalement pour attirer le mâle, comme quelques auteurs l'ont pensé. Cependant il paraît que le mále en profite pour se rendre auprès de la femelle. M. Olivier dit s'être souvent servi de cette ressource pour attirer le mâle sur sa main, et que rarement elle a été saus succès. Les derniers anneaux du ventre du mâle du lampyre, qu'on trouve le plus communément aux environs de $\mathrm{Pa}-$ ris, ne sont point aussi lumineux que ceux de la femelle; on voit seulement quatre points de lumière, deux sur chacun des deux derniers anneaux. Dans les pays chauds, les lampyres mâles brillent autant que les femelles, mais on ne peut s'en apercevoir que lorsquu'ils volent; la partic brillante de leur corps est cachée par les ailes et les élytres, pendaut qu'ils sont en repos.

Ces insectes forment un genre, compose d'une soixantaine d'espèces. 
Ce genre est divisé en deux familles, d'après la forme des antennes.

PREMIERE FAMILLE.

Antennes filiformes.

\section{Le Lampyre luisant, Lampyris splen- didula.}

Il a environ cinq lignes de long; le corpes est allongé, un peu aplati; İes antennes sont noirâtres, un peu moins longues que le corselet; la tête est d'un jaume fauve; les yeux sont noirs; le corsclet est noir, avec les hords jaunattres; les ćlytres sont obscures, presque noires, un peu chagrinćes; le dessous du corps est fauve, avec des nuances brumes; les pates sont brunes.

La femelle est beaucoup plus grande que le mâle; elle est d'une couleur obscure, avec le dessous des trois derniers ameaux jaune. On la trouve, en été, dans presque toute I'Europe; l'éclat vif et lumincox qu'elle xipand par les trois derniers anneaux de 
l'abdomen, la fait distinguer dans tous le's tcmps. Cette espèce est la plus communc.

\section{Le Lampyre mauritanique, Lampyris mauritanica.}

Il est plus grand que le précédent; tout le corps est jaunatre; le corselet est jaune, arrondi; l'ćcusson est jaune; les élytres sont d'un jaune obscur : clles ont chacune trois lignes longitudinales élevées.

La femelle est deux fois plus grande que le unile, et plus ou moins rougeâtre; clle n'a que des rudimens d'élytres.

On le trouve dans les départemens méridionaux de la France, et sur la côte de Barbarie.

\section{Le Lampyre enflammé, Lampyris ignita.}

Il a environ cinq lignes et demic de long; le corps est de forme ovale, aplati; les antennes sont courtes, olsscures; la títe et la poitrine sont d'un brun noiritre; le corsclet est brui, avec deux taches jaunes it sa partic 
antéricure, séparées par un double trait brun; les élytres sont bruncs, avec une tache. jaune le long du bord extérieur; près de la base, elles ont quelques stries longitudinales plus obscures; le dessous de l'abdomen est jame; les ailes et les pates sont d'un brum clair.

On le trouve à Cayenne et it Surinam.

\section{Le Lampyre Pensylvanique, Lampyris Pensyluanica.}

Il a euviron quatre lignes de long ; les antennes sont brunes, moins longues que te corselet; la tite est jaunattre; les yeux sont noirs et très saillans; le corselet est jaune, avec une tache noire au milieu, et deux petites taches oblongues, rapprochées, vougeâtres; les élytres sont d'un brun jaunattre, chagrincies: elles ont quelques lignes élevées; le dessous du corps est obscur; les trois ou quatre dernicrs ameaux de l'abdomen sont d'un beau jaune; les pates sont jaune's, avec un peu de noiratre sur les cuisses et sur le's jambes; les tarses sont noiritres.

On le trouve dans la Pensylvanie. 
Le Lampyre pyrale, Lampyris pyralis.

Il a enyiron sept lignes de long; les antennes sontmoirires; la tẻte est jaune; les yeux sont noirs; le corselet est grand, aplati, rougeâtre, avec une tache noire au milieu; l'écusson est noirâtre; lesélytres sont noirâtres, avec la suture et le bord extérieur jaunes: elles ont quelques lignes longitudinales élevées; le dessous du corselet est rouge; la poitrine est noire; l'abdomen noir, avec l'extrémité jaane; les cuisses sont jaunes; les jambes et les tarses noirâtres.

On le trouve dans l'Amérique septentrionale.

\section{Le Lampyre marginé, Lampyris margináta.}

Il a environ cing lignes; les antennes sont noires; la tête est jannâtre; les yeux sont arrondis, un peu saillans, assez gros; le corsclet est noir au milieu, et jaune sur ses bords; les élytres sont noires, aver la suture et les bords extérieurs jaunes; IN 

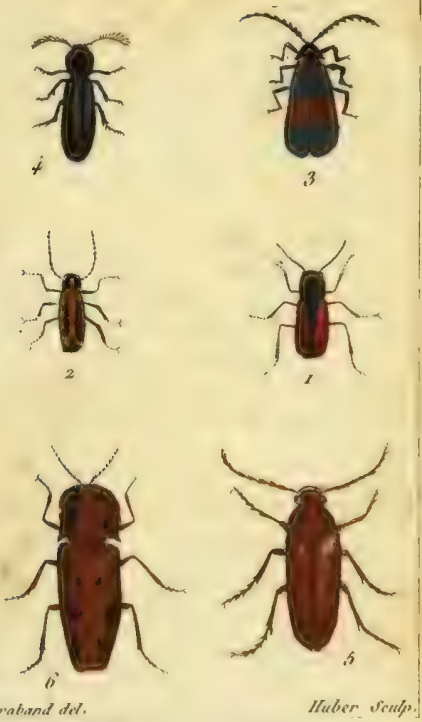

Bamatiand ded.

1. Mral, bronzé

2. Jamk, margusé

5. IAv, recticule

¥. Mél. Buprestoide.

5. Ceb. longicone G. Taupin tricolos. 

dessous du corps est noir, avec la moitic de l'abdomen jaune; les pates sunt noires, avec la base des cuisses et des jambes fauve.

On le trouve dans l'Amérique méridionale.

\section{Le Lampyre brillant, Lampyris lucida.}

Il est un peu plus grand que le précédent; les antennes sont d'un brun jaunâtre, un peu plus longues que le corselet; la tète est noirître; le corselet est grand, d'un jaune fauve, avec quatre lignes longitudinales, noirîtres, dont deux grandes sur le milieu, et une plus courte de chaque côté; l'écusson est noirâtre; les élytres sont noiràtres, avec la suture ct le bord extérieur jaunes; le dessous du corps et les pates sont d'un fauve obscur; l'abdomen est entièrement jaune en dessous.

On le trouve dans l'Amérique.

\section{Le Lampyre hémiptère, Lampyris hemiptera.}

Il a environ trois lignes de long; il est allongé, noir; les antenues sont un peu plus 
longues que le corselet; les élytres sont trìs courtes, et il n'y a point d'ailes an-dlessous; le dernier anneau de l'abdomen est jaunâtre.

On le trouve en France : il cst assez rare aux environs de Paris.

DEUXIEME FAMILLE.

Antennes pectinces.

\section{I.e Lampyre flabellicorne, Lampyris flabellicornis.}

Il est un peu plus grand que le lampyre luisant; les antennes sont noirâtres, très pectincéc, assez grandes; la tète est noire et cachíe; le corsclet est noir, avec les bords d'un jaune paile, et les rebords noirs; les élytres sont légèrement chagrinécs, avec denx ou trois lignes longitudinales peu élcvées, très peu marquées; elles sont noires, et ont une ligne longitudinale, courte, pâle, vers le bord extéricur de la base; le dessous du corps est noir, avec l'extrímité de l'al)domen d'un jaune pále; les pates sont noires.

On le trouve au Brésil. 


\section{CVIe GENRF. LYCUS.}

Caractères génériques. Antennes filiformes, comprimées, souvent en scie; premier articie plus petit et arrondi.—Quatre antennules inégales; les antéricures nn pen plus longues, composces de quatre articles, le premier plus petit, le second et le troisième conrts, égaux, le quatrièmé plos grand, tronqué; les postérieures de trois articles, le premier plus petit, le second conique, le troisième plus gros, comprimé, presque sécuriforme. - Téte étroite, plus ou moins allongée. - Corselet aplati, un peu bordé.

MI. Famicrus est le premier auteur qui ait fait un genre de ces insectes. Tous les naturalistes qui ont écrit avant lui les ont placés avec les pyrochres et les lampyres. Les lycus ont beancoup de rapport. avec ces derniers; mais ils en different par la partie antéricure de la téte; celle des lyeus est plus avancée que celle des lamprres; ils on different encote par quelques parties de leur bouche, et par les antenues.

less antennes des lycus som composées de: III. 
onze articles: clles sont filiformes, fortement comprimées; les deux premiers articles sont petits, les autres égaux, quelquefois en scie; elles sont de la longueur de la moitié du corps, rapprochées à leur base, et insérées à la partic antéricure de la tête, au-devant des yeux.

La tête est petite, inclinée, plus ou moins avancée antérieurement, et formant une esjèce de bec, à l'extrémité duquel sont placées les partics de la bouche; les ycux sont petits, arrondis, saillans; la bouche est composée d'une lèvre supérieure, de deux mandibules courtes, cornées, arquées et aiguës; de deux mâchoires membraneuses, arrondies, ciliées et simples; d'une lèvre inférieure, et de quatre antennules inégales.

Le corselet est aplati, rebordé, arrondi antérieurement, avec une pointe saillante de clıque côté du bord postérieur; il est plus étroit que les élytres; l'écusson est petit, arrondi postérieurement.

Les élytres sont cornées, un peu flexibles, plus ou moins réticulées, de la longueur de l'abdomen, quelrquefois larges et dilatées; 
elles recouvrent deux ailes membraneuses, repliées.

Les pates sont de longueur moyenne, fortement comprimées; les tarses sont composés de cinq articles courts, le dernier est cylindrique, un peu arqué, et terminé par deux crochets assez forts.

Le corps est allongé, aplati; quelques espèces ont les élytres extrêmement dilatées.

On trouve ces insectes sur les flcurs; ils enfoncent leur tête au fond des corolles, et en retirent les sucs. On ne connaît point la larve des lycus: quelques auteurs croient. qu'elle vit dans la terre.

On trouve peu de ces insectes en Europe: ils forment un genre dont on ne connait encore qu'une vingtaine d'espèces. Nous en décrirons quelques unes.

\section{Le Lycus large, Lycus latissimus.}

Il a environ neuf lignes de long; ses antemes sont noires, plus longues que le corsclet; la téte est noire, petite, termince antérieurement en forme de bec; le cor. 
selet est un peu dilaté, noir au milieu, avec les còtés fauves; les ćlytres ont quatre lignes longitudinales élevées; clles sont dila-, tíes, larges vers leur extrémité; clles sont fauves, avec une tache noire sur le milieu du bord extérieur, et toute l'extrémité noire; elles ont quelquefois un peu de noir it la suture; les pates et tout le dessous du corjes sont noirs; les côtés de l'abdomen sont quelquefois rougeâtres.

On le trouve dans l'Afrique équinoxiale.

Le Lycus sanguin, Lycus sanguineus.

Il a environ cinq lignes de long; les antemes sont noires, moins longues que la moitié du corps; la tite est noire, un peu avancéc antéricurement; le corselet est presque carré, inégal, raboteux, rouge, avec une tache noire sur le milieu; lécusson est noir'; les élytres sont d'un rouge sanguin; elles ont des lignes longitudinales élevées; les ailes, le dessous du corps et les pates sont noirs. "

Il habite l'Lurope : il est très commun 
dans les départemens méridionaux de la France; on le trouve aux cnvirons de Paris.

Le Lycus réticulé, Lycus reticulatus.

Il a enviton huit lignes de long; ses antcunes sont noires, plus longue's que la moitié du corps; les articles sont larges et très comprimés; la tète est noire; le corselet est noir sur le milieu, avec les côtés fauves; les pointes du bord postérieur sont très saillantes; l'écusson est noir; les élytres sont noires, avec une grande tache fauve à la base, et une bande transversale de méme couleur sur le milicu; les élytres sont un peu dilatées; clles ont chacune quatre lignes longitudinales élevées, saillantes, et entre clateune de petites lignes transwersales élevées.

On le trouve dans l'Amérique septentrionalc.

\section{Le Lycus bicolor, Lycus bicolor.}

Il a environ cing lignes de long; les antemes sout noires, de la longuesir de la moitić du corps; la tête est rouge; les yeux 
sont noirs; le corselet est rouge ; les élytres sont rouges depuis la base jusque vers le milieu, et d'un noir blenâtre depuis le milieu jusqu'à l'extrémité; les ailes sont noires; le dessous du corps et les pates sont rouges; les tarses noiråtres.

On le trouve dans l'Afrique équinoxiale.

Le Lycus rostré, Lycus rostratus.

LCs antennes sont noires, cn scie; la tête ('st noire, avancée, cylindrique; le corselet est dilaté, plus étroit que les élytres, noir au milieu, avec les côtés et le bord antévieur d'un jaunc fauve; les ćlytres sont d'un jaune fauve, avec une grande tache noire près de la base, et une à l'extrémité; elles ont trois lignes longitudinales élevées; $l e$ dessous du corps est noir, avec les côtés de l'abdomen fauves; les pates sont noires.

On le trouve au cap de Bonne-Espérance.

Le Lycus dentelé, Lycus serratus.

If a cnviron huit lignes de long; les an- 
temnes sont noires, un peu en seie, presque aussi longues que la moitié du corps; la tête est noire, avancíe; le corselet est jaune fative, avec une ligne longitudinale noire au milieu; les élytres sont fauves, avec trois grandes taches noires, une vers la base, une sur le milicu, et l'autre à l'extrémité; le dessous du corps est noirátre; les pates sont noires, avec la base des cuisses fauve.

On le trouve a Cayenne et à Surinam.

Le Lycus flabellicorne, Lycus flabellicornis.

Il a environ cinq lignes de long; les antémes sont noires, souvent en scic, un peu plus longues que la moitié du corps; il est entièrement d'un noir mat, à l'exception de Ia partie antéricure et des bords latéraux du corselet, qui sont d'un jaune rotıgeattre ; les élytres ont quatre lignes longitudinales élevées, et entre chacune de petites lignes iransversales.

On le trouve dans l'Amérigue septentrio. nale. 
Le Lycus nain, Lycus minulus.

Il a environ quarre lignes de long; les antennes sont noires, avec l'extrémité fauve; la tête et le corselet sont noirs; l'écusson est noir; les élytres sont d'un rouge sangyin : elles ont chacune quatre lignes longitudinales élevées, entre lesquelles il y a deux rangées de points enfoncés, grands et serrés.

On le trouve au nord de l'Europe.

\section{Le Lycus aurore, Iycus aurora.}

Il a environ cing lignes de long; les antennes sont noires, presque en seie, de la longucur de la moitić du corps; la tite, le dessous du corps et les pates sont noirs; te corselet est d'un rouge sanguin, un peur raboteux, avec une ligne longitudinale courte, élevéc, sur la partic antéricure; les élytres sont d'un rouge sanguin: clles ont quatre lignes longitudinales élevées, et entre cha cunc deux rangées de points enfoncés.

II habite l'Allemagne. 


\section{DES MẺLASIS. \\ CVII GENRE.}

\section{MELASIS.}

Caractères gínériques. Antennes pectinées d'un seul côté, de la longueur du corselet, composées de ouze articles, le premier long, les deux suivans simples, courts, les antres latéralement prolongés. - Quatre antemunles; les antéricures unc fois plus longues, composćes de quatre articles, le premier petit, les deux suivaus arrondis, lc quatricme un pen plus gros et ovale; les postérieures filiformes, courtes, composées de trois articles, le premier petit, le second arroucli, le quatrième ovale. - Th́te assez grosse, un peu enfoncće dans le corselet. - Corps allonge, cylindrique.

LF: scul insecte qui compose ce grenre a été placé par Linné avec les taupius, et par I. Fabricius avec les hispes. M. Olivies l'en a séparé, et lui a douné le nom de mélasis, yui signnifie noir. Ie mélasis diffère des * taupins par la forme de ses antennes, qui somt pectinées, et pax les parties de la bonche. Il differe aussi des hispres par les an- 
tennes et par le nombre des articles des tarses.

Les antennes sont de la longucur du corselet, et insérćes à la partic antéricure de la têtc, au-dessous des yeux.

La téte est arrondie, inclinće, un peu enfoncée sous le corselet; les yeux sont petits, arrondis, peu saillans; la bouche est composée d'unc lèvre supéricure, de deux mandibules courtes, cornćes, arquées et pointues; de deux mâchoires conrtes, presque membraneuses, arrondies, un peu ciliées; d'une lèvre inférieure, et de quatre antennules inégales.

Le corselet est arrondi, de la largeur des élytres, terminé en pointe de chaque côté du bord postérieur; l'écusson est très petit.

Les élytres sont dures, de la longueur de l'abdomen ; elles recouvrent deux ailes membraneuses, repliées.

Les pates sont de longueur moyenne; les jambes sont comprimécs; les tarses sont composés de cinq articles, dont les premiers sont plus longs et plus gros que les autres; 
it dernier est mince, et armé de deux petits crochets.

La larve du mélasis n'est pas connue; mais on soupçonne qu'elle vit dans l'intérieur du bois mort et carié, et se nourrit de sa substance, parce qu'on trouve l'insecte parfait sur les vieux arbres. Il paraît lourd, et vole peu.

On le trouve rarement aux environs de Paris.

\section{Le Mélasis buprestoïde, Melasis buprestoides.}

Il a environ quatre lignes et demie de long; il est noir, point luisant; les antennes sont de la longueur du corselet; le premier article est long, les deux suivans sont courts, simples; les autres sont prolongés latéralement; le corselet est pointillé; il a une petite ligne courte, peu enfoncée sur le milicu; les élytres sont striées et un peu chagrinées; les pates et les antennes sont d'un brun ferrugineux. 
Le mâle est ordinairement une fois plus grand que la femelle:

Il habite l'Etrope; on le trowve rarement anx environs de Paris.

\section{Le Nélasis élatéroïle, Mclasis elateroides.}

\section{G. Céropleyte. Latn.}

Il est long de quatre lignes environ; noir, strié; son corselet est moins bombé que celui du précédent; ses tarses ont le pénultième article bilobé; les antennes sont branchnes d'un côté dans les mâles, en scic dans les femelles.

On trouve cet insecte aux cnvirons de Paris, sur le tronc des chines; il est tris rare. 


\section{G G NRE.}

\section{CEBRION.}

Caractires génériques. Antennes filiformes presque sétacées, légèrement en scie, composées de onze articles, le second et le troisième très courts. Quatre antennules filiformes, inégales; les antéricures un peu plus longues, conposées de quatre articles, dont le premier est court, les autres égaux; les postérierres de trois articles, le premier court, les autres égaux. - Tête courte, corps oblong.

Cr. genre a ité établi par M. Olivier. M. Fabricius, dans ses premiers ouvrages, avait placé l'une des deux espréces qui le composaient, avec les cisteles, dont cet insecte différe par le nombre des articles des tarses.

Les cébrions ont beaucoup de ressemblance avec les taupins, par la forme du corselet; mais on les distingue de ces insectes par leurs antennes, qui sont beaucoup plus longues, et par les parties de la bouche. 
Les antemnes des cébrions sont presque de la longueur du corps, filiformes, lígèrement en scie; elles sont insérées à la partic antérieure de la téte, au-dessous des yeux.

Ia tète est courte, presque aussi large que le corselet, un peu inclinéc; les yeux sont arrondis, saillans; la bouche cst composée d'une lèvre supéricure, de deux mandibules avancées, grandes, cornées, arquées et pointues; de deux mâchoires courtes, presque membraneuses, bifides; d'une lève inféricure, et de quatre antennules inégales.

Le corselet est terminé, de chaque côté de sa partic postéricure, par unc pointe aiguë très avancée, de méme que celui des taupins ; en dessous, il est muni d'une pointe qui s'enfonce dans une cavité; l'écusson est petit, peu visible.

Les élytres sont un peu flexibles, de la longueur de l'abdomen; elles recouvrent deux ailes membrancuses, repliées.

Les pates sont assez. longues; les cuisses postéricures ont un appendice ovale à leur base; les tarses sont filiformes, composís de 
cinq articles ; les trois prenicrs sont iganx, le quatrieme est plus court; le dernier est long et terminć par deux crochets assez forts; le corps est oblong.

Ce genre est composé de peu d'espéces, dont les habitudes ne sont pas bien connues. Ces insectes habitent le midi de la France et de l'Italie; ils volent ordinaircment dans le milieu des chemins, et apres rne graude pluic : ils ont le vol brusque et rapide, ee qui fait qu'ils heurtent tous les corps qu'ils rencontrent. Quoique le corsclet des cébrions soit exactement conformé comme celui des taupins, ils n'ont point, comme ces insectes, la faculté d'exécuter des sauts, au moyen de cette partie, caractère qui doit suffire pour les distinguer des taupius, malgré la ressemblance qui existe entre enx.

\section{Le Cébrion longicome, Cebrio lon- gicornis.}

I. male a environ neuf lignes de long; les antennes sont noiratres, filiformes, un peu en scie, presque aussi longues que le 
corps; la tête est noiràtre, couverte d'us léger duvet; le corselet est noirûtre, couvert de poils roux, avec les côtés du bord postéricur terminés en angyle très aigu; les elytres sont testacées, légèrement strićes, et pointillées; le dessous du corps est tustacé; les pates sont noiraitres; les cuisses testacées.

La femelle est un peu plus grande qu: le mâle, dont elle diffère par les antenues, qui sont plus courtes que la tète, et par le défaut d'ailes; ses antennes paraissent n'avoir que dix articles, dont le premier est allongé, et les autres sont plus gros; la tète est ferrugineuse; les yeux sont noirs; le corselet est ferrugineux, lisse, finement pointillé, terminé de chaque côté du bord postérieur en angle très aigu; les élytres sont testacées, lisses, pointillées, strićes, plus courtes que l'abdomen, et écartées l'une de l'autre à leur extrémité; le dessous du corps et les pates sont testacés.

Cé insecte a été décrit par M. Olivier sous le nom de cébrion brévicorne; nous avons, le premier, fait connaître que ce n'í. tait que la femeile du cébrion longicorne. 
On trouve ceite espèce dans le midi de la France, en Italie, en Ispagne.

$\Lambda$ la suite des cébrions viennent naturellementse placer les genres suivans de M. Latreille.

\section{G. Rhipicène.}

(Voyez les Caractères, tome $\mathrm{xx}$, page 218.)

La Rhipicère marginée, Rhipicera marginata.

Cette magnifique espèce est longue de plus d'un pouce; son corps est d'un noir verdàtre bronzé; il est grarni d'un duvet roussâtre; les élytres sont d'un brun cuivreux; leur base, leur suture et le bord extérieur, sont d'un testacé pille; Ia base des cuisses est ferrugineuse; les antenues sont en panache, de la longueur de la tete et du corselet; elles sont noires : celles du mâle ont trente-deux articles, et ces articles sont beaucoup plus allongés que ceux de la femelle, qui n'en a que vingt-deux. Le's jambes et les tarses sont noirs.

On trouve ee bel insecte au Bresil; il n'est pas tre's rare dans co pays. 


\section{G. Dascille.}

(Voyez les Caractères, tome xr, page 218.)

\section{Le Dascille Cerf, Dascillus Cervinus.}

Cet insecte a près de six lignes de long; son corps est noirâtre et soyeux en dessous; en dessus il est d'un brun cendré; ses élytres sont rebordées.

On le trouve aux environs de Paris; il est rare.

Le Dascille cendre, Dascillus cinereus.

Il est de la taille du précédent, et ne paraît ètre qu'une variété locale. Son corps est livide, arec les élytres et les pates brunes.

On le trouve en Allemagne, en Italie, dans la Suisse, et en France aux environs de Strasbourg. 


\section{G. Élode.}

(Voyes les Caractires, tome 11, page 2ig.)

L'F́lode pâle, Elodes pallida.

Cet insecte a environ denx lignes de long; il est d'un jaune pâle; sa tìte et l'extrémité de ses élytres sont d'un brun obscur; ses antennes sont brunes, et ses pates d'un fauve pâle.

On trouve cet insecte aux environs de Paris, sur les arbres qui croissent dans les lieux humides et marécageux.

\section{L'Élode livide, Elodes livida.}

Elle est de la même taille que la précédente; tout son corps est lisse, glahre, livide; ses antennes seules sont olseures.

On la trouve aux environs de Paris, daus les mèmes lieux que la précédente.

L'Élode pubescente, Elodes pubescens.

Elle n’a pas plus d'une ligne de longueur; son corps est noir, pubescent; sa tête est 
brune, avec les antennes ferrugimeuses et le corselet gris obscur; ses élytres sont aussi grises, avec la suture un peu noiritze; ses pates sont un peu grisútres.

On la trouve dans les mèmes lieux que les précédentes.

\section{G. Scirte:}

(Voyce les Caractères, tome x, page 219.)

Le Scirte hémisphérique, Scirles hemisphericus.

Il a presque une ligne de longuenr; son corps est presque orbiculaire, déprimé, d'un noir foncé; ses cuisses postérieures sont renflées.

On le tronve sur les feuilles des arbres, dans les lieux humides et marécageux. 


\section{GEIRE.}

\section{TAUPIN.}

Caractères generiqnes. Antennes filiformes, en seie, souvent pectinces, premier article plus gros, ar roudi, le second très petit. - (liatre antennules; les antéricures courtes, composíes de quate articles, le premier petit, le second et le troisicme Egaux et conirgues, le quatrième plus grand, sécuriforme; les postélicures très courtes, de trois articles, le premier et le seeond très courts, égaux, le troisième plas geand, sécuriforme. - Corselet terminé en dessous par une pointe reçue dans une cavité de la poitrine.

ON a donné aux insectes qui composent ce genre le nom d'clater ou de notopeda, parce que, lorsqu'ils sont renversés sur le dos, ils ont la faculté de satuter et de s'élever en l'air. On les a aussi nommés scaraljées à ressort; mais M. Geoffroy leur a dommí en français le nom de taupin.

Ies taupins ont beaucoup de ressemblance avee les buprestes; comme cux, ils ont les antennes filiformes ou en scic, et Ia trite cnfoncese on partic dans le corselet.

fors antemnes des fanpins sont plus ou 
moins longues, presque d'égale grosseur dans toute leur étendue. Les mâles de quelques espèces les ont pectinées, et les femelles les ont en scie; elles sont insérées à la partie antérieure et latérale de la títe, atu-dessous et jrès des yeux.

La téte est petite, moins large que le corselet, dans lequel elle est enfoncic en partie; les yeux sont très petits, arrondis, peu saillaus; la bouche est composée d'une lève supéricure, de deux mandibules courtes, cornées, unidentées et arquées; de deux mîchoires membraneuses, d'une lèvre inférieure, et de quatre antennules.

Le corselet est allongé, presque aussi large que les élytres, convexe, arrondi en devant, terniné de chatue côté de sa partic postéricure par une pointe anguleuse en forme d'épine courte et roide, dirigrée vers l'abdomen; en dessous, il est garni d'une pointe qui entre dans une cavité placéc à la partie supéricure de la poitrine; l'écusson est allongé, arrondi, quelquefois plus large ¿t sa partic postérieure qu'à sa partic antérieure. 
Les élytres sont très dures, écailleuses, un peu convexes, ordinairemént de la longrueur de l'abdomen; elles recouvrent deux ailes membrancuses, repliées quand l'insecte n'en fait point usage.

I.es pates sont assez courtes; les tarses filiformes, divisés en einq articles; les quatre premiers sont presque éganx, le dernier est atlongé, cylindrique, un pen renflé à son extrémité, et terminé par deux crochcts assez forts et pointus.

I.es taupins ont le corps allongé, un peu aplati; on les trouve ordinairement sur les fleurs, sur les troncs des arbres cariés ct sous les écorces. Ils marchent lentement, et se laissent tomber lorsqu'on veut les prendre. Tous ces insectes out la faculté de sauter et de s'élever en l'air comme par une espèce de ressort, lorsqu'ils sont sur le dos, mais jamais autrement. En sautant, ils s'élivent perpendiculairement it une eertaine hauteur; de sorte qu'ils retombent it peu près au mime cndroit où ils étaient placés. Leur but, en sautant de cette manière, est uniguement pour se remettre sur 
leurs pieds, ce qu'ils ne pourraient faire sans un travail long et pénible, à cause du peu de longucur de leurs patcs. Qnand il arrive qu'ils retombent sur le dos, ce qui n'est pas rare, ils réitèrent les sauts jusqu'ì ce qu'ils se trouvent sur lcurs pates. Après avoir dit de quelle utilitć ces sauts sont aux taupins, nous allons parler des parties qui servent à les exćcuter.

Le corsclet est terminé, de chaque côté de son bord postéricur, par une pointe en forme d'épine roide, et en dessous, exactement au milicu du bord postérienr, il est garni d'une troisième pointe Iongue, roide, très dure. Cette pointe est placéc dans la meme ligne que le corps, et s'avance vers la poitrine beaucoup au-delà du bord du corselet; elle est large à son origine, diminue peu à peu de grosseur, et se termine en pointe mousse ou un peu arrondie. En dessous, et prìs de son extrémitć, on remarque une petite éminence en forme de dent. Sur la poitrine, entre son bord antérieur et la base des deux pates intermédiaires, on voit un tron ovale assez pro- 
fond, dont le bord postéricur est arrondi, ct le bord antéricur échancré. C'est dans cetic partic que la pointe du corselet s'enfonce quand l'insecte baisse la tète et lo corselet, soit qu'il marche, soit qu'il reste en repos. Tels sont les principaux instrumens au moyen desquels le taupin s'élive en l'air, ce qu'il exécute de la manière suivante. L'insecte, placé sur le dos, baisse la tète et le corselet vers le plan de position: par ce mouvement, la pointe du corselet sort entièrement du trou ovale. Dans le même temps, l'insecte applique ses pates contre le dessous du corps, et les y tient fortement serrées; ensuite, rapprochant le corselet de la poitrine, de manière que la dent de la pointe vienne s'appuyer sur le bord du trou, il le pousse subitement et fortement contre ces mimes bords, de sorte que la dent se dóbande rapidement, et la pointe rentre dans sa cavité comme par un ressort. Comme ce mouvement sc fait avec vitesse, le corselet avec ses pointes latíxales, la tête, et mème une partie du dessus des élytres, se heurtant arec force contre le III. 
plan de position, font, par leur ćlasticité, élever le corps en haut. On peut se convaincre de l'exactitude de ces observations : en tenant un de ees insectes par le ventre ct renversé avec ses doigts, on lui verra faire tous ces mouvemens. Plus le plan de position oì il se trouvera placé sera ferme, plus le saut será élevé. On remarquera aussi qu'il appuic les deux épines latérales du corselet contre les bords inférieurs des élytres, et qu'elles se débandent en mème temps que la pointe du milieu rentre dans la cavité de la poitrine, ce qui augmente la force élastique qui le porte en l'air : c'est. ce mouvement libre du corselet sur la poitrine, qui fait que ces insectes sautent commc par un ressort.

Si on presse le ventre du mâle entre les doigts, on en fait sortir trois parties assez longues, dont celles des côtés servent d'étui ì celle du milicu. Dans leur situation naturelle, ces trois partics sont enfermées dans un second fourreau qui s'ouvre vers le côté, et quii est soutenu par deux lames concaves, icailleuses, qui forment comme un troisième 
fourreau. Il y a apparence que la partic allongée du milieu est celle qui caractérise le sexe du malle.

Par la pression, on fait sortir du ventre de la femelle une longue partic cylindrique, au bout de laquelle se tronvent deux autres pièces allongées, coniques et pointues, entre lesquelles on voit une troisième partie qui paraît creuse; toutes ces pièces rentrent dans une espice de fourreat, qui lui-mème est placé au-dedans du ventre. Cette partic creuse est probablement le conduit des oufs, dont on trouve un assez grand nombre dans le ventre de ces femelles. Ces wenfs sont tris petits, ovales, blanchâtres et luisans.

Les larves de ces insectes sont peu connues; il paraît qu'elles viveut dans les bois. Degéer, qui a ćlevé une de ces larves, dit que tout le corps et la téte sont couverts d'une peau écailleuse, garnie de quelques poils fins, assez longs; aux trois premiers anneaux du corps sont attachées trois paires de pates écailleuses, divisées en articulations, et terminces par un crochet assez long et pointu; la tète est de figure ovale, 
garnic de sleux petites antennes, coniques, divisées en articulations, et placées vers les côtés; deux dents noires qui se rencontrent sont situces au-devant de la tète, et on voit cn dessous quatre barbillons qui ont leur attache à une espèce de levre inféricure; ces barbillons sont coniques et divisés en articulations comme les antennes; la lèvere supéricure est garnic de touffes de poils en forme de brosse; le dernier anneau du corps est couvert en dessus d'une plaque à peu près circulaire, qui a des rebords un peu élevés et dentelés, ayant de chaque côti trois petites pointes mousses, et vers le derricie deux longues parties écaillouses, divisées chacune de mème en denx pointes mousses ou arrondies; res deux parties sont en opposition l'une de l'autre, en forme de croissant, et la larve semble avoir unc courte queue fourchue. Cet amean a encore en dessous un gros mamelon charnu et blanchatre, que la larve pent entierement retirer dans le corps, et l'en faire sortir comme le limaçon fait de ses cornes. Ce mamelon lui sert de septieme pate; elle le 
jose et l'appuic contre le plan où elle marche.

Parmi les taupins on en connait plusicurs espèces qui ont, comme les lampyres, la faculté de briller; leurs parties lumineuses sont deux petites taches jaunitres, arrondies, saillantes, placécs sur le corselet, qui luisent dans l'obscurité tant que l'insecte est vivant. Selon le témoignange de plusieurs nuteurs, la lumière que les taupins répandent est si forte et si brillante, qu'elle permet de lire l'écrituèc la plus fine, surtout quand on en tient huit ox dix dans un flacon de verre. M. Brown dit que toutes les parties internes de l'insecte sont lumineuses, mais que la lumière ne saurait pénétrer que par les deux taches du corselet; pour s'en convaincre, il sépara un pea les anneaux du ventre les uns des autres, et alors la lumière se fit voir au travers de la membrane qui joint les anneaux cusemble. l'endant le jour, ces insectes se tiement en repos et sont comme engourdis, d la manicre des phalines, et on les rencontre rarement. C'est pentant la nuit quilils sont un 
mouvement, et qu'ils volent et luisent de tous les côtés. On les attrape aisément à la lueur d'un flambeau, (qu'ils suivent comme font les phalènes. Les Indiens s'en servent dans leurs voyages nocturnes en les attachant a leurs souliers; et les femmes font leur ouvrage à la lueur qu'ils répandent. M. Brown ajoute, en outre, qu'ils ont le poutvoir de luire à volonté; cette faculté leur est commune avec les lampyres.

Ce genre est composé de plus de cent espìces, dont on trouve une grande partic aux environs de Paris; nous en décrirons quelques unes des plus remarquables.

\section{Le Taupin tricolor, Elater tricolor.}

Il a environ un pouce de long; les antennes sont noires, couvertes d'une poussière blanchâtre; la tête est fauve; les yeux sont noirs ; le corselet est noir, couvert d'une poussic̀re écailleuse, fauve, avec deux très petits points noirs sur le milieu; l'ćcusson est fauve; les ćlytres sont légèrement strićes, rouges, couvertes d'une ponssic̀re écait- 
leuse fauve, avec chacune un point noir près de la suture en deçà du milieu; une tache de la même couleur sur le milieu, le long du bord extérieur, et une autre formant une bande transversale intcrompue près de l'extrémité; le dessous du corps est d'un brun rougeâtre, couvere d'une poussière écailleuse blanche; les patessont noires, couvertes d'une poussic̀re blanche.

Cette espèce est la même, et le mème individu décrit par M. Olivier, qui dit qu'il a une tache noire sur le milieu du corsclet. Cet insecte a effectivement une tache noire; mais dans l'insecte très frais, elle ne doit pas plus exister que les taches rouges que l'on voit sur les élytres, qui sont dues an défaut de la poussière écailleuse qui a été enlcvée de dessus ces parties par le frottement.

On le trouve à Cayenne.

Le Taupin oculé, Elater oculatus.

Il varic beaucoup pour la grandeur; on en trouve qui ont près de deux pouces de 
long, et d'autres qui n'ont guere plus d'un pouce; les antennes sont noires, légèrenent en scie, à peine de la longueur du corselet; la tète est noire, pointillée; le corselet est noir, couvert de petits points blancs, formés par des poils très fins; il est remarquable par deux grandes taches ovales d'un noir velouté, entourées d'un ccrcle blanc, et semblables à des yeux; les ćlytres sont légèrement strićes et parsemées de petits points blanes, de mème que le corselet; le dessous du corps est noir, couvert d'une poussière cendrée; les pates sont noires.

On le trouve dans l'Amérique septentrionale et id la Caroline.

\section{Le Taupin louche, Elater luscus.}

Ce taupin ressemble beaucoup au précedent, dont il n'est peut-être qu'une variété. Il varie de meme pour la grandeur. Il est d'un noir moins foncé, ct couvert d'un léger duvet court et cendre; le corselet est pett allongrí; les sleux taches moires sont heatcoup plus petiles et moins marrues. 
On le trouve dans l'Amórique septentrionale, a la Caroline, ox̀ il est très multiplié. Le taupin oculé es? moins commun.

\section{Le Taupin lumineux, Elater nocti- lucus.}

Il a un peu plus d'un pouce de long; les antennes sont légèrement en scie; tout le corps est noirâtre, légùrement couvert d'un duvet cendré; le corselet est convexe; il a de cliaque côté, vers l'angle postćricur, une tache ronde, convexe, lisse, de couleur jaume; les élytres ont des stries peu marquées, formées par des points enfoncés.

On Ic trouve dans l'Amérique méridionale et aux Antilles.

Cet insecte rípand pendant la nuit une lumicre phosphorique tres brillante, par les deux taches jaunes de son corselet.

\section{Le Taupin phosphorique, Elater phosphoreus.}

Il 'st de la longueur du précédent, mais 
moins large; les antennes sont plus longues que le corselet, un peu comprimées, légèrement en scie; tout le corps est d'un brun rougeâtre, légèrement couvert de poils courts, cendrés; le corselet a de chaque côté, près de l'angle postérieur, unc petite tache ronde, convexe, lisse, de coulenr jaune; les élytres sont légèrement striées.

On le trouve dans l'Amérique méridionale, à Cayenne et à Surinam.

Il répand, comme le précédent, une lumière phosphorique par les taches de son corsclet.

Le Taupin fuscipède, Elater fuscipes.

Il a environ dix-luuit lignes de long; tout le corps est noir, lisse; les antennes sont brunes; la tête et le corselet sont fortement pointillés; les ćlytres sont légèrement striées, ct les stries sont pointillées; les pates sont brunes.

On le trouve en Afrique, ati cap de Bonne-Espérance. 
Le Taupin ferrugineux, Elater ferrugineus.

Il a environ dix lignes de long; les antennes sont noires, en scie ; la tête est nọire; le corselet est convexe, finement pointillé, d'un rouge ferrugincux; les élytres sont d'un rouge ferrugineux; légèrement strićes; le dessous du corps et les pates sont noirs.

On le trouve en Europe, sur le trone carié des saules.

Le Taupin rhombifere, Elater rhombeus.

Il est moins grand et plus allongé que le précédent; Ies antennes sont ferrugineuses, légèrement en scie, plus longues que le corsclet; tout le corps est ferrugineux, tant en dessus qu'en dessous; les yeux sont noirs; le corselet est lisse, finement pointillé; les élytres sont légèrement strićes, couvertes en quelques endroits d'un léger duvet cendré.

On le trouve aux environs de Paris, sur lcs chiènes. Il est trìs rare. 
Le Taupin pectinicorne, Elater pectinicornis.

Il a environ six lignes; le mâle est plus allongé que la femclle; les antennes sont noires, très pectinées dans le mâle; celles de la femelle sont en scie; tont le corps est d'un vert bronzé, brillant, tant en dessus qu'en dessous; le corselet est finement pointillé; les élytres sont striées et pointillées; les pates sout noirâtres.

On le trouve dans presque toute l'Europe, sur le tronc carié des saules.

\section{Le Taupin bronzé, Elater ceneus.}

Il est ì peu pris de la grandenr du précident, mais plus large; les antennes sont noires, plus courtes que le corselet, lígèrement en scie; tout le dessus du corps est. d'un bleu foncé, luisant, quelquefois verdatre; le corselet est finement pointillé; les élytres sont légèrement strićes et pointillies; le dessous du corps est d'un noir bronzé luisant; les pates sont d'un rouge sanguir. 
On le trouve en Allemagne; il est rare aux environs de Paris.

\section{Le Taupin nébuleux, Elater murinus.}

Il a environ hunt lignes de long; les antennes sont brumes, plus conrtes que le corsclet; tout le corps est noirutre, couvert en dessus, en quelques endroits, d'un duvet conclé et roussitre; le corsclet a deux petits tubercules peu élevés, arrondis it sa partic supérieure; les elytres sont légerement striées; les pates sont noires; les tarses sont ferruginetx.

On le tronve dans tonte l'Europe : il est très commun aux cnvirons de Paris.

\section{Le Taupin marqueté, Elater tessel- latus.}

Il a environ six lignes de long; il est moins large que le pricédent; les antemes sont noirtices, en scie, moins longrues que le corsclet; tout le dessus du corpes est cuivreux, hrillant, couvert de poils cendrés gui forment des ondes sur les clytres; Io

III. 24 
corselet est finement pointillé; les élytres sont striées; le dessus du corps est bronzé, noirâtre; les pates sont de la même coulcur.

On le trouve dans toute l'Europe : il n'est pas très commun aux environs de Paris.

Le Taupin soyeux, Elater holosericeus.

Il est de la grandcur du précédent, mais moins allongé; les antennes sont noirittres, légèrement en scie; le corselet est noir, couvert de poils fins, soyeux, cendrés ct jaunâtres; les élytres sont noirâtres, légèrement striées, et couvcrtes d'un duvet soyeux, cendré et jaunâtre, qui forme des bandes et des ondes; le dessous du corps est noir; les pates sont brunes.

On le trouve dans toute l'Europe : il est très commun aux environs de Paris.

Le Taupin cuivreux, Elater cupreus.

Il a environ sept lignes de long; les antennes sont noires, pectinćes, de la longueur du corselet; la tête et le corselet sont 
d'un vert cuivreux brillant, finement pointillés, et couverts d'un léger duvet; les élytres sont lisses, d'un jaune verdàtre depuis la base jusqu'au-delà du milieu, et d'un vert bronzé brillant à l'extrémité; elles sont légèrement striées, et les stries sont pointillées; le dessous du corps et les pates sont d'un vert noirdtre bronzć.

On le trouve en Angleterre et en Suisse.

Le 'Taupin porte-croix, Elater cruciatus.

Il est de la grandeur du précédent, mais un peu plus large; les antennes sont noires, en scie, à peine de la longueur du corselet; la tête et le corselet sont finement pointillés; ce dermier est noir, avecune ligne longitudinale rouge de chaque côté; l'écusson est noir; les élytres sont striées, jaunes, avec la suture noire, une ligne longitudinale courte à la base, et une bande transversale un peu au-delì du milieu, noires; lo dessous du corps est noir, luisant, avec une raie longitudinale rouge de chaque 
côté du corselet; les pates sont d'un rouge noircître.

On le trouve presque dans toute l'Europe : il est rarc aux environs de Paris.

\section{Le Taupin cantharoïdc, Elater cantharoides.}

Il a environ cing lignes de long; il est de forme allonşéc; les antennes sont légèrement en scie, de la longueur de la moitić du corps; la tête est noire; la bouche est fauve; les yéux sont noirs et très saillans; le front a un avancement tranchant de couleur fauve; le corselet est fauve, avec une ligne longitudinale enfoncéc sur le milicu; les angles postérieurs sont très saillans; les élytres sont d'une couleur testacéc pâle; elles ont des stries finement pointillées; le dessous du corps est noirâtre; les pates sont testacées, avec les cuisses noirâtres.

Il habite l'Europe: on le trouve aux environs de Paris. 
Le Taupin marron, Elater castaneus.

Il est de la longueur du précédent, mais beaucoup plus large; les antennes soni noires, pectinćes dans le mâle, en scie dans la femelle; la tète et le corselet sont noirs, converts de poils soycux roussìtres; l'écusson est noir : les élytres sont jaunes, avec l'extrémité noire; clles sont striées, et les stries sont pointillées; le dessous du corps et les pates sont d'un noir trìs luisant.

Il habite l'Europe: on le trouve aux environs de Paris, sur différens arbres.

Le Taupin hématode, Elater hematodes.

Il est un peu moins grand que le précédent; les antennes sont noires, pectinćes dans le mále, en scie dans la femelle; la tète est noire; le corselet est noir, couvert d'un duvet soyeux, ferrugineux; l'écusson est noir; les élytres sont striées et pointillées, d'un rouge sanguin; Ic dessous du corps et les pates sont d'un noir luisant. 
Il habite l'Europe : il est rare aux environs de Paris.

Le Taupin sanguin, Elater sanguineus.

Il a environ six lignes de long; les antennes sont en scio, noires, de la longueur du corselet; la tête et le corselet sont noirs, luisans; l'écusson est noir; les élytres sont d'un rouge sanguin, striées, et les stries sont pointillées; le dessous du corps et les pates sont d'un noir luisant.

Il habite l'Europe : on le trouve aux environs de Paris, sur les saules et sur différens arbres.

Le Taupin thoracique, Elater thoracicus.

Il a environ quatre lignes; les antennes sont noires, légèrement en scie, de la longueur du corsclet; la tête est noire; le corselet est convexe, d'un rouge sanguin; les élytres sont d'un noir bleuâtre, légèrement strićes; le dessous du corps et les pates sont noirs. 
Il habite l'Europe : on le trouve aux environs de Paris, sur le tronc carié des arbres.

\section{Le Taupin ensanglanté, Elater} cruentus.

Il a environ six lignes de long; les antennes sont noires, en scie, it peine de la longueur du corselet; la tête est noire, couverte de poils d'un beau rouge; le corselet est noir, point luisant, avec les bords extćricurs d'une belle couleur rouge formée par des poils; les élytres sont très noires, point luisantes, et fortement pointillées; lc dessous du corps est d'un noir luisant; les pates sont noires.

On le trouve sur la côte de Barbarie et à la Caroline.

\section{Le Taupin rufipède, Elater rufipes.}

Il a près de quatre lignes de long; les antennes sont ferrugineuses, filiformes; tout le corps est d'un brun noirâtre, luisaur; le corselet est lisse, coivexe; les ély- 
tres sont légèrement strićes; les pates sont fauves.

On le trouve aux environs de Paris, sous les écorces des arbres.

Le Taupin bipustulé, Elater bipustulatus.

Il est à peu près de la grandeur du précédent, noir luisant; les antennes sont légèrement en scie; les élytres sont strićes; elles ont unc petite tache d'un ronge sangruin à leur base; les pates et les antennes sont brunes.

Il habite l'Europe : on le trouve aux environs de Paris.

\section{Le Taupin ceint, Elater baltealus.}

Les antennes sont noires, légèrement en scie; la tète et le corselet sont noirs; l'écusson est noir; les élytres sont striécs, et les stries sont pointillées; clles sont d'un rouge sanguin depuis la base jusque vers les deux tiers, et d'un noit plus ou moins foncé dans le reste de leur longuewr; le dessous 
du corps est noir; les pates sont d'un brun rougeâtrc.

On le trouve en Europe.

Le Taupin nain, Elater minutus.

Il est de la grandeur du précédent; les antennes sont filiformes, noirâtres; le corselet est noir, luisant; les élytres sont noires, strices; les pates sont d'un brun ferrugineux.

On le trouve en Europe : il est commun aux environs de Paris, sous les écorces des arbres.

Le Taupin clavicorne, Elates clavicornis.

G. Throsque, Latr.

Il a moins d'une ligne de long; il est noirattre; ses antennes sont terminées par une massue de trois articles perfoliés; son corps est ovoïde; son corselet est trapézoïdal, presque aussi long que large, appliqué exactement ì la partic postéricure contre les élytres, et ayant ses angles nostóricurs saillans; son sternum est en pointe 
obtuse et large, et n'est pas pourvu du ressort particulicr qui caractérise les taupins; ses élytres sont légèrement strićes; ses pates sont de la couleur du corps.

On trouve cet insecte anx environs de Paris : il n'est pas commun.

\section{CX' GFNRE.}

\section{BUPRESTE.}

Caractères génériques. Antennes courtes, filiformes, en scie; articles éganx, le premier gros et arrondi. - Quatre antennules inćgales, filiformes; Ics antérienres composées de quatre articles, et le's postérieures de trois, le dernier article obtus, presque tronqué. - Tète à moitié enfoncée dany le corselet.

Les anciens donnaient le nom de buprestes à des insectes auxquels ils avaient reconnu la propriété de faire périr les beufs. Linné a donné le mème nom aux insectes de ce genre, quoiqu'ils n'aient point cette propriété malfaisanto, et ce nom a été adopté par presque tous les auteurs qui ont écrit depuis lui. M. Geoffroy ayant trouvé 
que ce nom ne pouvait convenir à ces insectes, les a nommés richard, d̀ cause de leurs couleurs brillantes, et en latin cucujus ; mais M. Olivier leur a conscrvé le nom de bupreste, parce qu’il est le plus généralement adopté.

Les buprestes ont beaucoup de ressenblance avec les taupins, par les antennes et la forme de la tête; mais ils n'ont point, comme cux, la faculté de sauter lorsqu'ils sont sur le dos ; leur corselet n'a point aux angles postéricurs les deux épines qu'on voit au corselet des taupins, ni en dessous cette longue pointe qui entre dans une cavitć de la poitrine, y agit comme un ressort, ct sert à ces insectes pour exécuter leurs sauts.

Les antennes sont plus courtes que le corselet; elles sunt insérées à la partic antéricure de la tête, entre les yeux.

La tête est assez grosse, arrondie, enfoncée en partic sous le corselet; les yeux sont grands, ovales, peu saillans; la bouche est composéc d'une lèvre supéricure, de deux mandibules courtes, assez grosses, 
creusées intérieurement en ģouftic̀re ct unidentées; de deux mâchoires conrtes, ciliées et dentées à leur base; d'une lèvre inféricure et de quatre antennules.

Le corselet est plus étroit ì sa partic antéricure qu’à sa partie postérieure, qui est presque aussi large que les élytres; il est convexc ou aplati; dans quelques especes, les bords latéraux sont arrondis ct tranchans; dans d'autres, il est terminé postéricurement par trois angles peu saillans, l'un placé sur le milieu, et les deux autres aux deux cxtrémités des bords latéraux, un de chaque côté; l'angle du milieu tient souvent lieu d'écusson; en dessous, le milicu de la partie postéricure du corselet sc prolonge en une pointe dure, aplatic, arrondie à l'extrémitć, plus ou moins maxquée, selon les espéces, ct qui s'enchisse dans une cavilé qui se trouve à l'origine de la poitrine; mais cette piece n'est point it ressort comme dans les taupins; l'écusson est très petit et arrondi.

Les élytres sont tries dures, strićes, pointillées, souvent couvertes de rugosités; elles 
sont arrondies ì leut extrémitć, on terminées par une, deux ou trois petites pointes aiguës, ou dentelées extéricurcment depuis le milieu jusqu’à l'extrémité : elles recouvrent deux ailes membrancuses, qui ne sont point replices dans l'inaction, mais étendues, et en recouvrement l'une sur l'autre : ces ailes sont de la longucur des élytres.

Les pates sout de longueur moyenne; les cuisses sont un peu renflées; les jambes sont un peu plus grosses it leur extrémité qu'à leur origine; les tarses sont composis de cinq articles presque inaux, comrts, larges, convexes en dessus, aplatis en dessous; le dernier est armé de deux crochets assez forts, arqués et distans.

Le corps est plus ou moins allongé; l'abdomen est convexe en dessous, de figure conique; il est composé de cing anneaux distincts, et d'un sixicme, renfermé dans le précédent; de sorie gue, pour le faire paraître, il faut presser le ventre forted ment : en contimuant la pression, on fail cortir de l'ouverture de cet amean los pax- 
ties gui caractérisent le sexe. Du derrière du mâte, il sort deux parties : l'une, qui est placce en dessus, estlonguc ct membrancuse, fortifićc par des pièces écailleuses, et terminée par une lame mince, ovale et écailleuse; l'autre partie est en forme de stylet. roide, de substance cornée, qui augmente un peu de volume près de son extrémité, et qui se rétrécit ensuite, pour se terminer en pointe mousse. Dans l'endroit où elle commence ì se former en pointe, elle a de chaque côté un petit crochet un peu courbé : le bont de cette partic est garni de quelques poils, et accompagné de deux petits tubercules latéraux, qui sont un peu velus. Cettc partie, placée en dessous de la première, est de mème longueur, et parait être celle qui caractérise le sexe du mâte, ou le fourrean qui la renferme. Fn pressant le ventre de la femelle, on fait sortir du derrière une partic coriace, plate, en forme de lame, conposée de trois pièces, dont les deux latérales servent de fourreat à welle dn milieu : clles sont toutes trois pointues ì leur extrémité. Cette partic est une esprece de 
tarière propre à percer le bois pour y déposer les œufs.

Les buprestes marchent très lentement, mais ils ont le vol très agile; ils sont ornés des couleurs les plus brillantes et les plus riches; l'or le micux poli, l'émeraude et l'azur brillent quelquefois sur le méme individu, et lui forment un vètement de la plus grande beanté. On en trouve peu dans le nord de l'Europe; mais ils sont tre's abondans dans les climats chauds des deus hémisplières, et ces contrées fournissent les plus grands et les plus beaux. On les trouve sur les arbustes, sur les buissons et sur les fleurs; ils se laissent tomber dans les broussailles lorsqu'on les approche.

La larve de ces insectes n'est point connue; mais il est probable qu'elle vit dans le bois: on trouve assez souvent l'insecte parfait dans les chantiers et les magasins de bois.

ILes buprestes forment un genre compose d'environ cent quarante espècés : nous allons passer à la description de quelgues unes.

Ce geure est divist: en cinq familles. 
PREMIERE FAMXILE.

Élytres anidentées.

Cette première famille est composée de deux espèces, qui sont le bupreste unidenté et le bupreste changeant. Ce dernier habite les Indes orientales.

DEUXXEME FAMILLE.

Ėlytres bidentées.

Le Bupreste géant, Buprestis gigantea.

Il a plus de deux pouces de longucur; il est un peu déprimé : les antennes sont plus courtes que te corselet, noirûtres, vertes a leur base; la tête est verte; les yeux sont bruns; tout le corps est d'un vert cuivreux, un peu bronzé, brillant; le corselet est lisse, marqué à sa partic supérieure de deux grandes taches lisses brillantes; les élytres sont d'un vert cuivreux à leur bord extérieur et à la suture, et d'un rouge cuivreux brillant sur le mi- 
lieu; clles sont raboteuses et ont plusieurs lignes tongitudinales; leure extrémitć est bidentce; la femelle a deux taches oblongues, velues à la partic postéricure de la poitrine; les pates sont de méme couleur que le dessous du corps.

Cette espèce se trouve à Cayenne et à Surinam : elle y est commune. Les naturels du pays se font des colliers et divers autres ornemens avee ses élytres, qu'ils percent, ct dans lesquelles ils passent un fil : on voit de ces colliers qui ont plus de cinquante élytres les unes à côté des autres.

\section{Le Bupreste bande-dorée, Buprestis} vittata.

Il a seize à dıx-Iuit lignes de long : il est de forme allongée; les antennes sont noires, bleuâtres à leur base, moins longues que le corselet, un peu en scie; la tète est verte, raboteuse, avec une ligne enfoncée ì sa partic supéricure; les yeux sont bruns, saillans; le corselet est pointillí, d'un vert bleuatre Irès brillant, avee une tache dore, lisse, 
294

HISTOIRE NATURELTE

de chaque côté de sa partie postérieure; les élytres sont d'un vert bleuâtre très brillant, avec une raie longitudinale d'un rouge doré: elles sont pointillées, et elles ont quelques lignes élevées; le dessous du corps est d'un rouge doré très brillant; les pates sont d'un vert bleuâtre.

On lc trouve aux Ind̉es orientales.

Le Bupreste chevalier, Buprestis equestris.

Il a un peu plus d'un pouce de long; les antennes sont en scie, d'un noir bronzé; la tête est verte, raboteuse; les yeux sont bruns; le corselet est vert, raboteux : il a un enfoncement assez grand au milicu de la partic postérieure, et un autre petit de chaque côté; les élytres sont strićes, d'un beau vert, avec un grand nombre de petites taches irrégulières d'un vert foncé; le dessous du corps est raboteux, d'une couleur de cuivre doré, brillante; les pates sont vertes.

On le trouve à Cayenne. 



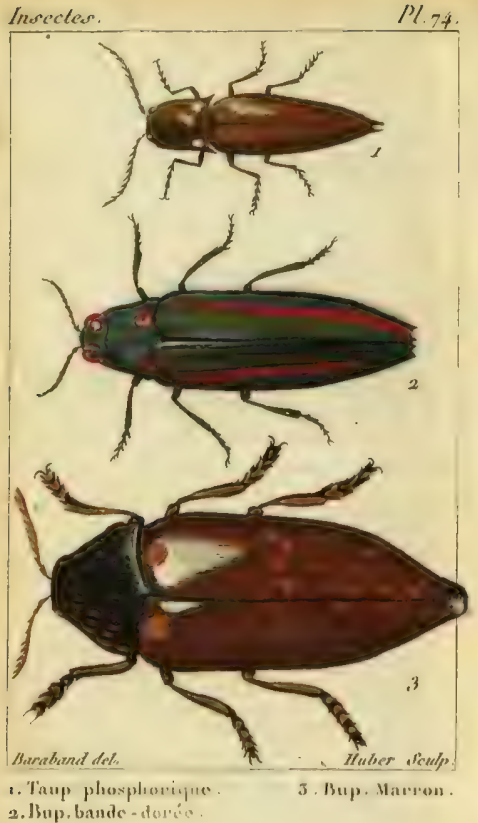


THOISYIME FAMILLE.

\section{Ėlytres tridentées.}

Le Bupreste Chrysis, Buprestis Chrysis.

Il a environ deux pouces de long; les antennes sont noiratres, en scie, moins longues que le corselet; la partie supérienre du corps est très élevée, convexe; la téte rt le corselct sont-d'un serí doré très brillant, avec des pointsrnfowets assez gros; les élytres sont lisses, finement pointillées, d'un brun marron : elles ont un reflet verdâtre à leur base; leur extrémité est tridentée; le dessous du corps eşt d'un vert doré trìs brillant; le sternum es avancé; les pates sont brunes, et les cuisses Jim brum violet.

On le trouve aux Indes orfentales.

Ie Bupreste inarron, Buprestis castanea.

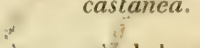

Il est a peu pris de la grandeur du précédent, et de mème forme; les antennes 
sont en scie, d'un brun jaunâtre; la tète est noiritre, un peu raboteuse; le corselet est conrexe, noirâtre, avee des points enfoncés, allongés, assez grands, couverts d'un duvet roussître; les élytres sont raboteuses : clles ont it leur base une tache ronde, enfoncúe, couverte d'un duvet roussître, et plusicurs autres petites taches semblables sur le milicu; le dessous du corps est noir, avec une tache roussittre, forméc par des poils, de chaqque côté des anneaux de l'abdomen; les pates sont d'un brun jaunitre; le sternum est avancé.

On le trouve au Sénégal.

\section{Le Bupreste sternicorne, Buprestis} sternicornis.

Il est de moitić moins grand que le précédent, auçuel il ressemble par la forme; les antennes sont noirâtres, en scie, moins longues que le corselet; la tète est verte, brillante, pointillée; les yeux sont bruns; tout le corps est d'un vert doré très brillant, tant en dessus qu'en dessous; le corselet est 
convexe, couvert de points enfoncés; point d'écusson ; les élytres sont légèrement pointillées: clles ont plusieurs rangées de points peu enfoncés, de coulem cendrée, et un point beaucoup plus grand à la base de chaque élytre; les pates sont vertes; les tarses noirs; le sterium est avancé.

On le trouve aux Indes orientales.

\section{Le Bupreste interrompu, Buprestis interrupta.}

Il est plus grand que le précédent, auquel il ressemble par la forme; les antennes sont noires, en scic; la tête est d'un noir bleuatre, pointillée, point luisante : elle a une ligne enfoncée, couverte d'un duvet Wanchatre; le corselet est noir, avec des points enfoncés couverts d'un duvet blanchâtre; les élytres sont légèrement pointillées, noires, avec quelques lignes courtes, enfoncés, convertes d'un duvet blanchitre, dont une à la base, et une interrompue audelà du milicu; le dessous du corps est bronzé, brillant, couvert d'uu duvet blan- 
chittre; les pates sont bronzées; le sternum est avancé.

On le trouve au Sénégal.

\section{Le Bupreste rayé, Buprestis lineala.}

Il a environ sept lignes de long; les antennes sont filiformes, bronzées, presque aussi longues que le corselet ; la tète est cuivreuse, brillante, pointillée; le corselet cst cuivreux, pointillé, avec un peu de fauve à la partic antérieurc et sur les côtés; l'écusson est très petit, arrondi; les élytres sont d'in vert foncé un peu bronzí, avec deux raics longitudinales fauves; l'extéricure s'étend de la base à la pointe; l'intérieure ne va que jusqu'au-delà du milieu; l'extrémité est tridentéc; le dessous du corps est d'une belle couleur cuivense; les pates sont de la mème couleur que le dessous du corps.

On le trouve dans l'Amérique méridio. nale. 
QUATRILME FAMILLE.

Élytres en scie.

Lc Bupreste Mariane, Buprestis

Mariana.

Il a environ un pouce de long; les antennes sont bronzées, filiformes, légèrement en scic, de la longueur du corselet; tout le dessus du corps est raboteux, cuivreux, brillant; le dessous est d'un rouge cuivreux très brillant; la tête a une ligne enfoncéc sur le milieu; le corselet a des enfoncemens assez profonds, et une ligne longitudinale, lisse, sur le milieu; les élytres ont trois ou quatre lignnes longitudinales élevées, et quelques impressions inćgales, plus enfoncées les unes que les autres; les pates sont rabotcuses et cuivreuses.

Cet insecte varic pour les couleurs : il est quelquefois moins brillant.

On le trouve dans presque toutc l'Furope, dans la Sibcric. M. Olivier l'a sourent trouvi en provence, sur les trones 
vermoulus des pins, et dans les chantiers de l'arsenal de Toulon.

\section{Le Bupreste déprimé, Buprestis depressa.}

Il a environ neuf lignes de long; les antennes sont filiformes, d'une couleur bleuattre foncée; tout le corps est d'une couleur verte très foncée et cuivreuse; la tète et le corselet sont fortement pointillés, un peu chagrinés; ce dernier est un peu déprimé ; l’écusson est très petit; les élytres ont des stries régulières, formées par des points enfoncés très rapprochés; les pates soni d'un bleu foncé.

On le trouve dans l'Amérique méridionale, aux Antilles, à Cityenne.

\section{Le Bupreste éclatant, Buprestis} rutilans.

Il a environ sept lignes de long; les :ntennes sont noiratres, litiformes, moins longues que le corselet; la lide est un pert rit- 
boteuse, d'un vert doré; le corselet est un peu raboteux, d'un vert bleuitre, avec les còtés d'un rouge doré; les élytres sont rahotenses, strićes, d'un vert blenatte, avec les côtés d'un rouge doré, et plusieurs points d'un noir violet; le dessous du corps et les pates sont d'un vert bleuâtre tris brillant.

On le trouve dans les départemens méridionaux de la France, et en Allemagne.

\section{Le Bupreste chrysostigmate, Buprestis chrysostigma.}

Il a environ six lignes de long; les antennes sont d'un vert bronzé, en scie, de la longuenr de la moitié du corselet; tout le dessus du corps est bronzé, point brillant; le dessons est cuivreux, brillant; le corsclet est pointillé; les élytres sont pointillées, avec trois lignes longitudinales élevíes, et trois petites taches enfoncées, d'un vert doré; l'écusson est vert, très brillant; les cuisses antiricures sont grosses et dentées dans l'un des deux sexes.

Il habite presque toute l'Europe, dans 11r. 
302

IISTOIRE NATURTLLE

les bois : on le trouve dans les chantiers it

Paris.

\section{Le Bupreste neuf-taches, Buprestis novem-maculata.}

Il a environ cing lignes de long; il est de forme cylindrique; les antennes sont noires, un peu en scie; tout le corps est d'un noir bleuâtre, luisan!; la tête a unc tache jaune sur sa partie antérieure; le corselet est finement pointillé : il a deux taches jaunes; les élytres sont pointillées, avec trois taches jaunes; le dessous du corps est sans rache.

On le trouve en $\Lambda$ frique et dans les dípartemens méridionaux de la France.

CINQUIEME FAMILLE.

Élytres entières.

T.e Bupreste fasciculé, Buprestis fascicularis.

Il a environ un pouce de lomg; le dessus du corps est vert, bronzé; les antennes 
sont noires; la tète est raboteuse; les yeux sont bruns; le corselet est convexe, raboteux, couvert de poils cendrés; les élylies sont raboteuses : clles ont des points enfoncés, d'où partent des faisceaux de poils cendrés, roussattres; le dessous du corps est bronze, un peu velu, avec un faisceau de poils de chaquue côté des anneaux de l'abdomen; les pates sont d'un vert bronzé.

On le trouve au cap de Bonne-Espérance.

\section{Le Bupreste lugubre, Buprestis lugubris.}

II a environ dix lignes de longr; les antemnes sont noires, en scie; tout le dessus du corps est un peu bronzé, obscur; la tète et le corselet sont un peu raboteux; les élytres ont quelques dívations longitudinales plus obscures que le fond des élytres; te dessous du corps et les pates sont ruivreux.

On le trouve en Allemagne. 


\section{Le Bupreste carié, Buprestis cariosa.}

Il a près d'un pouce et demi de long; tout le corps est très noir, parsemé de petits points blancs; les antennes sont noires, en scie, presque aussi longues que le corselet; la tìte est raboteuse; le corselet est presquic aussi large que les élytres, arrondi sur les côtés, raboteux, blanchâtre, avec plusicurs taches élevécs, lisses, d'un très beau noir ; les élytres ont des stries pointillées; le dessous du corps est d'un noir luisant.

On le trouve en Italie, sur le lentisque; dans la Russic méridionale, sur le rhus cotinus.

\section{Le Bupreste Ténébrion, Buprestis Tenebrionis.}

Il est de moitié moins grand que le précédent; les antennes sont noires, en scic; tout le corps, tant en dessus qu'cn dessous, est très noir, point luisant; le corselet est aussi large que les élytres, arrondi sur les cótés : il est variolé, et les ćlévations sont 
lisses, luisantes, les enfoncemens sont raboteux et blanchâtres; les élytres ont de petits points enfoncés; les pates sont très noires.

On le trouve sur la côte de Barbarie, dans Ies départemens méridionaux de la France, sur le prunier épineux et sur le poirier sauvage, en Italie, en Allemagne, èt dans la Sibérie.

\section{Le Bupreste rustique, Buprestis nustica.}

Il a prùs de sept. lignes de long; les antennes sont d'un noir bronzé; tout le corps est d'un vert bronzé, plus brillant en dessous qu'en dessus; la tète et le corselet sont pointillés; les élytres sont striées, moins brillantes que le dessons du corps; les pates sont d'un vert bronzé.

On le trouve dans presque toute l'Eu-rope. 


\section{Le Bupreste large-col, Buprestis laticollis.}

Il a près de six lignes de long; les antennes sont noirâtres, cuivrcuses à leur base; la tète est petite, cuivreuse, finement pointillée, enfoncíe dans le corselet; le corselet est plus large que les élytres, pointillé, de couleur bronzée; les élytres sont bronzées; elles ont des stries per marquées, formées par des points enfoncés un peu oblongs; le dessous du corps est cuivreux, bronzé et brillant; les pates sont de la mème couleur que le dessous du corps.

On le trouve en Barbarie.

Le Bupreste rubis, Buprestis manca.

Il a environ cinq lignes de longr; les antennes sont noirattres, en scic; la tète est d'un vert doré; le corselet est un peu déprimé, noir en dessus, d'un rouge cuivreux sur les còtés; lés élytres sont chagrinées, d'un noir violet point luisant; le dessous du corps est d'un rouge cuivenx trien brillant; lespates sont d'un rouge cuivrenx; 
tout le corps est légèrement couvert d'un duvet cendré.

On le trouve en France, en Espagne, en Italie et en Allemagne, sur les buissons.

Le Bupreste de la ronce, Buprestis rubi.

Il est de la grandeur du précédent, mais plus allongé; tout le corps est bronzé, luisant en dessous; les antennes sont en scie, moins longues que le corselet; la tête et le corselet sont pointillés; les élytres sont chagrinćes, avec quatre lignes transversales, ondées, grisattres; les pates sont d'un noir bronzé.

On le trouve dans les départemens méridionaux de la France, et aux environs de Paris, sur les feuilles de la ronce.

\section{Le Bupreste ondé, Bupi estis undata.}

Il ressemble beaucoup aupréeédent, mais il est un peu plus grand; les anteunes sont d'un vert bronzé; la téte ct le corsclet sont d'une coulcur cuivreuse, fronzée; les ély- 
tres sont cuivreuses, bronzies, brillantes, depuis la base jusqu'au-delà du milieu; le reste est d'un noir bleuâtre bronzé, avec deux lignes transversales ondées, blanchátres; le dessous du corps et les pates sont d'un vert noirittre brillant.

On le trouve en Allemagne, et rarement aux environs de Paris, sur les Acurs et dans les chantiers.

\section{Le Bupreste deux-points, Buprestis} biguttata.

Il a près de six lignes de long; le corps est étroit, allongé, d'un vert bleuâtre, bronzé; les antennes sont d'un noir bronzé, en scie, un peu plus longues que la tête; la lête est pointillée; les yeux sont bruns; le corselet est reborilé de chaque côté, sinué ì sa partic postéricure, et légèrement chagriné; les ćlytres sont chagrinées; clles ont un point blane près de l'extrémité de chaque côté de la suture; l'abdomen a six points blancs de chargue côté, dont trois en dessus et trois en dessous; le dessous du 
corps et les pates sont d'un vert bleuatre, bronzé, brillant.

On le trouve en Angleterre et aux environs de Paris.

\section{Le Bupreste du saule, Buprestis salicis.}

Il a environ trois lignes de long; les antennes sont d'un noir bleuâtre, en scie; la tète est verte ou bleutatre; le corselet est vert, avec deux taches d'un bleu foncé; les ćlytres sont pointillées, d'un rouge cuivreux, avec la base d'un vert doré; le dessous du corps et les pates sont d'un vert bleuâtre, luisant.

On le trouve en France, en Allemagne, sur les saules.

\section{Le Bupreste Nitidule, Buprestis}

\section{Nitidula.}

Il est de la grandeur du précédent; les antennes sont vertes; la tite est verte, chagrinée; les yeux sont bruns; le corselet est vert, chagrinc, de la largeur des ćlytres; 
les élytres sont vertes, chagrinées; le dessous du corps et les pates sont d'un vert brillant; tout le corps est un peu déprimé.

On le trouve en Europe; il est assez rare aux environs de Paris.

\section{Le Bupreste plébéien, Buprestis plebeia.}

Il a environ sept lignes de long; les antennes sont bronzées, en scic; la tète est. rabotcuse, bronzée; le corselet est bronzé, légèrement raboteux, avec un sillon longittdinal peu marquué sur le milieu; les élytres sont bronzíes, un peu rabotenses, avec quelques taches cuivreuses; le dessous du corps et les pates sont d'me couleur cuivreuse peu brillante.

On le trouve aux Indes orientales.

Le Bupreste ruficolle, Buprestis ruficollis.

Il a près de quatre lignes de long; les antenues sont noires, en scie, de la longueur de la moitié du corselet; la tète est noire, 
un pen cuivreuse; le corselet est d'un rouge cuivreux, un peu sinuć postéricurement; l'écusson est large; les élytres sont noires, finement chagrincéc; le dessous du corps et les pates sont noirattres, bronzés, brillans.

On le trouve dans l'Amérique, d̀ la Caroline.

\section{Bupreste vert, Buprestis viridis.}

Il est de la grandeur du précédent, mais plus allongé; les antennes sont bronzées, en scie, un peu plus longues que la téte; tout le corps est vert ou d'un vert bronzé, plus brillant en dessous qu'en dessus; la tête est chagrinée; le corsclet est lérèrement chagriné, sinué postéricurement : il a une ligne longitudinale, enfoncéc, sur le milieu : il est aussi large que les élytres; les élytres sont chagrinées, un peu en seie à leur extrémiti.

On le trouve dans presque toute l'Europe, satr différentes fleurs : il est trìs commun aux environs de Paris, dans les chanliers. 


\section{Le Bupreste nain, Buprestis minuta.}

Il a environ une ligne de long; il est de forme presque triangulaire, d'une couleur bronzée très brillante; la tête est un peu enfoncée; le corselet est presque lobé postérieurement; les élytres ont unc élévation A leur base latérale, et quatre lignes transversales, ondées, de couleur cendrée; le dessous du corps et les pates sont d'un noir bronzé.

On le trouve dans presque toute l'Europe, sur les fleurs.

\section{Le Bupreste uni, Buprestis plana.}

Il a environ dix lignes de long; les antennes sont bronzées, en scie, un peu plus longues que la tête; la tête est raboteuse, cuivreuse; les yeux sont bruns; le corselet est pointillé, d'un vert doré; les élytrès sont verdâtres, peu brillantes sur le milicu, cuivreuses a la suture', couvertes de petits points enfoncés; le dessous du corps est 
doré, brillant, avec des points enfoncés; les pates sont dorées, brillantes.

On le trouve dans les départemens méridionaux de la France, et sur la cote de Barbarie: il est très rare.

\section{Le Bupreste échancré, Buprestis} emarginata.

$$
\text { G. Aphanistique. Lixk. }
$$

Il a moins d'une ligne de longueur; ses antennes sont terminées en massue, d'un noir bronzé; son corps est allongé, linéaire, ct entièrement bronzé; lat tète est profondément sillonnée, et clle paraît comme échancréc antérieurement; le corselet a deux lignes transversales, enfoncées; il est 11 . peu lobé postéricurement; l'écusson est petit et triangulaire; les élytres sont pointillées, entières; les pates sont de la couleur du corps.

On le tronve aux environs de Paris : il n'est pas commun. 


\section{X I I G E R E.}

\section{COLLIURE.}

Caractères génériques. Antennes filiformes, de onze articles, le premier un peu plus gros et plus long que les antres. - Quatre antennules filiformes. Tète conique, déliée par-derrière; yeux saillans. - Corselet ítroit, long et cylindrique.

LE seul insecte qui composait ce genre, a été placé par Linné avec les attelabes. Des'écr l'en a séparć, en a fait un genre, auquel il a donné le nom de colliure, à cause de la longueur du corselet de cet insecte, qui forme une espèce de col très long.

Les antennes sont filiformes, d'égale grosseur dans toute leur longueur, aussi longues que le corselet; les tarses sont composés de cing articles.

Degíer compare cet insecte ì la raphidic, ¿ laquelle, selon cet auteur, il ressemble par la forme de la téte et par celle du corselet; et il croit qu'il fait une nuance entre les insectes à quatre ailes membraneuses, réticulées, et ceux à ctuis écailleux. 
Comme nous ne connaissons le colliure: que par les descriptions de Linné et de Degéer, nous donnerons un extrait de celle: faite par ce dernier auteur.

\section{Le Colliure surinamois, Colliuris surinamensis.}

Attelabus surinamensis. LinN.

\section{G. Casnonic. Latr.}

Ce petit insecte, qui n'est long que de quatre lignes, a été envoyé de Surinam. Il est d'une figure des plus singulières, et absolument semblable, par la tite et le corselet, à la raphidie commune d'Furope; il a deux etuis écailleux, qui couvrent les ailes; la tête et le corsclet sont de conleur noire; les étuis et le dessous du corps bruns; les antennes tachetées de blanc et de noir, et Ies pates rousses; les cuisses de la première et de la seconde paire de pates ont, proche du corps, une tache blanche en forme d'anneau; la títe est allongée, délice parderrière, et garnic de deux gros yeux très saillans; les antennes sont en filets déliés, 
de grosseur égale, et environ de la longueur de la tête et du corselet; le corselet est fort long ct délié; il a presque la longueur du corps ou du ventre; il serait cylindrique, s'il n'était pas plus gros postérieurement; il est un peu courbé en are en dessous, et il est attaché à la tìte par une espèce de petit col; et de l'autre bout, il tient à la poitrine par une autre petite partic, ou articulation distincte; les deux pates antérieures ont leur attache à l'extrémité de ce long corselet; les étuis sont assez larges et peu convexes, garnis de cannelures longitudinales assez profondes, et terminés chacun par deux pointes très fines; les pates sont longues et déliées; les tarses divisés en cinc articles; les deuts sont assez longues, et se croisent par leurs pointes. Degéer, t. Iv, page 79 . 


\section{GENRE.}

\section{CICINDELE.}

Caractères génériques. Antennes filiformes, presque sétacées; articles cylindriques, égaux, le second très court. - Six antennules filiformes; les antérieures composces de deux articles allongés, égaux; les moyenues plus longues, composées de quatre articles, dont le premier très court et le second très Jong; les postéricures de quatre, dont les deux derniers très courts. - Yenx saillans. Tarses filiformes. - $\Lambda$ ppendice à la base des caisses postérienres.

M. Geoffnoyn'a fait qu'un seul genre des carabes, des cicindèles et des élaphres. Il lui a donné le nom de bupreste, l'a divisé en trois familles, et il a nommé cicindèles, les téléphores et les malachies. Linné a formé deux genres des buprestes de cet auteur : le premicr, sous le nom de carabe, est composć de ceux de la première et de la troisiente famille, et la deuxieme famille compose son gemre cicindele. Mais M. Fabricius a séparé des cicindeles, des insectes 
dont il a fait un genre, auquel il a donné lc. nom d'élaphre.

Les cicindèles ont beaucoup de rapport avec les carabes, par la forme des antennes, par quelques parties de la bouche, et par l'appendice des cuisses postérieures; mais elles en different par la forme de la tète, par les yeux, le corselet et les pates.

Les antennes sont filiformes, de la longueur de la moitié du corps; elles sont insérées à la partie antéricure de la tète, audevant des yeux.

La tête est grosse, prosque aussi large que le corselet; les yeux sont grands, arrondis, très saillans; la bouche est composée d'une lèvre supérieure, de deux mandibules très grandes, arquées, avancées, très pointues, armées ì leur partic intéricure de plusieurs dents aigués; de deux matchoires presque cylindriques, cilićes intérieurement, trrminées en pointe longuc très aigruë, courbée; d'une lèvre inféricure, et de six antennules inégales; les antéricures et les inter médiaires sont insérćes au dos des mâchoires, les postérieures at la levere inféricure. 
Le eorselet est plus étroit que les élytres, jresque cylindrique, ordinairement muni en dessus de denx éminences séparées par un sillon enfoncé; il a aussi deux lignes transversales, l'une à la partic antéricure, et l'autre à sa partic postérieure; il est légèrement rebordé; l'écusson est trìs petit, triangulaire.

Les élytres sont un pen convexes, légèrement rebordées, assez dures; elles reconvrent deux ailes membraneuses, replicées.

Les pates sont longues, minces, couvertes de porils longrs très fins; les jambes sont terminées par deux longues épines droites; less tarses sont filiformes, divisés en cinç articles allongés, presque égaux; le dernier est terminé par deux petits crochets, minces et pointus.

Les cicindèles sont voraces et carnassic̀res; clles vivent de différens insectes, qu'elles attrapent; elles sont très vives, et courent. fort vite pendant le jour, surtout lorsque le soleil brille; on a beatueoup de perine à les attraper; dis yuion approche d'elles, dlles fuient et senvolent promptement, mais of- 
dinairement elles ne volent pas loin, elles prennent terre à peu de distance de l'endroit d'oì elles sont parties. Elles habitent ordinairement les terrains secs et sablonneux. Quand on prend un de ces insectes, il cherche à pincer avec ses mandibules, mais ces parties n'ont pas assez de force pour faire de mal; clles sont très mobiles à leur base; lorsqu'il veut s'en servir, il les ouvre, les écarte considérablement l'une de l'autre, saisit sa proie et la pince fortement.

Selon M. Gcoffroy, les larves de ces insectes vivent dans la terre, et on les rencontre difficilement. Elles sont longues, cy- lindriques, molles, blanchâtres, armées de six pates brunes, écailleuses; leur tête est brune; elle a en dessus une espèce de plaque ronde, brune et écailleuse, au-devant de laquelle est la bouche, qui est armée de deux fortes mâchoires; cette larve se creuse en terre des trous cylindriques, profonds, dans lesquels elle se loge. Elle se tient en embuscade à l'ouverture de ce trou, et sa téte est à fleur de terre; dans cette position, clle attend patiemment les insectes qui se 
promenent près de son trou; lorsqu'ils passent dessus, elle les saisit avec ses matchoires, qui sont très fortes, ou, par un monvement de sa tite, scmblable à celui d'une bascule, ils sont précipités au fond de sa retraite, où elle les mange à loisir. C'est ainsi que, sans sortir, cette larve trouve moyen de faire tomber dans ses piéges les autres insectes dont elle se nourrit. C'est au fond de ces trous qu'on rencontre ordinairement la larve des cicindeles; pour la trouver, il faut creuser peu à peu le terrain dans lequel ce trou est pratiqué; mais comme souvent, dans cette opération, la terre, en s'ćcroulant, remplit le trou, il est nécessaire d'user de précaution; c'est de commencer par enfoncer dedans une paille ou un petit morceau de bois, qui sert ì en indiquer le fond. Là, on trouve la larve; dès qu'clle est hors de terre, elle se replic en zigzag.

Les cicindèles sont fort belles; plusieurs sont ornies de couleurs très brillantes : elles forment un genre composé de près de cent cinquante especes : on n'en connait que six aux environs de Paris. 
La Cicindèle champêtre, Cicindela campestris.

Elle a environ sept lignes de long; les antennes sont bronzées, cuivreuses à la base, noiratres à l'extrémité; la tète et le corselet sont verts, avec quelqgues taches cuivreuses; les élytres sont lisses, vertes, avec six points blancs; le dessous duc corps est d'un vert brillant, avec les côtés de la poitrine et les pates d'un rouge cuivreux.

On la trouve dans toute l'Europe, dans les endroits secs et sablonneux : elle est très commune aux environs de Paris.

La Cicindèle hybride, Cicindela hybrida.

Elle est de la grandeur de la précédente, d'un vert bronzé, point brillant en dessus; les élytres ont une tache blanche a la base extérieure, une à l'extrémité, et unc bande transversale sinuée vers le milieu; le dessous du corps est d'un vert brillant, avec les cô- 
tés de la poitrine et les pates d'un rouge cuivreux.

On la trouve dans les mémes endroits que la cicindèle champètre : clle est très commune aux environs de Paris.

\section{La Cicindèle sylvatique, Cicindela sylvatica.}

Elle est un peu plus grande que la précédente; tout le dessus du corps est d'un noir foncé mat; le dessous d'un noir violet brillant; la tête ct le corselet sont un peu chagrinés; les élytres sont légèrement raboteuses; clles ont une tache blanche en croissant près de la base extérieure, une bande transversale sinuée vers le milieu, et une tache ronde près le l'extrémité; les pates sont noires.

On la trouve dans les endroits arides et sablonneux de l'Europe : clle est moins commune que les précédentes aux cnvirons de Jaris. 


\section{La Cicindèle sinuée, Cicindela flexuosa.}

Elle a environ six lignes de longr; la tîte est bronzée, point luisante; la lèvre supé rieure est jaune; le corselet est bronze; les élytres sont bronzées, avec un reflet rongeâtre; clles ont une tache blanche en croissant à la base extérieure, un point oblomy près de la suture, une tache sinuée vers le milieu, et une tache en croissant ì l'extrimité; le dessous du corps est d'un vert bronzé, brillant, avec les côtés converts d'un duvet blanchàtre; les pates sont cuivreuses; les cuisses sont couvertes d'un duvet blanchâtre.

On la trouve dans le midi de la France: elle est très rare aux environs de Paris.

\section{La Cicindèle du Cap, Cicindela Capensis.}

Elle est un peu plus grande que la précédente; la tète cst bronzéc ; les yeux sont entourés de poils blanchâtres assez longs; la 
lìre supérieure est jaune; le corselet est bronzé en dessus, d'un rougse cuivreux en dessous, avec les côtés couverts de poils blanchattres; les élytres sont blanches, avec une ligne longitudinale cuivreuse près de la suture: il part du côté extérieur de cette ligne trois ramifications qui s'étendent sur l'élytre; le dessous du corps est d'un violet rougeâtre trìs brillant; les pates sont cuivreuses, et les cuisses couvertes d'un duvet cotonneux blanchattre.

On la trouve au cap de Bonne-Espérance, dans les endroits sablonneux.

\section{La Cicindèle germanique, Cicindela} germanica.

Elle n'a que cinq lignes de long; les antennes sont noires, avec les premicrs articles. bronzés; la tête est verte, bronzée; la lèvre supéricure jaune; le corselet est d'un vert bronzé; les élytres sont vertes, avec un petit point blanc à l'angle extérieur de la base, tume tache oblongue vers le milieu du bord extérieur, et une autre en croissant à l'ex. III. 
trémité; le dessous du corps et les pates sont d'un vert bleuâtre, brillant.

On la trouve en Europe, daus les endroits secs et sablonneux; clle est moins commune que la cicindèle champétre, anx environs de Paris.

\section{La Cicindèle qquadrirayée, Cicindela} quadrilineata.

Elle est de forme allongée et a près de huit lignes de longueur; les antennes sont noirâtres, bronzées à la base; la tête et le corselet sont bronzés, cuivreux: le dessous du corsclet est très brillant; les cótés sont couverts d'un duvet cendré; les élytres sont bronzées, avec le bord extérieur blane; elles ont près de la suture une ligne longitudinale blanche qui ne s'étend pas jusqu'it l'extrémité; le dessous du corps est d'um rouge cuivreux, très brillant, avec les cótés légèrement couverts d'un duvet cendré; les pates sont cuivreuses.

On la trouve aux Indes orientales. 



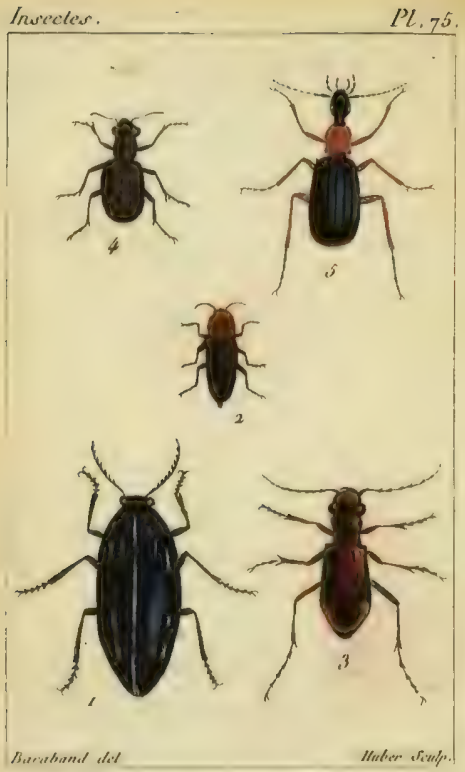

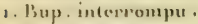

2. Bup, rubis.

4. Weph agyatinge.

5. (iv Cimolinoise. 
La Cicindèle carolinoise, Cicindela if carolina.

G. Mégacéphale. Larn.

Cette belle espèce a enviyon huit lignes de longuenr; les antennes sont d'un brun - jaunatre, aussi longues que la inoitié du corps; la tète est d'un vert bleuatre brillant; les yeux sont bruns; la lèvre supérieure est jaune; le corselet est d'jun vert brillant, avec deux taches cuivreisses sur le milieu; les ilytres sont pointillés, d'un vert bleuàtre brillant sur les côtés, d'un rougre cuivreux très brillant sur le milieu; elles ont une tache jaune en croissant à l'extrémité; le dessous di corps est d'un vert bleuitre brillant; les pates sont fauves.

On la trouve à la Caroline; clle y est assez multipliée.

La Cicindèle à levre, Cicindela labiata.

G. Thérute. L.ати.

Cette belle espece est longue de près de dix lignes; tout le corpsest en dessus d'un 
beau bleu foncé, avec des reflets violets; la lèvre supérieure est d'un jaune roussîtré, avec une tache d'un noir obscur au milieu de sa base; elle est très grande et a huit petites dentelures ì sa partie antérieure; les mandibules sont d'un ronge ferrugineux, ainsi que les palpes et les cuisses; l'extréunité des jambes est d'un bleu noirâtre, ainsi que les palpes.

Cet insecte se trunve dans les îles du nord de la Nouvelle-IIollande, an port Praslin, à Bourou, etc. MM. Lesson, Garnot et Gaudichaud, médecins de la marine, qui ont recueilli cette espèce pendant leurs voyages autour du monde, nous ont appris que ses mours diffèrent de celles des autres cicindèles; elle se tient sur les feuilles des arbres, et vole avec une grande rapidité, et qu'elle exhale une odeur de rose très prononcéc.

\section{La Cicindèle huit-points, Cicindela octoguttata.}

Elle est moins grande que la cicindèle champitre; les antennes sont noirattres, avee 
les premicrs articles verts; la tìte est bronzée; les yeux sont bruns; la lievre supérieure est. jaune; le corselet est d'un vert bronzé; les élytres sont vertes, avec trois points blancs sur chaque, et deux lunules blanches; le dessous du corps est bleu, avec les côtés cuivreux; les pates sont cuivreuses.

On la trouve 'dans l'Amérique méridionale.

\section{La Cicindèle à long cou, Cicindcla} longicollis.

G. Colliure. Lams.

Cette espèce est longue de près de sept lignes et demie; son corps est étroit, allongé, et entièrement d'un beau bleu; le corselet est allongé et cylindrique ou presque cylindrique; l'abdomen est étroit; les élytres sont trìs ponctuées, et échancrées ì leur extrémité; les cuisses seules sont ferrugineuses.

On trouve eet insecte dans les Indes orientales, on Chine, on Cochinchine, at siam et ì Java : il est rare. 


\section{La Cicindèle aptère, Cicindela aptera.}

$$
\text { G. Tricondyle. LaTR. }
$$

Cet insecte varie pour la taille, depuis neuf lignes de long jusqu'à onze; sa coulcur est d'un bleu foncé, quelquefois un peu violet; la lèvre supérieure est grande, elle a six dentelures en avant; les antennes sont it peu près longues comme la tète et le corselet pris ensemble, elles sont filiformes ct d'un noir bleuåtre; les palpes sont de la même couleur; les yeux sont jaunâtres, très saillans; le corselet est allongé, il est globuleux À son milieu, et rétréci aux deux extrémités, où il forme deux espèces de cupules dans lesquelles s'articulent la téte et le métathorax; les élytres cmbrassent l'abdomen, elles sont soudées, et on voit une légère impression sur leur milien qui indigue la place de la suture; elles ont des rides transversales très marquices at la base, et qui vont en s'affaiblissant jusqu'aux deux tiers de la longueur; l'extrémité est tont-à-faii lisse; le dessous du corps est d'un bleu foncé, un 
peu violet; les cuisses sont cylindriques et d'un rouge ferrugincux obscur; les jambes et les tarses sont d'un violet foncé.

Cette belle espèce a été rapportée par MM. Durville et I.esson; ils l'ont trouvée dans la Nouvelle-Guinée et à la NouvelleIrlande.

La Cicindèle échancrée, Cicindela emarginata. G. Drypte. Latr.

Elle a près de quatre lignes de long; elle ressemble un peu à un carabe : les antennes sont fauves; le premier article est allongé, avec l'extrémité noire; la tète est d'un vert bleuatre; la lèvre supérieure et les mandibules sont fauves; le corselet est cylindrique, d'un vert bleutitre; les élytres sont d'un vert blenatre, striées, et les stries sont poin. tillées; l'extrémité des élytres est échancrée; le dessous du corps est d'un bleu brillant; les pates sont fauves.

Flle est vare aux environs de laris; on la trouve dans les bois, it la fin du printemps. 


\section{CXIII' GENRE.}

\section{ÉLAPHRE.}

Caractères génériques. Antennes sétacées; articles courts et égaux, le premier plus gros. - Six antennulês presque égales, filiformes; les antérieures composées de denx articles égaux, les moyennes de quatre articles cylindriques, les postérieures de trois', dont le premier plus court. - Appendice à la base des cuisses postérieures.

M. Fabricrus a le premier fait un genre de ces insectes. M. Geoffroy les a placés avec les carabes, auxquels il a donné le nom de buprestes, et Linné les a rangés parmi les cicindèles, qui sont des buprestes de Geoffroy.

Les élaphres ont extérieurement bealcoup de ressemblance avec les cicindèles; mais ils en diffèrent par quelques parties de la bouche.

Les antennes des élaphres sont sétacées, composées de onze articles, dont le premicr est plus gros, les autres sont égaux; elles sont insérées à la partie antérieure et latérale de In rite, atu-dessous des yeux. 
Ia tîtc est un peu plus large que le corselet; les yeux sont gros, arrondis, très saillans; la bouche est composée d'unc lèvre supéricure, de deux mandibules cornées, avancées, arquées, et pointues; de deux mâchoires arquées, très pointues, ciliées intérieurement; d'une lèvre inférieure, et de six antennules presque égales.

Le corselet est moins large que les ilytres, trìs peu rebordé; dans quelques espèces il est en forme de coeur; il a un sillon longitudinal plus ou moins profond sur le milieu de sa partic supérieure; l'écusson est petit, arrondi postérieurement.

Les élytres sont très dures, un peu convexes; elles couvrent deux ailes membraneuses, replices quand l'insecte n'en fait pas usage pour voler.

Les pates sont de longueur moyenne; les cuisses un peu renflées; les jambes sont moins déliées que celles des cicindèles; les tarses sont filiformes, composés de cinq articles; le premier et le dernier sont plus longs que les autres; Ic dernier est terminé par deux petits 
crochets; les cuisses postérieures ont a leur base un appendice ovale.

Les élaphres sont de petits insectes assez brillans; ils ressemblent aux cicindèles par la lígèreté et par la manière de vivre; mais on ne les trouve pas dans les mémes lieux, ils habitent les endroits humides; ils sont carnivores et se nourrissent de petits insectes, principalement de larves aqquatiques. On les voit courir avec beaucoup de vitesse sur le sable qui borde les eaux. Leur larve n'est pas connue.

Ces insectes forment un genre composé d'une dizaine d'espèces; on les trouve toutes en Europe. Nous allons passer à la description de quelques unes.

\section{L'Élaphre uligincux, Elaphrus uliginosus.}

Il a un peu plus de trois lignes de long; les antenues sont de la longueur du corselet, noiràtres, avec les premiers articles bronzés; la tète est cuivreuse; les yeux sont noirittres, 
très saillans; le corselet est bronzé, pointillé, raboteux, avec une ligne courte enfonçée sur le milieu; les élytres sont bronzées, raboteuses, avec des élévations lisses, cuivreuses, brillantes; le dessous du corps et les pates sont d'une couleur noiratre bronzée.

On le trouve aux environs de Paris, sur le bord des eaux.

\section{L'Élaphre riverain, Elaphrus riparius.}

Il est un peu plus petit que le précédent; les antennes sont noirâtres, de la longueur du corselet; la tête est bronzée, pointillée; les yeux sont noirs, saillans; le corselet est bronzé, un peu cuivreux, pointillé, raboteux; les élytres sont bronzées; elles ont des taches rondes, enfoncées, et des élévations lisses, cuivreuses, brillantes; le dessous du corps et les cuisses sont bronzés; les pates sont d'un brun ferrugineux.

On le trouve dans tonte l'Europe, sur le bord des mares et des étangs; il est commun aux environs de Paris. 


\section{L'Élaphre aquatique, Elaphrus aquaticus.}

Il est de moitié plus petit que le précédent; les antennes sont presque aussi longues que le corselet, noirâtres, avec les premiers anneaux fauves; tout le corps est bronzé, luisant; la tête est striée; le corselet est pointillé; les yeux sont bruns, saillans; les élytres sont lisses le long du bord extérieur et près de la suture; sur le milieu, elles ont des stries légèrement marquées, formées par de petits points enfoncés; les cuisses sont bronzées; les jambes sont d'un brun rougeâtre.

On le trouve dans toute l'Europe, dans les endroits humides; il est commun aux environs de Paris.

L'Élaphre flavipède, Elaphrus flavipes.

Il a deux lignes de long; les antennes sont noirâtres, presque aussi longues que le corselet; la tête est bronzée, pointillée; les yeux sont noirs, saillans; le corselet est 
bronzé, pointillé, avec une ligne longitudinale peu enfoncée sur le milieu; les élytres sont pointillées, presque chagrinées, avec deux petits points enfoncés près de la suture; elles sont bronzées et noirâtres; le dessous du corps est noir luisant; les pates sont jaunes.

On le trouve dans presque toute l'Europe ; il est moins commun que les précédens aux environs de Paris.

FIN DU TOME TROISIÈME. 
